UCID-21754

\title{
Capabilities for Measuring Physical and Chemical Properties of Rocks at High Pressure
}

Compiled by

W. B. Durham

January, 1990

This is an informal report intended primarily for internal or limited external distribution. The opinions and conclusions stated are llose of the author and may or may not be those of the Laboratory.

Work performed under the auspices of the U.S. Department of Energy by the Lawrence Livermore National Laboratory under Contract W-7405-Eng-48. 


\section{DISCLAIMER}

This report was prepared as an account of work sponsored by an agency of the United States Government. Neither the United States Government nor any agency Thereof, nor any of their employees, makes any warranty, express or implied, or assumes any legal liability or responsibility for the accuracy, completeness, or usefulness of any information, apparatus, product, or process disclosed, or represents that its use would not infringe privately owned rights. Reference herein to any specific commercial product, process, or service by trade name, trademark, manufacturer, or otherwise does not necessarily constitute or imply its endorsement, recommendation, or favoring by the United States Government or any agency thereof. The views and opinions of authors expressed herein do not necessarily state or reflect those of the United States Government or any agency thereof. 


\section{DISCLAIMER}

Portions of this document may be illegible in electronic image products. Images are produced from the best available original document. 
This document was prepared as an account of work sponsored by an agency of the United States Government. Neither the United States Government nor the University of California nor any of their employees, makes any warranty, express or implied, or assumes any legal liability or responsibility for the accuracy, completeness, or usefulness of any information, apparatus, product, or process disclosed, or represents that its use would not infringe privately owned rights. Reference herein to any specific commercial products, process, or service by trade name, trademark, manufacturer, or otherwise, does not necessarily constitute or imply its endorsement, recommendation, or favoring by the United States Government or the University of California. The views and opinions of authors expressed herein do not necessarily state or reflect those of the United States Government or the University of California, and shall not be used for advertising or product endorsement purposes.

\author{
This report has been reproduced \\ directly from the best available copy. \\ Available to DOE and DOE contractors from the \\ Office of Scientific and Technical Information \\ P.O. Box 62, Oak Ridge, TN 37831 \\ Prices available from (615) 576-8401, FTS 626-8401.
}

Available to the public from the

National Technical Information Service

U.S. Department of Commerce

5285 Port Royal Rd.,

Springfield, VA 22161

\title{
Papercopy Prices
}

A 02

A03

A04

A05

A06

A07

A08

A09

A10

A11

A12

A13

A 14

A15

A16

A17

A18

A19

A20

A 21

A22

A23

A 24

A25

A99
1- 10

11- 50

51- 75

76-100

101-125

126-150

151-175

176-200

201-225

226-250

251-275

276-300

301-325

326-350

351-375

376-400

401-425

426-450

451-475

476-500

501-525

526-550

551-575

576-600

601 \& UP 


\section{PAGES $\mathrm{i}$ to $\mathrm{ii}$ WERE INTENTIONALLY LEFT BLANK}




\section{Contents DE90 013515}

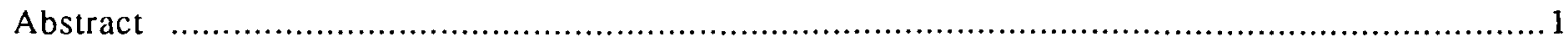

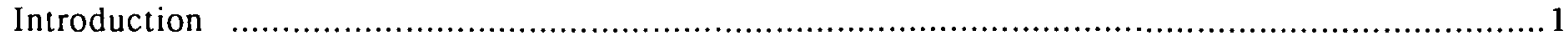

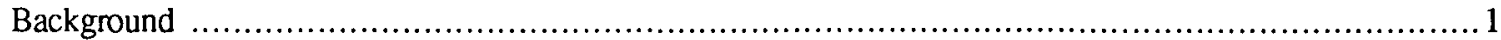

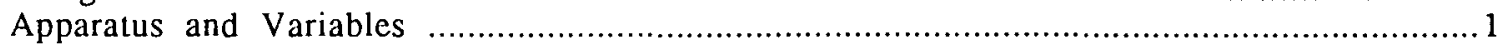

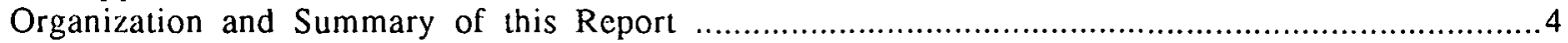

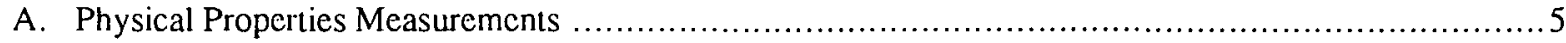

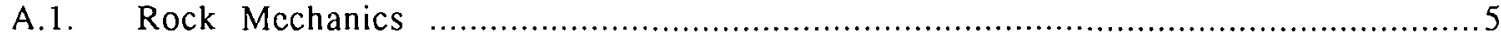

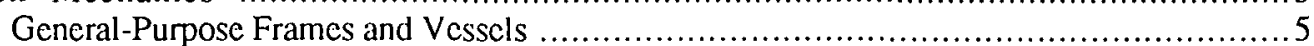

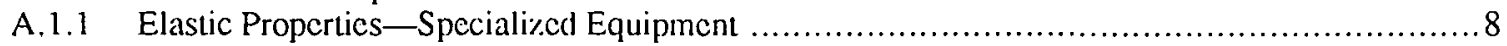

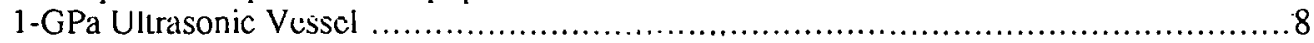

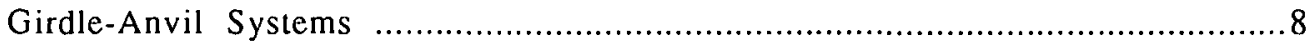

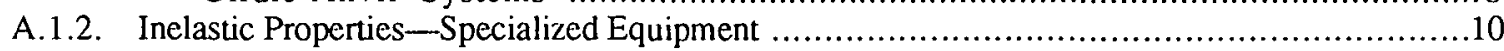

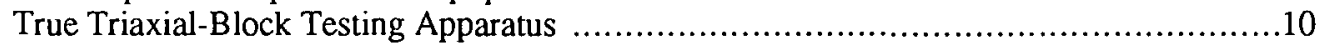

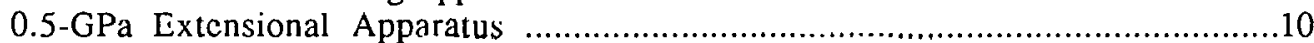

0.3-GPa Externally Heated Vessel ...................................................... 10

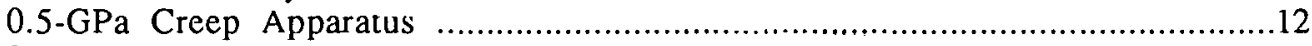

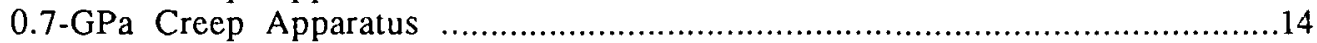

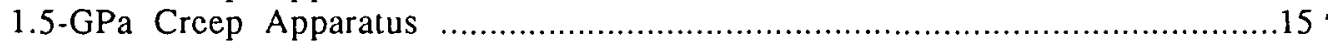

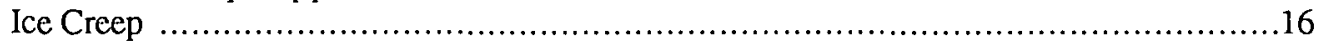

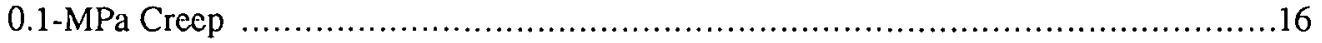

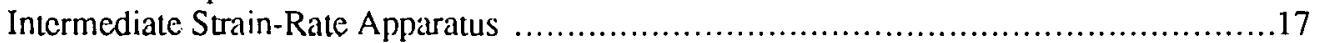

Rotating-C.up Viscometer .............................................................. 18

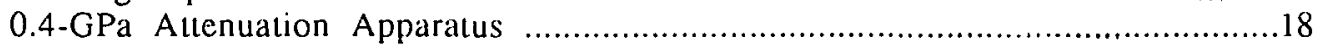

A.2. Hydrologic Properties ..........................................................................20

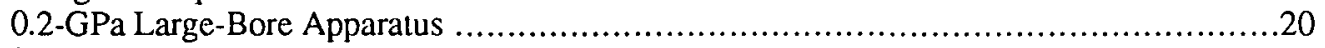

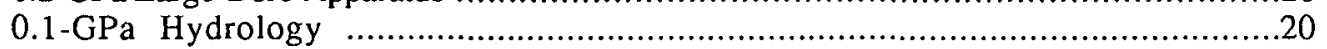

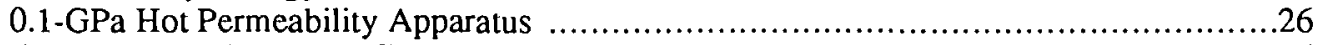

Three-Dimensional Profilometer ..........................................................26

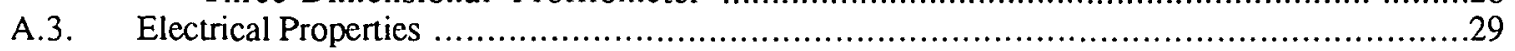

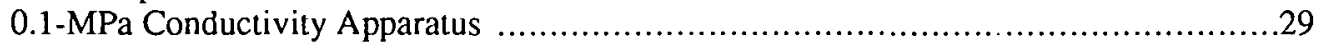

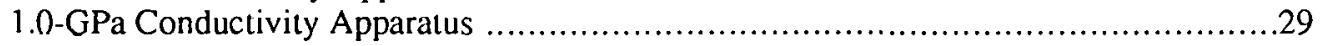

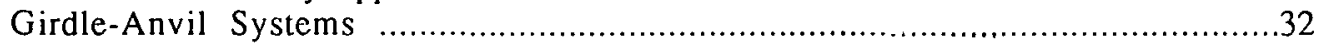

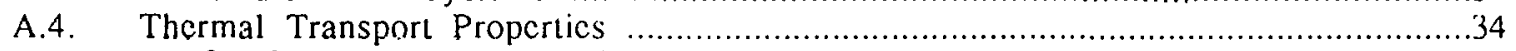

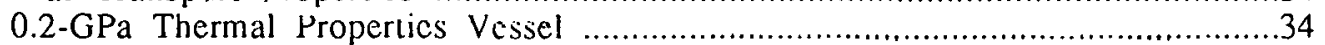

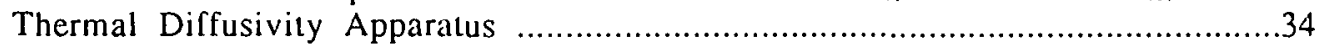

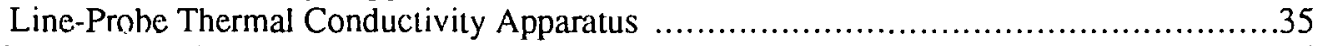

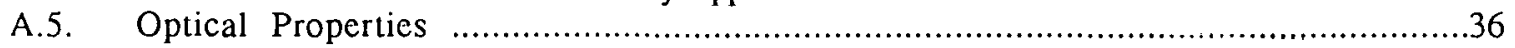

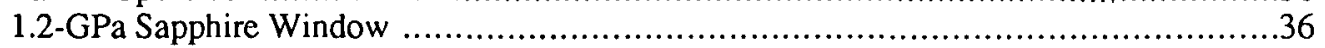

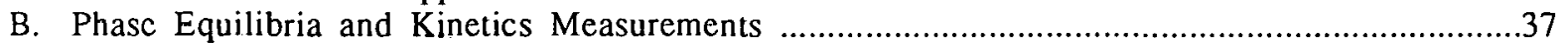

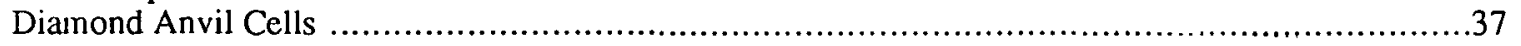

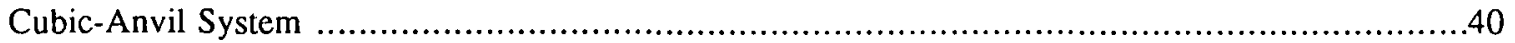

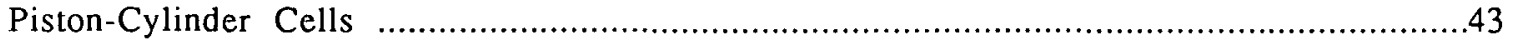

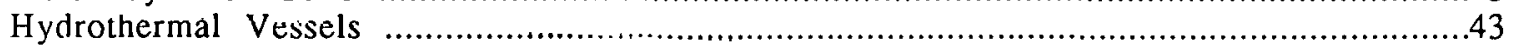

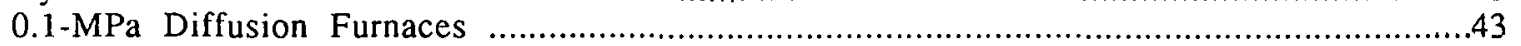

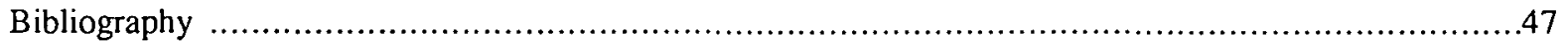




\title{
Capabilities for Measuring Physical and Chemical Properties of Rocks at High Pressure
}

\begin{abstract}
The Experimental Geophysics Group of the Earth Sciences Department at Lawrence Livermore National Laboratory (LLNL) has experimental equipment that measures a variety of physical properties and phase equilibria and kinetics on rocks and minerals at extreme pressures (to 500 $\mathrm{GPa}$ ) and temperatures (from 10 to $2800 \mathrm{~K}$ ). These experimental capabilities are described in this report in terms of published results, photographs, and schematic diagrams.
\end{abstract}

\section{Introduction}

\section{Background}

Experimental geophysics began at the Lawrence Livermore National Laboratory in the early 1960 s as an outgrowth of the Plowshare Program, whose purpose was to develop peaceful applications for nuclear explosives. Research activity in rock mechanics expanded rapidly thereafter when underground nuclear testing began. We needed to know the mechanical properties of specific Nevada Test Site rocks at high pressure in order to contain our own tests, and of rocks in general in order to interpret the seismic information emanating from nuclear tests by other countries. Several large testing frames, pressure vessels, and pumping capabilities were acquired at that time. The equipment base left behind by the nuclear test containment and seismic monitoring programs allowed us to broaden our research horizons, in turn allowing us to further expand our research capabilities. We now pursue a very diverse program of study of the physical and chemical behavior of rocks and minerals under extremes of pressure and temperature for a wide variety of earth-science applications. This document catalogs the research capabilities of the Experimental Geophysics Group of the Earth Sciences Department at Livermore. It is an updated and revised version of an earlier document by Heard and Duba (1978).

\section{Apparatus and Variables}

The fundamental purpose of our research is to understand the behavior of rocks and minerals under conditions appropriate to the interiors of the earth and other planets. The usual experimental approach is to impose relevant conditions (i. e., pressure, temperature, chemical environment) on a sample, perhaps stimulate the sample (with an electric field, differential stress, chemical gradient, temperature gradient), and observe the response (i. e., change of shape, electrical conductance, change of phase) and the evolution of the response with time.

The equipment described in this report is listed in Table 1. Nearly all have an independent capability to control hydrostatic pressure $P$. The other most common environmental variables are temperature $T$ and the normal components $\sigma_{1}, \sigma_{2}$, and $\sigma_{3}$ of the general stress tensor $\sigma_{i j}$. Other variables appearing in the table are imposed linear deformation rate $\dot{u}$, angular strain rate $\dot{\omega}$, pore pressure $P_{p}$, and oxygen fugacity $f_{\mathrm{O}_{2}}$. Table 1 also lists the properties measured or the nature of the experiments that can be performed, the experimental range of the imposed temperature and hydrostatic pressure, and a short description of each apparatus.

Our capabilities in pressure range to $500 \mathrm{GPa}$ ( 5 million atmospheres) in the tiny confines of the diamond-anvil cell, to $25 \mathrm{GPa}$ in the $1-\mathrm{mm}^{3}$ volume of the cubic-anvil system, to $2.2 \mathrm{GPa}$ in the $\geq 1-\mathrm{cm}^{3}$ volume of the liquid/gas pressure cylinders. Temperature capabilities range from 10 to $2800 \mathrm{~K}$.

The majority of our experimental equipment uses the $\geq 1-\mathrm{cm}^{3}$-volume class of samples. Simulating geologically relevant stress levels in those samples is the main complication that distinguishes our equipment from that of materials science laboratories. Hydrostatic stresses (pressures) in the crust and upper mantle increase roughly at $100 \mathrm{MPa}$ per 3 to $4 \mathrm{~km}$ depth. Simulation of pressures at even modest depths 
Table 1. Index of capabilities discussed in this report.

\begin{tabular}{|c|c|c|c|c|c|}
\hline $\begin{array}{c}\text { Apparatus name/ } \\
\text { section no. }\end{array}$ & Variables & $\begin{array}{l}\text { Properties } \\
\text { measurable }\end{array}$ & $\begin{array}{l}\operatorname{Max} P \\
(\mathrm{GPa}) \\
\end{array}$ & $\begin{array}{l}T \text { range } \\
(\mathbf{K})\end{array}$ & Description \\
\hline $\begin{array}{l}\text { 11-MN press } \\
(\text { A.1.) }\end{array}$ & $P, \sigma_{1}$ & $\begin{array}{l}\text { Elastic constants, } \\
P-V \\
V_{p}, V_{s}\end{array}$ & $\begin{array}{l}2.0 \\
0.3\end{array}$ & $\begin{array}{l}300 \\
300\end{array}$ & $\begin{array}{l}\text { Internal volume } 38-\mathrm{mm} \text {-diam } \times 200-\mathrm{mm} \text {-Iength; } \\
\text { two identical vessels available. } \\
\text { Internal volume } 160-\mathrm{mm} \text {-diam } \times 150-\mathrm{mm} \text {-length. } \\
\text { Frame is equipped with double-acting concentric } \\
\text { hydraulic rams. }\end{array}$ \\
\hline $\begin{array}{l}\text { 3.6-MN press } \\
(\Lambda .1 .)\end{array}$ & $\boldsymbol{P}, T, \boldsymbol{P}_{p}, \sigma_{1}$ & $\begin{array}{l}\text { Elastic constants, } \\
\text { compressive or } \\
\text { tensile strength, } \\
P-V\end{array}$ & $\begin{array}{l}2.2 \\
1.0 \\
1.0 \\
0.7 \\
0.3\end{array}$ & $\begin{array}{c}300 \\
300 \\
300 \\
300 \\
300-550\end{array}$ & $\begin{array}{l}\text { Internal volume } 25-\mathrm{mm} \text {-diam } \times 60-\mathrm{mm} \text {-length; } \\
\text { two identical vessels available. } \\
\text { Internal volume } 38-\mathrm{mm} \text {-diam } \times 80-\mathrm{mm}-\text { length; } \\
\text { two identical vessels available. } \\
\text { Internal volume } 38-\mathrm{mm} \text {-diam } \times 100-\mathrm{mm} \text {-length. } \\
\text { Internal volume } 51-\mathrm{mm} \text {-diam } \times 100-\mathrm{mm} \cdot \text { length. } \\
\text { Max sample } 25-\mathrm{mm} \cdot \mathrm{diam} \times 80-\mathrm{mm} \text {-length. }\end{array}$ \\
\hline $\begin{array}{l}3.0+\mathrm{MN} \text { press } \\
(\Lambda .1 .)\end{array}$ & $P, \sigma_{1}$ & $\begin{array}{l}\text { Elastic constants, } \\
\text { strength, creep }\end{array}$ & - & - & $\begin{array}{l}\text { Can use any of the pressure vessels listed with the } \\
\text { 3.6-MN press. Frame is equipped with double- } \\
\text { acting, concentric, hydraulic rams. }\end{array}$ \\
\hline $\begin{array}{l}\text { 1.0.MN press } \\
\text { (A.1.) }\end{array}$ & $\sigma_{1}$ & $\begin{array}{l}\text { Unconfined } \\
\text { compressional } \\
\text { strength } \\
\end{array}$ & $10^{-4}$ & 300 & Typical sample $25-\mathrm{mm}$-diam $\times$ 64-mm-length. \\
\hline $\begin{array}{l}\text { 1.0.GPa ultrasonic } \\
(\text { A.1.1.) }\end{array}$ & $P$ & $v_{p}, v_{s}$ & 1.0 & 300 & Bore volume $90-\mathrm{mm}$-diam $\times 250-\mathrm{mm}$-length. \\
\hline $\begin{array}{l}\text { True triaxial block } \\
\text { testing } \\
\text { (A.1.2.) }\end{array}$ & $\begin{array}{l}\sigma_{1}, \sigma_{2}, \sigma_{3}, P_{p} \\
\text { nuid in- } \\
\text { jection rate }\end{array}$ & $\begin{array}{l}\text { Hydrofracture } \\
\text { propagation }\end{array}$ & $10^{-4}$ & 300 & $\begin{array}{l}\text { True triaxial apparatus that can test blocks up to } \\
\mathbf{4 0 0} \mathrm{mm} \text { on a side using a system of actuators and } \\
\text { flatjacks. }\end{array}$ \\
\hline $\begin{array}{l}\text { 0.5.GPa extensional } \\
(\Lambda .1 .2 .)\end{array}$ & $P, \sigma_{1}, \sigma_{3}$ & $\begin{array}{l}\text { General } \sigma-\varepsilon \text { in } \\
\text { compression or } \\
\text { tension }\end{array}$ & 0.5 & $3 \mathbf{3 0 0}$ & $\begin{array}{l}\text { Max sample } 25-\mathrm{mm} \text {-diam } \times 50 \text {-mm-length; ends } \\
\text { of sample loaded hydraulically. }\end{array}$ \\
\hline $\begin{array}{l}0.3 \cdot \text { GPa externally } \\
\text { heated. } \\
\text { (A.1.2.) }\end{array}$ & $P, T, \sigma_{1}$ & $\begin{array}{l}\text { Compressional } \\
\text { strength }\end{array}$ & 0.3 & $300-550$ & Max sample 25-mm-diam $\times 80-\mathrm{mm}$-length. \\
\hline $\begin{array}{l}0.5 \cdot G I^{\prime} \text { a creep } \\
(\Lambda .1 .2 .)\end{array}$ & $P, T, \dot{u}$ & $\begin{array}{l}\text { Plastic deformation, } \\
\text { thermal diffusivity, } \\
\text { acoustic emission }\end{array}$ & $\begin{array}{l}0.5 \\
0.4\end{array}$ & $\begin{array}{l}300-773 \\
300-773\end{array}$ & $\begin{array}{l}\text { Max sample } 10-\mathrm{mm} \text {-diam } \times 20 \text {-mm-length; four } \\
\text { pressure vessels available. } \\
\text { Max sample } 25 \text {-mm-diam } \times 50 \text {-mm-length; two } \\
\text { pressure vessels available. }\end{array}$ \\
\hline $\begin{array}{l}\text { 0.7-GPa crecp } \\
\text { (A.1.2.) }\end{array}$ & $P, T, \dot{u}$ & Plastic̀ deformation & 0.7 & $300-1273$ & Max sample $15-\mathrm{mm}-$ diam $\times 50-\mathrm{mm}$-length. \\
\hline $\begin{array}{l}\text { 1.5-GPa creep } \\
(\text { A.1.2.) }\end{array}$ & $P, \dot{u}$ & Plastic deformation & 1.5 & 300 & Max sample 25-mm-diam $\times 50-\mathrm{mm}$-length. \\
\hline $\begin{array}{l}\text { Ice creep } \\
(\text { A.1.2.) }\end{array}$ & $P, T, \dot{u}$ & Plastic deformation & 0.6 & $\begin{array}{c}77-300 \\
\end{array}$ & $\begin{array}{l}\text { Vertical creep rig with low cross-section, stainless- } \\
\text { steel, tensile-reaction yoke; externally cooled; } \\
\text { useful strain-rate range, } 3.5 \times 10^{-7}-3.5 \times 10^{-4} \mathrm{~s}^{-1} \text {; } \\
\text { Ar, } \mathrm{N}_{2} \text {, or He-pressure medium; typical sample } \\
25 \cdot \mathrm{mm} \text {-diam } \times 100-\mathrm{mm} \text { length. }\end{array}$ \\
\hline $\begin{array}{l}1 \text {-atm creep } \\
(A .1 .2 .)\end{array}$ & $T, \sigma_{1}, f_{\mathrm{O}_{2}}$ & $\begin{array}{l}\text { Creep of single } \\
\text { crystals }\end{array}$ & $10^{-4}$ & $300-1900$ & $\begin{array}{l}\text { Expected to be operational in } \\
\text { Summer, } 1990 \text {. }\end{array}$ \\
\hline $\begin{array}{l}\text { Intermediate } \\
\text { strain rate } \\
(\text { A.1.2.) }\end{array}$ & $P, T, \dot{u}$ & $\begin{array}{l}\text { Brittle and ductile } \\
\text { strength at } 10^{-2}<\dot{\varepsilon} \\
<10^{2} \mathrm{~s}^{-1}\end{array}$ & $\begin{array}{l}0.07 \\
1.0\end{array}$ & $233-300$ & $\begin{array}{l}\text { 162-mm-diam-bore pressure vessel; typical } \\
\text { sample 75-mm-diam } \times 150-\mathrm{mm} \text {-length; } \\
63-\mathrm{mm} \text {-diam bore, two vessels available; typical } \\
\text { sample } 25-\mathrm{mm} \text {-diam } \times 50-\mathrm{mm} \text { length. Frame } \\
\text { limited to } 1-\mathrm{MN} \text { load capacity. }\end{array}$ \\
\hline $\begin{array}{l}\text { Rotating-cup } \\
\text { viscometer } \\
\text { (A.1.2.) }\end{array}$ & $T, f_{\mathrm{O}_{2}} \dot{\boldsymbol{\omega}}$ & Viscosity & $10^{-4}$ & $300-2000$ & $\begin{array}{l}\text { Rotating-cup viscometer for rheological } \\
\text { measurements on molten and partially molten } \\
\text { systems. }\end{array}$ \\
\hline $\begin{array}{l}\text { 0.4-GPa attenuation } \\
(\text { A.1.2.) }\end{array}$ & $P, T$ & $\begin{array}{l}\text { Low-frequency } \\
\text { attenuation }\end{array}$ & 0.4 & $300-1500$ & $\begin{array}{l}\text { Working volume } 115-\mathrm{mm}-\mathrm{diam} \times 580-\mathrm{mm} \text {-length. } \\
\text { Attenuation measured in torsion; sample size } \\
9 \cdot \mathrm{mm} \text {-diam } \times 20-\mathrm{mm} \text {-length. }\end{array}$ \\
\hline $\begin{array}{l}\text { 0.2-GPa large-bore } \\
\text { (A.2.) }\end{array}$ & $P, \sigma_{1}, P_{p}$ & $\begin{array}{l}\text { Elastic constants, } \\
V_{p}, V_{\text {, }} \\
\text { bulk permeability, } \\
\text { fracture per. } \\
\text { meabillty, electrical } \\
\text { conductivity }\end{array}$ & 0.2 & 300 & $\begin{array}{l}\text { Two vessels available; large sample capability, } \\
150 \text {-mm-diam } \times 300 \text {-mm-length. Maximum axial } \\
\text { force is } 18 \mathrm{MN} \text {. Permeabilities as low as } 10^{-24} \mathrm{~m}^{2} \\
\text { can be measured on large sample. Listed } \\
\text { properties can be measured simultaneously on } \\
\text { same sample. }\end{array}$ \\
\hline
\end{tabular}


Table 1. (Continued.)

\begin{tabular}{|c|c|c|c|c|c|}
\hline $\begin{array}{c}\text { Apparatus name } / \\
\text { section no. }\end{array}$ & Variables & $\begin{array}{c}\text { Properties } \\
\text { measurable }\end{array}$ & $\begin{array}{r}\operatorname{Max} P \\
(\mathbf{G P a})\end{array}$ & $\begin{array}{c}T \text { range } \\
(\mathbf{K})\end{array}$ & Description \\
\hline $\begin{array}{l}\text { 0.1.GPa hydrology } \\
\text { (A.2.) }\end{array}$ & $P, T$ & $\begin{array}{l}\text { Permeability, elec- } \\
\text { trical conductivity, } \\
\text { ultrasonic velocity }\end{array}$ & 0.1 & $300-573$ & $\begin{array}{l}\text { Two vessels available, max sample } 25-\mathrm{mm} \text {-diam } \\
\times 100 \text {-mm-length and } 100-\mathrm{mm} \text {-diam } \times 200-\mathrm{mm} \text { - } \\
\text { length. Permeability, electrical conductivity, and } \\
\text { velocities can be measured simultaneously on } \\
\text { same sample. Impedance tomographs and } \\
\text { ultrasonic tomographs can be made on larger } \\
\text { sample. }\end{array}$ \\
\hline $\begin{array}{l}\text { 0.1-GPa hot } \\
\text { permeability } \\
\text { (A.2.) }\end{array}$ & $\overline{P, T}$ & $\begin{array}{l}\text { Liquid/gas } \\
\text { permeability, } \\
\text { thermal } \\
\text { conductivity }\end{array}$ & 0.1 & $300-625$ & $\begin{array}{l}\text { Externally heated vessels; two available. Typical } \\
\text { sample size } 44 \text {-mm-diam } \times 76-\mathrm{mm} \text {-length, up to } \\
\text { four samples simultaneously. }\end{array}$ \\
\hline $\begin{array}{l}\text { 3-D profilometer } \\
\text { (A.2.) }\end{array}$ & - & $z(x, y)$ & 一 & 一 & $\begin{array}{l}\text { Analytical device used to digitize in three } \\
\text { dimensions the shapes of fractures in jointed and } \\
\text { faulted rock. High resolution in }(x, y) \text { plane allows } \\
\text { both surfaces of a joint to be compared with each } \\
\text { other. Max area covered }-300 \mathrm{~mm} \times 150 \mathrm{~mm} \text {. }\end{array}$ \\
\hline $\begin{array}{l}\text { 1-atm conductivity } \\
\text { (A.3.) }\end{array}$ & $T, f_{\mathrm{O}_{2}}$ & $\begin{array}{l}\text { Electrical } \\
\text { conductivity }\end{array}$ & $10^{-4}$ & $300-2000$ & $\begin{array}{l}\text { Three independent furnaces/gas-flow systems } \\
\text { available for long-duration tests. Gas mixture is } \\
\mathrm{CO} / \mathrm{CO}_{2} \text {. }\end{array}$ \\
\hline $\begin{array}{l}\text { 1.0-GPa con- } \\
\text { ductivity } \\
\text { (A.3.) }\end{array}$ & $P, T, f_{\mathrm{O}_{2}}$ & $\begin{array}{l}\text { Electrical } \\
\text { conductivity, low. } \\
\text { frequency } \\
\text { attenuation } \\
\text { (extensional wave) } \\
\end{array}$ & 1.0 & $300-1950$ & $\begin{array}{l}\text { Working volume } 38-\mathrm{mm} \cdot \text { diam } \times 250-\mathrm{mm}-\text { Jength; } \\
\text { conductivity sample is rectangular plate } 1-\mathrm{mm} \times 5 \text { - } \\
\mathrm{mm} \times 5 \cdot \mathrm{mm} \text {. Typical attenuation-sample } 10-\mathrm{mm} \text { - } \\
\text { diam } \times 9-\mathrm{mm} \text {-length. }\end{array}$ \\
\hline $\begin{array}{l}\text { Girdle anvil } \\
\text { (A.1.1.) } \\
\text { (A.3) }\end{array}$ & $P, T$ & $\begin{array}{l}V_{p}, V_{a}, \text { electrical } \\
\text { conductivity }\end{array}$ & 15.0 & $300-1700$ & $\begin{array}{l}\text { Highest pressures are achieved using specially } \\
\text { designed 9.1-MN wide-platen press frame. } \\
\text { Sample size and pressure ranges are variable and } \\
\text { interdependent. Bridgman anvil cells, girdles and } \\
\text { belts are available to accommodate samples as } \\
\text { large as } 7-\mathrm{mm} \cdot \text { diam } \times 4-\mathrm{mm}-\mathrm{length} \text { at } 7.0 \mathrm{GPa} \text { and } \\
1-\mathrm{mm} \times 5 \cdot \mathrm{mm} \text { at } 15.0 \mathrm{GPa} \text {. }\end{array}$ \\
\hline $\begin{array}{l}\text { Thermal properties } \\
\text { (A.4.) }\end{array}$ & $P, T$ & $\begin{array}{l}\text { Thermal con- } \\
\text { ductivity, thermal } \\
\text { diffusivity, thermal } \\
\text { linear expansion }\end{array}$ & $\overline{0.2}$ & $-250-773$ & $\begin{array}{l}\text { Externally heated horizontal vessel; typical } \\
\text { sample } 100-\mathrm{mm} \text {-diam } \times 250 \text {-mm-length. }\end{array}$ \\
\hline $\begin{array}{l}\text { Thermal diffusivity } \\
\text { (A.4.) }\end{array}$ & $P, T$ & Thermal diffusivity & $\overline{0.4}$ & $300-675$ & $\begin{array}{l}\text { Uses } 0.5 \text {-GPa creep system without piston drive. } \\
\text { Max sample } 25 \text {-mm-diam } \times 63 \text {-mm-length. }\end{array}$ \\
\hline $\begin{array}{l}\text { Line-probe thermal } \\
\text { conductivity } \\
\text { (A.4.) }\end{array}$ & $P, T$ & $\begin{array}{l}\text { Thermal con- } \\
\text { ductivity }\end{array}$ & 0.1 & $300-625$ & $\begin{array}{l}\text { Uses pressure vessels and external heaters of } 0.1 \cdot \\
\text { GPa hot permeability system. Typical sample } \\
83-\mathrm{mm} \text {-diam } \times 150-\mathrm{mm} \text {-length. }\end{array}$ \\
\hline $\begin{array}{l}\text { 1.2-GPa sapphire } \\
\text { window } \\
\text { (A.5.) }\end{array}$ & $P, T$ & $\begin{array}{l}\text { Phase equilibria, } \\
\text { optical properties, } \\
\text { single-crystal elastic } \\
\text { constants } \\
\end{array}$ & 1.2 & $300-1500$ & $\begin{array}{l}\text { Vessel has 6-mm-diam aperture with sapphire } \\
\text { window for directly viewing sample; typical } \\
\text { sample 10-mm-diam } \times 10 \text {-mm-length }\end{array}$ \\
\hline $\begin{array}{l}\text { Diamond-anvil cells } \\
\text { (B.) }\end{array}$ & $P, T$, & $\begin{array}{l}\text { Optical reflectivity, } \\
\text { optical absorption, } \\
\text { electrlcal resistivity, } \\
\text { FTIR, fluorescence } \\
\text { and emisslon } \\
\text { spectroscopy, } \\
\text { Raman spec- } \\
\text { troscopy, time- } \\
\text { resolved } \\
\text { fluorescence, } \\
\text { Mössbauer } \\
\text { spectroscopy, x·ray } \\
\text { crystal structure, } \\
\text { P-V, melting, } \\
\text { reaction kinetics, } \\
\text { and phase equilibria }\end{array}$ & $\begin{array}{l}50 \\
400\end{array}$ & $\begin{array}{c}10-300 \\
300-1000, \text { or } \\
300-2800 \\
\text { (pulsed) }\end{array}$ & $\begin{array}{l}\text { Sample sizes range from } 20-\mu \mathrm{m} \text {-diam } \times 2-\mu \mathrm{m} \text {-thick } \\
\text { to } 300-\mu \mathrm{m} \text {-diam } \times 150-\mu \mathrm{m} \text { thick }\end{array}$ \\
\hline $\begin{array}{l}\text { Cubic-anvil system } \\
\text { (B.) }\end{array}$ & $\vec{P}, T$ & $\begin{array}{l}\text { Phase equilibria, } \\
\text { diffusion kinetics, } \\
\text { phase trans- } \\
\text { formations }\end{array}$ & 25 & $300-2700$ & $\begin{array}{l}\text { Two-stage cubic-anvil "MA-8" assembly. Sample } \\
\text { volume at } 25 \mathrm{GPA} \sim 1 \mathrm{~mm}^{3} \text {. Larger volumes at } \\
\text { lower pressures. Used in mnjuncliun with } 11-\mathrm{MN} \\
\text { press. }\end{array}$ \\
\hline
\end{tabular}


Table 1. (Continued.)

\begin{tabular}{|c|c|c|c|c|c|}
\hline $\begin{array}{c}\text { Apparatus name/ } \\
\text { section no. }\end{array}$ & Variables & $\begin{array}{c}\text { Properties } \\
\text { measurable }\end{array}$ & $\begin{array}{c}\mathbf{M a x} P \\
(\mathbf{G P a})\end{array}$ & $\begin{array}{c}T \text { range } \\
(\mathbf{K})\end{array}$ & Description \\
\hline $\begin{array}{l}\text { Piston cylinder } \\
\text { (B.) }\end{array}$ & $P, T$ & $\begin{array}{l}\text { P-V, } \\
\text { phase equilibria, } \\
\text { diffusion kinetics, } \\
\text { phase trans- } \\
\text { formations }\end{array}$ & $\begin{array}{l}3.0 \\
4.0 \\
4.6 \\
4.6 \\
\end{array}$ & $\begin{array}{c}300 \\
300-673 \\
300-1800 \\
300-673 \\
300-1800\end{array}$ & $\begin{array}{l}\text { Highest pressures are achieved using 6.8-MN } \\
\text { (Kennedy) press frame; lower pressures when a } \\
\text { 3.0-MN frame is used. } \\
\text { Max sample } 51-\mathrm{mm} \text {-diam } \times 76-\mathrm{mm} \text {-length. } \\
\text { Max sample } 10-\mathrm{mm} \text {-diam } \times 40 \text {-mm-length. } \\
\text { Max sample 13-mm-diam } \times 40 \text {-mm-length; six } \\
\text { cells available. } \\
\text { Max sample } 19-\mathrm{mm} \text {-diam } \times 40 \text {-mm-length; two } \\
\text { cells available. } \\
\text { Max sample } 25-\mathrm{mm} \text {-diam } \times 40 \text {-mm-length; six } \\
\text { cells avallable. }\end{array}$ \\
\hline $\begin{array}{l}\text { Hydrothermal } \\
\text { (B.) }\end{array}$ & $P, T$ & $\begin{array}{l}\text { Phase equilibria in } \\
\text { hydrothermal } \\
\text { systems }\end{array}$ & $\begin{array}{l}0.4 \\
1.0\end{array}$ & $\begin{array}{l}300-1200 \\
300-1000\end{array}$ & $\begin{array}{l}\text { Four vessels available. All vessels are cold-seal } \\
\text { type. } \\
\text { Four vessels avallable. }\end{array}$ \\
\hline $\begin{array}{l}\text { 1-atm controlled } \\
\text { atmosphere } \\
\text { (B.) }\end{array}$ & $T, f_{\mathrm{O}_{2}}$ & $\begin{array}{l}\text { Phase equilibria, } \\
\text { atomic diffusion }\end{array}$ & $10^{-4}$ & $300-1900$ & $\begin{array}{l}\text { Standard gas-mixing furnaces for conducting } \\
\text { experiments under controlled oxygen fugacities. } \\
\text { One furnace has been adapted for vacuum } \\
\text { operation with isotopically enriched gases. }\end{array}$ \\
\hline
\end{tabular}

therefore requires large and heavy cylinders of metal to contain high-pressure fluids without bursting. The items in Table 1 are for the most part bulky but able to generate and withstand tremendously high forces.

The emphasis in this report is on the mechanical nature of each apparatus. Electronic equipment and computational steps in data reduction are mentioned only where they assume key roles in the experiments. In particular, we make no further mention of automated data acquisition and control of environmental variables. Microcomputers and microprocessor-based controllers have proliferated to the point where the reader may safely assume that most of the routine operations are handled by computers.

\section{Organization and Summary of this Report}

Table 1 lists and briefly describes each apparatus mentioned in this report. More detailed descriptions, organized according to type of measurement, follow this section. There are two main categories of measurement, physical properties (Section $A$ ) and phase equilibria and kinetics (Section B). Diverse equipment defies neat organization (whether on paper or in the lab). Nevertheless, we have subdivided these two categories, and sometimes subdivided again, in an effort to make this diversity comprehensible to those outside the laboratory. Physical properties are subdivided into mechanical (Section A.1.), hydrologic (A.2.), electrical (A.3.), thermal (A.4.), and optical (A.5.). Mechanical properties, in turn, are subdivided into sections: elastic (Section A.1.1.) and inelastic (A.1.2.).

Rock mechanics (Section A.1.) constitutes the largest single part of the Experimental Geophysics Laboratory. We have several general-purpose presses with interchangeable pressure vessels that can be used for measuring mechanical properties at room temperature. The press frames have reaction capacities of $11 \mathrm{MN}, 3.6$ MN (there are three of these), 3.0 MN, and 1.0 MN. The vessels for use in these presses have pressure capacities up to $2.2 \mathrm{GPa}$.
Elastic properties (Section A.1.1.) can be measured statically, using strain gauges, or dynamically, using sonic velocities, in any of the general-purpose press/ vessel systems as long as the high-pressure end plug has electrical feedthroughs. One vessel, the 1-GPa ultrasonic vessel, was specially designed for making ultrasonic measurements. Most room-temperature measurements of inelastic properties (Section A.1.2.) can also be handled by the general-purpose press frames listed above. Two pieces of equipment can impose a stress state that is other than uniaxial compression under confining pressure: the true triaxial block testing apparatus allows independent control of normal stress in three orthogonal directions on rectangular blocks measuring up to $400 \mathrm{~mm}$ on a side; the 0.5-GPa extensional apparatus has the unique feature that $\sigma_{3}$ aligns with the cylinder axis of the sample, causing the sample to lengthen rather than shorten as in the more conventional designs. Specialized equipment for high- or lowtemperature deformation tests include the 0.3-GPa externally heated vessel (used with one of the 3.6-MN frames), the externally heated $0.5-$ GPa creep apparatus, the internally heated 0.7-GPa creep apparatus, the room-temperature 1.5-GPa creep apparatus, the ice 
creep apparatus for testing at $T<273 \mathrm{~K}$, and the 1 -atm creep apparatus. The intermediate strain-rate apparatus, which operates at strain rates in the range $10^{-2}$ to $10^{2} \mathrm{~s}^{-1}$, also has a capability for operating at $T<273 \mathrm{~K}$. The rotating-cup viscometer measures the viscosity of silicate melts and partial melts at $T \leq 1700 \mathrm{~K}$. For measuring anelasticity of rocks, we have recently constructed the 0.4-GPa attenuation apparatus that operates at seismic frequencies at elevated $T$ and $P$.

We have three types of apparatus for measuring the hydrologic properties of rock and fractures in rock (Section A.2.). Two of them measure several properties simultaneously in order to diagnose changes to the pattern of fluid flow. The 0.2-GPa large-bore apparatus, of which there are two, measures fluid flow as well as electrical conductivity, sonic velocity, elasticity, and fracture closure on large samples at room temperature and under differential stresses up to several hundred $\mathrm{MPa}$. The 0.1-GPa hydrology apparatus measures fluid flow, sonic velocity, and electrical conductivity at temperatures as high as $573 \mathrm{~K}$. The third type of apparatus, the 0.1GPa hot permeability vessel, of which there are two, measures liquid and gas permeability only, at temperatures as high as $800 \mathrm{~K}$. A related piece of analytical equipment is our 3-D profilometer, which converts fracture topography to digital form for use in computer simulations.

Specialized equipment for measuring electrical properties of rocks (Section A.3.) includes the 1-atm conductivity apparatus for work on single crystals and polycrystals under conditions of high $T$ and controlled $t_{\mathrm{O}_{2}}$, the 1.0-GPa conductivity vessel, and the girdle-anvil systems used mainly in the wide-platen 9.1-MN press. As mentioned in the previous paragraph, two other apparatuses measure electrical conductivity in conjunction with other physical properties measurements.

Our capabilities for measuring thermal transport properties of rocks at elevated $T$ and $P$ (Section A.4.) include the thermal properties apparatus, which measures conductivity and diffusivity on rocks up to $125 \mathrm{~mm}$ in diameter; the thermal diffusivity apparatus, for diffusivity measurements on 25-mm-diameter samples; and the line probe apparatus for conductivity measurements on 75-mm-diameter samples.

We can measure optical properties of minerals (Section A.5.) under gas confining pressure, using the 1.2GPa sapphire window vessel, and in the diamondanvil cell to pressures well above $200 \mathrm{GPa}$.

Our equipment for measuring phase equilibria and kinetics (Section B) includes several diamond-anvil cells, capable of reaching pressures of $250 \mathrm{GPa}$ or more; a cubic-anvil system capable of reaching $25 \mathrm{GPa}$ (used in the 11-MN press); several piston-cylinder devices capable of reaching 3.0 to $4.6 \mathrm{GPa}$ (used in either a specially designed $6.8-\mathrm{MN}$ press or in the $3.0-\mathrm{MN}$ press) and sixteen cold-seal hydrothermal vessels that operate at $1.0 \mathrm{GPa}$ or below. Most of these apparatuses are designed for use at elevated temperatures. Atomic diffusion as well as phase equilibria can be studied in our 1-atm controlled-atmosphere apparatus, which provides a high-temperature, controlled $f_{\mathrm{O}_{2}}$ annealing environment.

\section{A. Physical Properties Measurements}

\section{A.1. Rock Mechanics}

\section{General-Purpose Frames and Vessels}

Because of our continued historical interest in properties of the upper crust, we have extensive capabilities for measuring the mechanical properties of rock at elevated pressure and room or near-room temperatures. These measurements include elastic constants, inelastic strain under hydrostatic loading (so-called " $P-V$ " measurements), and inelastic strain under nonhydrostalic loading.

The equipment for making these measurements includes five general-purpose press frames and seven interchangeable pressure vessels that fit within these frames. The press frames have reaction capacities of $11 \mathrm{MN}, 3.6 \mathrm{MN}$ (there are three of these), 3.0 MN, and $1.0 \mathrm{MN}$. Each is simply a monolithic block of steel into which a rectangular opening has been cut (Fig. 1). A hydraulic ram rests on the base of the opening and pushes (through the experimental loading column) against the top of the opening. The stated capacity of the frames is the maximum allowable working force and is approximately $25 \%$ of their ultimate tensile strength. Two of the frames, the $11-\mathrm{MN}$ and the 3.0-MN, are equipped with double-acting concentric rams. The outer ram is a clamping ram, which is useful for confining the ends of a pressure vessel and the inner ram is used to drive a piston.

The pressure vessels used in these frames have pressure limits from 0.3 to $2.2 \mathrm{GPa}$. They are simple or compound cylinders of hardened steel surrounded by a mild steel or aluminum safety ring. Figure 2 shows the 2.0-GPa assembly. The vessels operate with a fixed plug at one end, through which electrical leads pass, and 


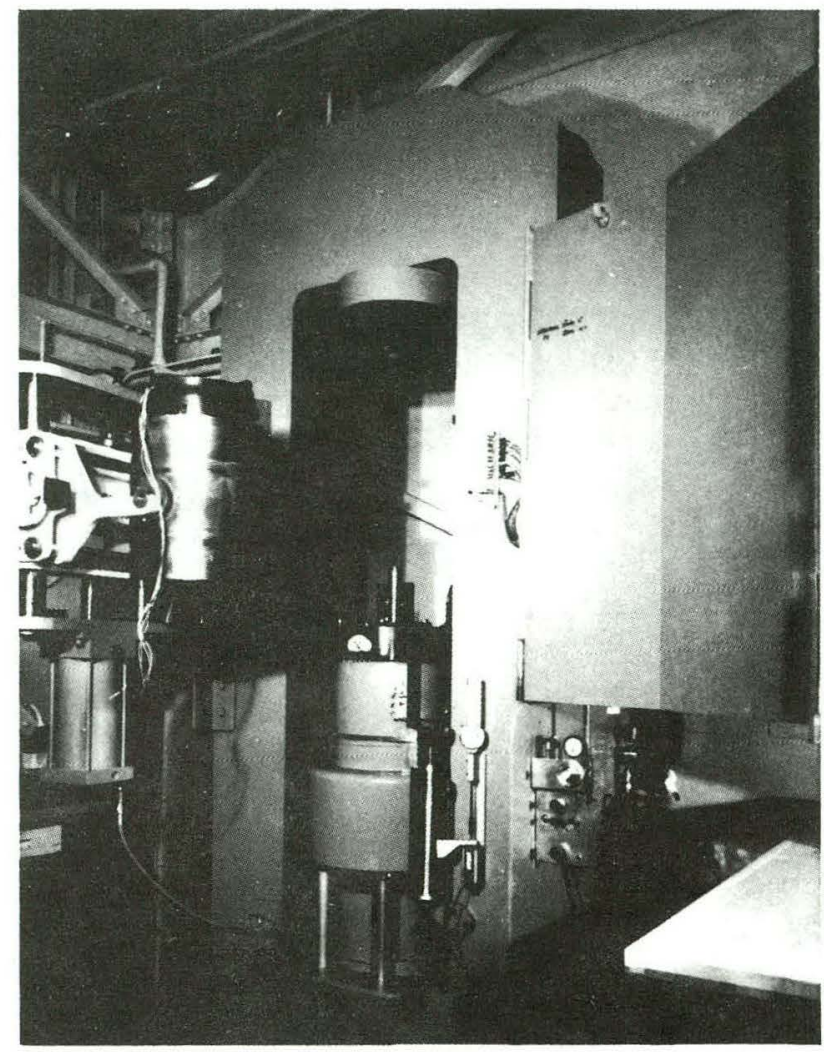

Figure 1. The 11-MN press frame and other components of the experimental system. The two concentric hydraulic rams sit inside the base of the frame, and the 2.0-GPa pressure vessel hangs to the side on its positioning fixture.

a moving piston at the opposite end. Static and sliding high-pressure seals use the Bridgman unsupported area principle (Fig. 2). The inner bores of the vessels range in diameter from 25 to $76 \mathrm{~mm}$. Typical sample dimensions used in the vessels are given in Table 1.

The fluid-confining-pressure medium is usually refined kerosene or oil, but under special circumstances can be pentane-isopentane, methanol-ethanol, silicone fluid, or any other liquid with a suitably low viscosity for the desired pressure range. The vessels are pressurized by an independently controlled intensifier and/or by the motion of the piston itself into the closed volume of the pressure vessel. For nonhydrostatic tests, the independent pressure system is a necessity that prevents pressure from changing as the piston is advanced or withdrawn. In these vessels the pressurizing system is coupled to the vessel through a high-pressure capillary line in the plug. Pressures are measured by the resistance change of a manganin coil immersed in the pressure fluid, by a Heise bourdon-tube gauge in the capillary line between the vessel and intensifier, or by a strain-gauge pressure transducer. Accuracies are about $0.5 \%$ or $1.0 \mathrm{MPa}$, whichever is larger.

Hydrostatic Measurements. The highest capacity vessel used for hydrostatic measurements in a fluid medium has a 2.0-GPa pressure limit and is used in the $11-\mathrm{MN}$ press frame. Working volume is a $200-\mathrm{mm}$ long, $38-\mathrm{mm}$ bore. Figure 1 shows the complete vesselpress system as assembled for use.

Pressure-volume $(P-V)$ behavior, acoustic velocity determinations, and the torsional deformation of copper have been measured to $2.0 \mathrm{GPa}$ in this system. The largest sample that may be accommodated is $32 \mathrm{~mm}$ in diameter by $76 \mathrm{~mm}$ long. Strains are determined by longitudinal and circumferential foil-strain gauges that are bonded to the 0.1 -to- 0.5 -mm lead or copper sample jackets. Figure 3 presents typical results (Heard et al., 1974).

This system also makes independent determinations of elastic moduli by measuring the compressional and shear-wave velocities of sonic waves under pressure (Abey and Bonner, 1975). Either time-of-flight (Birch,

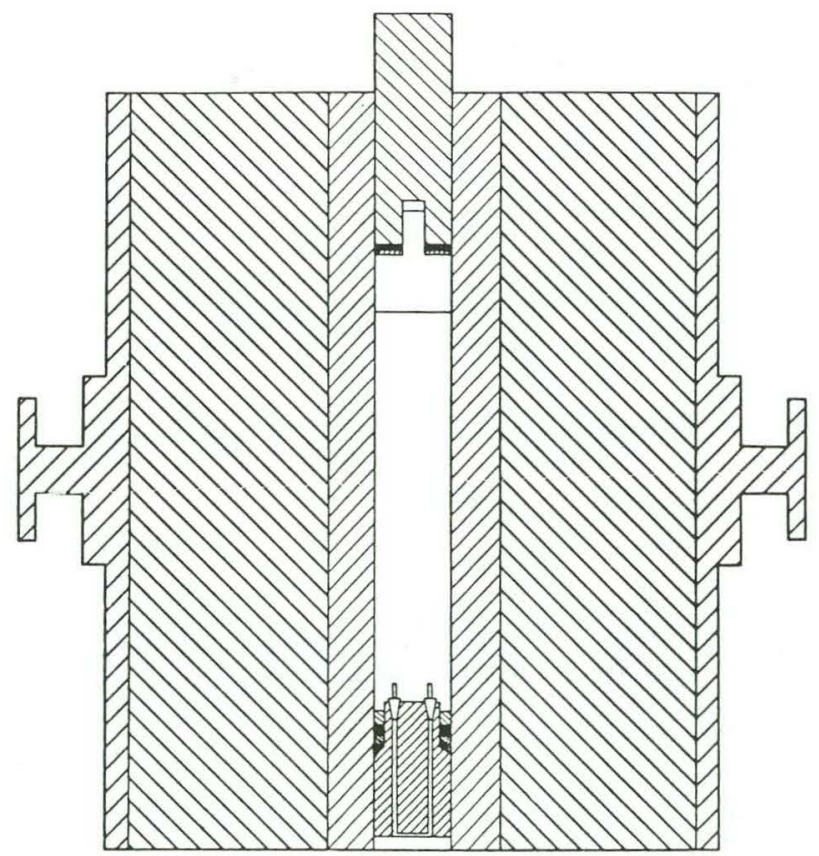

Figure 2. Schematic drawing of the 2.0-GPa hydraulic pressure vessel with closures. 


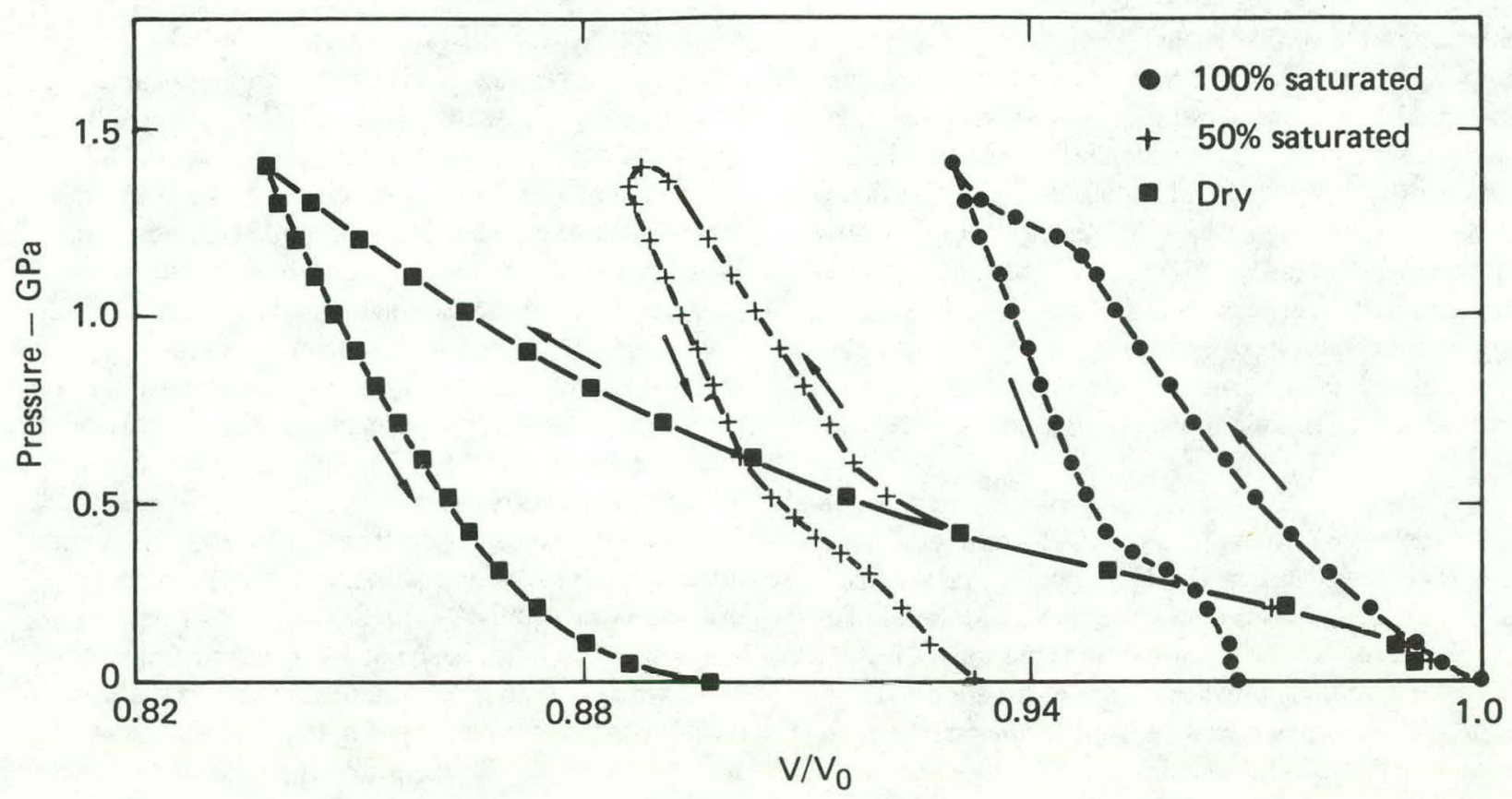

Figure 3. Hydrostatic $P-V$ loading and unloading curves for dry, $50 \%$-saturated, and $100 \%$ saturated Indiana limestone.

1961; Sears and Bonner, 1981) or the pulse-echo overlap (Abey and Bonner, 1975) methods can be used to determine transit times; exciting frequencies are usually 1 to $10 \mathrm{MHz}$. Torsional stress-strain behavior of both solid and hollow rods of any metal may be measured in this vessel at pressure (Abey, 1973). Sample loading is accomplished by a motor gearbox combination coupled to an internal torque gauge placed in the working volume of this vessel. Strain rates may be varied from $10^{-2}$ to $10^{-5} \mathrm{~s}^{-1}$.

Similar hydrostatic measurements can also be made in any of the other general-purpose vessels and press frames. For instance, pressure vessels with bores of 25,38 , and $51 \mathrm{~mm}$ may be accommodated in the 3.6-MN press; all vessels are operated similarly and have identical components, except for scale. Pressure limits for the three vessels are about $2.5,1.5$, and 1.0 $\mathrm{GPa}$, respectively. Figure 4 shows one of the 3.6-MN presses with one of the $38-\mathrm{mm}$ bore vessels in place.

Nonhydrostatic Measurements. Nonhydrostatic conditions are achieved by having the moving piston directly contact the test sample. The accepted terminology is to call these test conditions "triaxial" even though $\sigma_{2}=\sigma_{3}\left(\right.$ or $\left.\sigma_{1}=\sigma_{2}\right)$ at all times. The experimental

Figure 4. One of the three 3.6-MN press frames. The 0.3-GPa externally heated vessel rests atop the hydraulic ram inside the frame. The intensifier for generating fluid confining pressure is seen at the left. The manganin cell is inside the small vessel to the right of the intensifier.

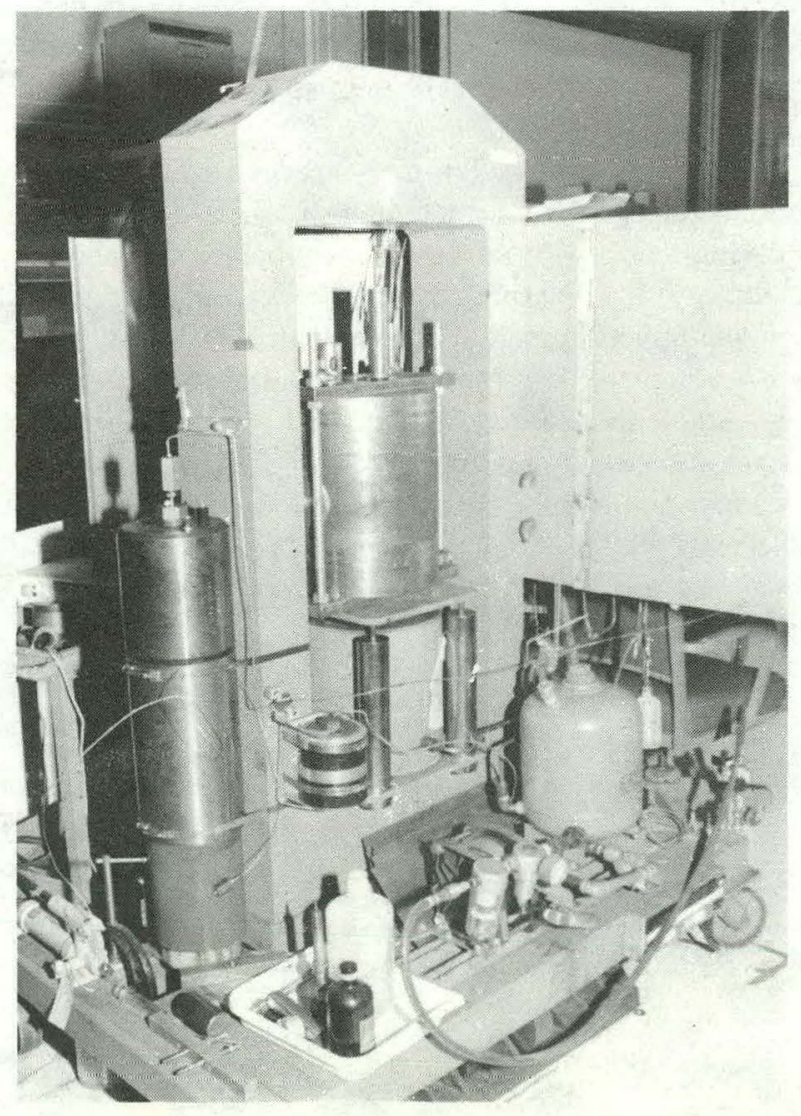


configuration is similar to that for hydrostatic measurements. Axial forces imposed by the loading piston are measured by an internal tungsten carbide load cell placed in series with the sample under pressure. Foil strain gauges cemented to the load cell form the sensing element; electrical leads exit the vessel through the lower plug. Axial stresses and strains are accurate to about $1 \mathrm{MPa}$ and $10^{-5}$, respectively. These values depend somewhat on sample size. Piston (and, hence, sample) displacements are determined externally with a linear potentiometer. Strain rates are limited to about $10^{-4}$ to $10^{-5} \mathrm{~s}^{-1}$.

For triaxial tests at room temperature, samples can be as large as $76 \mathrm{~mm}$ in diameter by $152 \mathrm{~mm}$ long, using the 11-MN press and the 0.3-GPa vessel. Axial force and deformation in this vessel are measured as described above. Radial deformation is measured using a system of cantilevers that monitor deformation in the horizontal centerplane of the sample. The largest possible sample that can be tested in the $3.6-\mathrm{MN}$ press is $40 \mathrm{~mm}$ in diameter by $80 \mathrm{~mm}$ long (in the 0.7 -GPa vessel). Extension tests under pressure are conducted in any of the three different vessels with a sample geometry and tension yoke similar to that described by Bridgman $(1947,1952)$. This yoke limits the diameter to $18 \mathrm{~mm}$ for samples used in extension. A state of true tension can also be achieved with dog-bone shaped samples. The sample jacketing used for either type of test is copper, lead, or one of the various types of high-strength polymers, such as tygon or viton. This apparatus is used primarily to determine axial stress-strain curves at pressures up to about $1.0 \mathrm{GPa}$.

Stress-strain behavior in both compression and extension can be measured at higher pressures (to $2.2 \mathrm{GPa}$ ) by using a plug without a capillary tube, thereby eliminating externai pressure control. In this mode of operation, confining pressure increases with axial stress, and only failure strengths for brittle or near-brittle materials are possible to measure, not the usual stress-strain curves at constant pressure. At the highest pressures, possible sample dimensions are limited to $10 \mathrm{~mm}$ in diameter by $40 \mathrm{~mm}$ long. Examples of results can be found in Heard et al. (1973), Schock and Heard (1974), and Heard et al. (1976).

\section{A.1.1. Elastic Properties-Specialized Equipment}

\section{1-GPa Ultrasonic Vessel}

The 1-GPa ultrasonic vessel system is designed to measure ultrasonic wave velocities and the anisotropy of rocks at hydrostatic pressures to $1.0 \mathrm{GPa}$. It consists of a pressure vessel with a bore $90 \mathrm{~mm}$ in diameter by $250 \mathrm{~mm}$ long. Pressure is measured by a manganin coil inside the pressure vessel and a Heise gauge outside. The pressure vessel can test rock samples as large as a cube $50 \mathrm{~mm}$ on a side. Such a sample is big enough to have three 6-mm-diameter ultrasonic transducers mounted on each face so that velocities in many directions can be measured simultaneously. In this way, velocity anisotropy of a sample can be determined without the uncertainty of sample-to-sample variation. The plug on the pressure vessel has 24 electrical leads so that 12 measurements of velocity can be made at once. These velocity measurements are sufficient for characterizing a sample whose velocity tensor has at least orthorhombic symmetry (McSkimin, 1964).

This system has been used to determine the ultrasonic wave velocities of Mesaverde rocks of the western tight-gas-sands formations. Figure 5 shows one sample with transducers. The assembly is potted in Scotchcast to prevent the pressure medium from penetrating into the sample. Figure 6 shows the velocities of one of the Mesaverde rocks as a function of confining pressure. Dynamic elastic moduli of the Mesaverde rocks are calculated and compared with those obtained by other methods, such as laboratory static deformation and field sonic logging (Lin and Heuze, 1987).

\section{Girdle-Anvil Systems}

Acoustic velocities measured with the pulse superposition technique can be performed to about $8 \mathrm{GPa}$ in

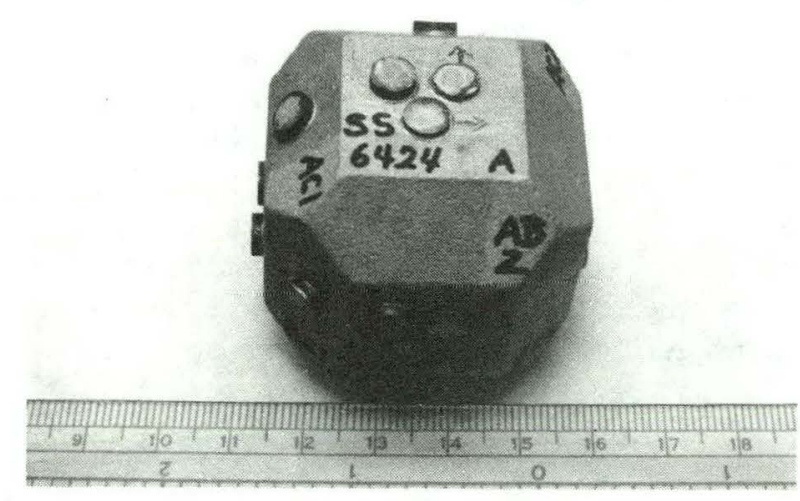

Figure 5. A Mesaverde sandstone sample with ultrasonic transducers. The three principal faces are A, $\mathrm{B}$, and $\mathrm{C}$. Face $\mathrm{A}$ is parallel to bedding. The diagonal faces $\mathrm{AB}, \mathrm{AC}$, and $\mathrm{BC}$ are between the corresponding two principal faces. The scale is in centimeters. 


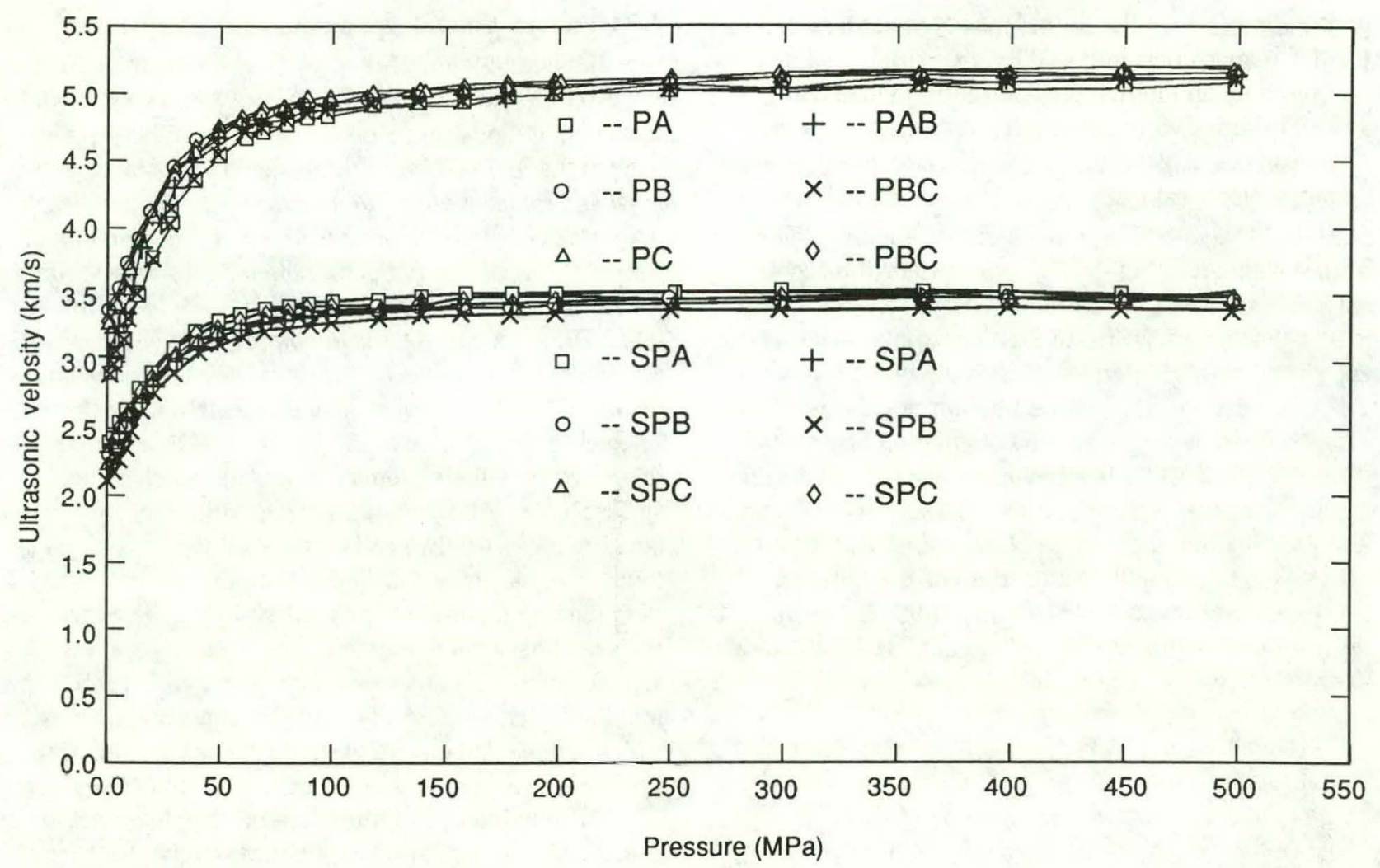

Figure 6. Ultrasonic velocities of a Mesaverde sandstone from 1958-m depth as a function of pressure. The upper group is P-wave; the lower group is S-wave. The symbols show wave directions. For example, PA is $\mathrm{P}$-wave in the direction perpendicular to face A; SAB is S-wave travels in the direction perpendicular to face $A$ and vibrates in the direction perpendicular to face $B$.

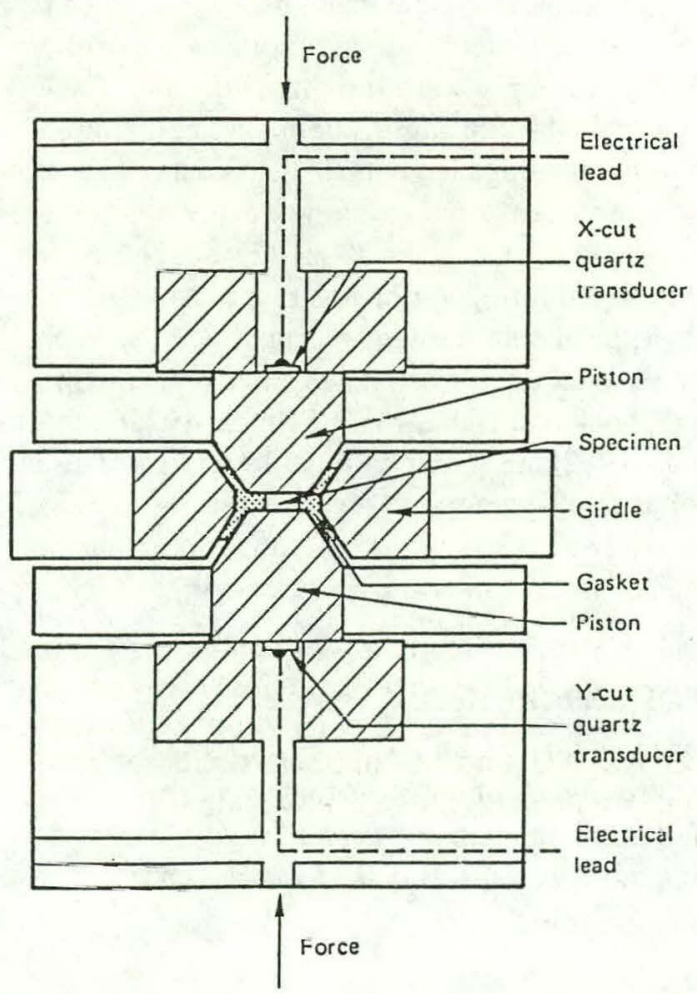

the girdle-anvil using an arrangement shown schematically in Fig. 7. In addition to measuring ultrasonic transmission, linear voltage displacement transducers (LVDTs) are used to measure piston displacement as a function of pressure. Thus, velocity data can be converted to include changes in sample length caused by pressure. Correction for compressibility of the tungsten carbide pistons can also be made. Samples up to $0.65 \mathrm{~cm}$ in diameter by $0.4 \mathrm{~cm}$ long can be measured in this apparatus. Temperatures up to $1300 \mathrm{~K}$ on smaller samples can be achieved at reduced pressures ( 5 to $6 \mathrm{GPa}$ ). See Gilmore (1968) for a discussion of these techniques.

Figure 7. Supported piston-anvil girdle assembly for ultrasonic measurements. 


\section{A.1.2. Inelastic Properties-Specialized Equipment}

\section{True Triaxial-Block Testing Apparatus}

The true triaxial-block testing apparatus uses a system of flatjacks and actuators to apply a true triaxial stress field $\left(\sigma_{1}>\sigma_{2}>\sigma_{3}\right)$ to a block of material. The frame is shown in Fig. 8. The apparatus will accommodate cubic samples up to $400 \mathrm{~mm}$ on a side. Stresses up to $35 \mathrm{MPa}$ can be applied to each face of the block. This apparatus can also operate in a uniaxial or biaxial mode. The large sample size afforded by this apparatus allows characterization of a rock mass containing heterogeneities on the order of a few inches in size. This versatile apparatus can be used to study topics such as hydrofracture propagation, thermal properties, fluid flow in porous or fractured media, and certain drilling problems. It is expected to be on-line by early 1990 . This apparatus is similar to that used by Blair et al. (1988) to study hydrofracture propagation in rocks.

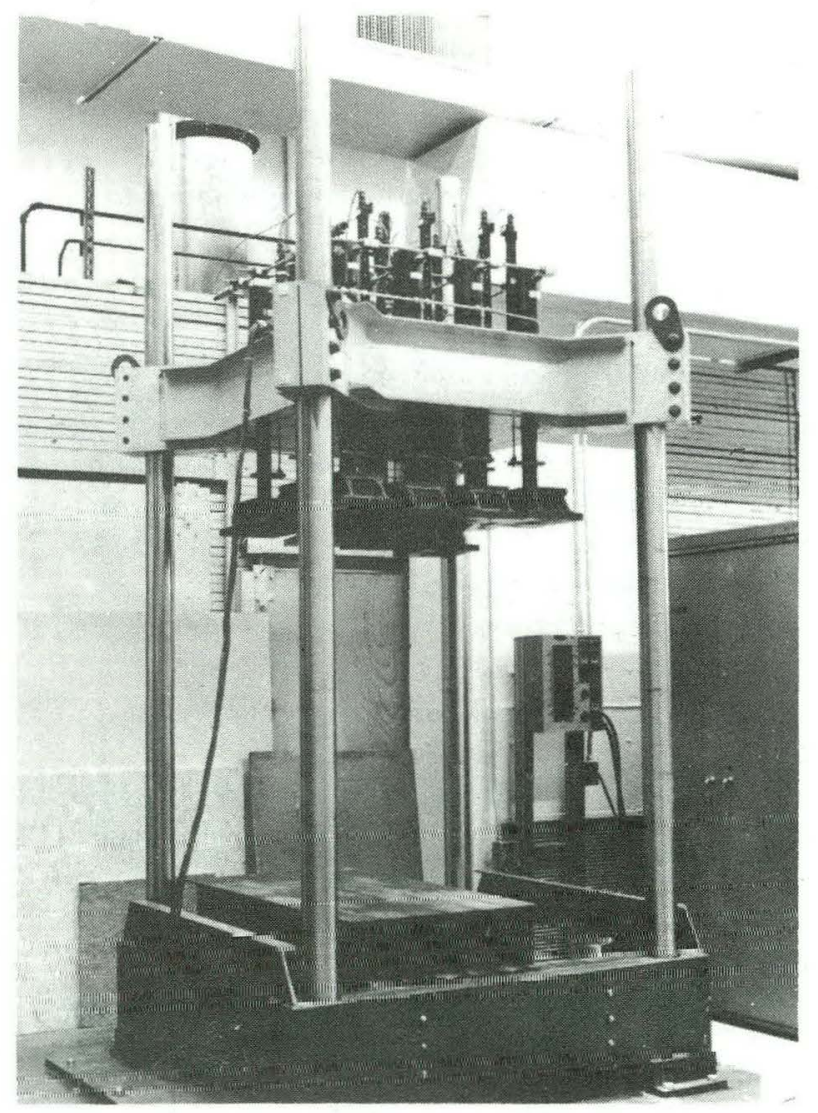

Figure 8. Loading frame used for triaxial block-testing apparatus.

\section{5-GPa Extensional Apparatus}

It is possible to achieve pressure-volume, uniaxial stress (compression, extension, or true tension), uniaxial strain, and other stress-strain conditions in a unique apparatus that has separate fluid systems to generate the axial and radial stresses. A schematic diagram of the 0.5-GPa extensional apparatus vessel is shown in Fig. 9. Maximum axial and radial pressures (and stresses) for a standard 25-mm-diameter cylindrical sample are 0.5 $\mathrm{GPa}$. Higher axial stresses in compression or lower axial stresses in extension (or tension) may be reached by grinding the central region to a diameter smaller than $25 \mathrm{~mm}$. The use of low-friction O-rings to separate these two pressure systems requires a smooth contact surface. Thus, this apparatus is best suited for lowporosity rocks $(<10 \%)$ and works well with a $0.03-\mathrm{mm}$ thick epoxy layer as a jacketing membrane. The unique fluid loading feature that generates the axial stress allows loading without any tractions at the ends of the sample; such tractions would be present with a solid loading piston because of compliance mismatch between sample and piston. A complete description of the apparatus is given by Schock and Duba (1972).

The maximum and minimum principal stresses are calculated directly from Heise bourdon-tube pressuregauge readings on each separate system and from the ratio of maximum and minimum diameters of the sample. Pairs of axial and circumferential strain gauges cemented to the thin epoxy jacket determine strains in the center of the sample. These gauges are spaced at $90^{\circ}$ intervals with gauges in each pair at $180^{\circ}$.

The addition of two manganin pressure cells (one for each pressure system) allows automated control of an experiment along any arbitrary loading path. The test can be controlled using stress, strain, or a combination of each as the sensing elements. All test data have been taken near room temperature, but relatively minor modifications would permit use to about $475 \mathrm{~K}$. The apparatus is best suited for operation at strain rates of $10^{-3}$ to $10^{-6} \mathrm{~s}^{-1}$. Typical data showing elastic moduli with pressure and uniaxial compression and extension stress response (Schock and Duba, 1972; Schock, 1978; Schock and I ouis, 1982) arc slıuwn in Figs. 10 and 11. This apparatus has also been used to measure ultrasonic velocity in uniaxial stress (rnmpression) to failuse (Bunner, 1974) The ettect of pressuie un strain gauges (Schock and Duba, 1973) has also been measured.

\section{$0.3 \mathrm{GPa}$ Exteı urally Heated Vessel}

One pressure vessel is designed for use at elevated temperatures in one of the 3.6-MN general-purpose frames. It has a temperature capability of $550 \mathrm{~K}$ and a confining pressure capability $0.3 \mathrm{GPa}$ and can 


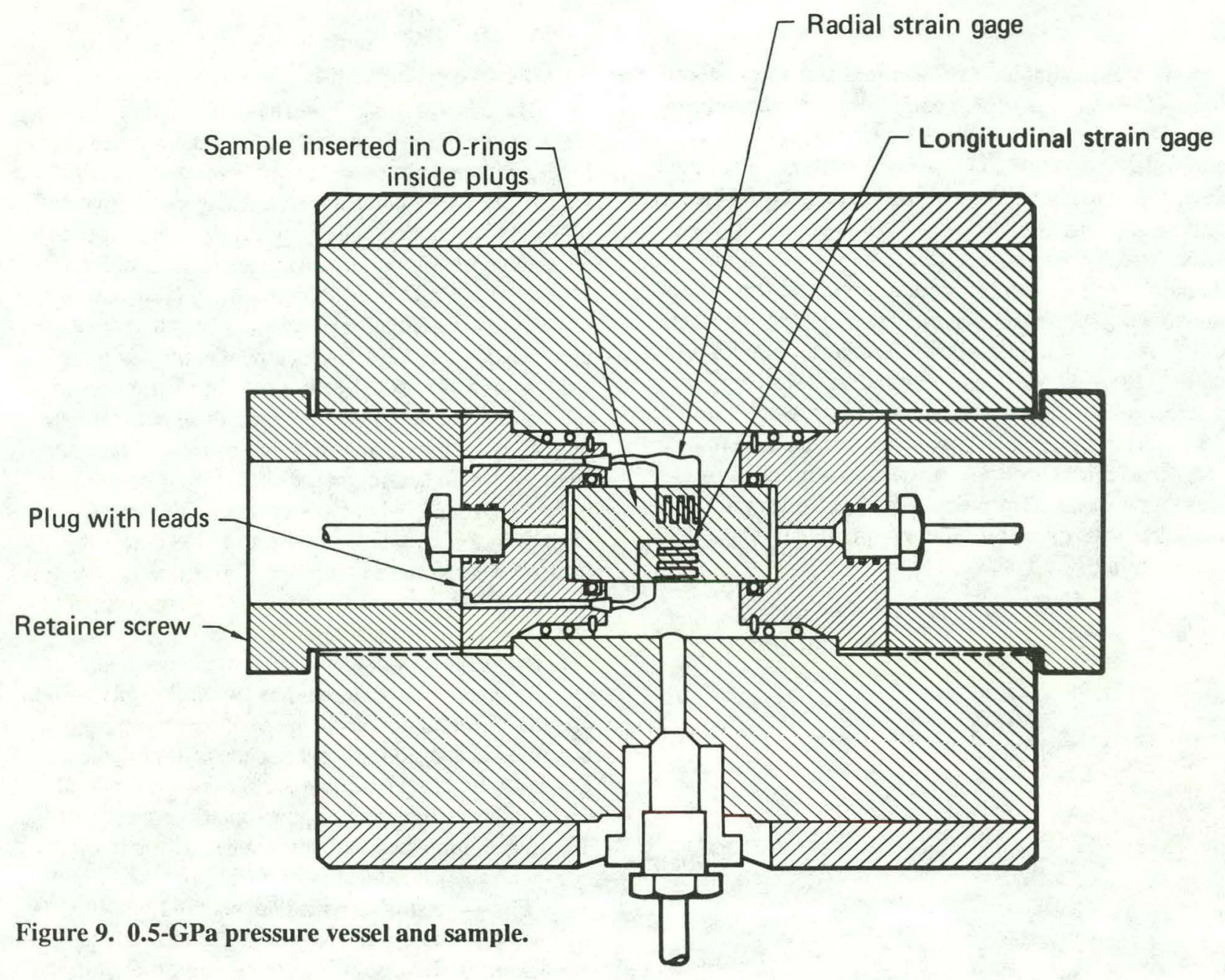

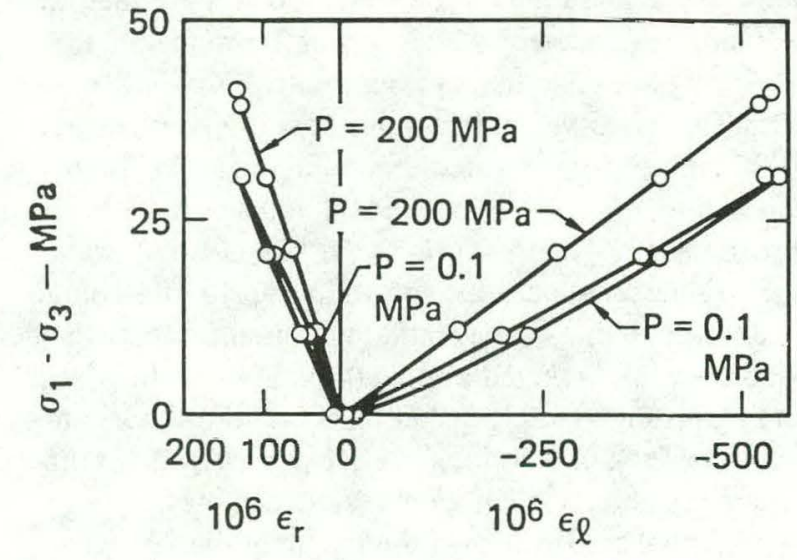

Figure 10. Stress difference vs axial and circumferential strain, Westerly granite, uniaxial stress loading.

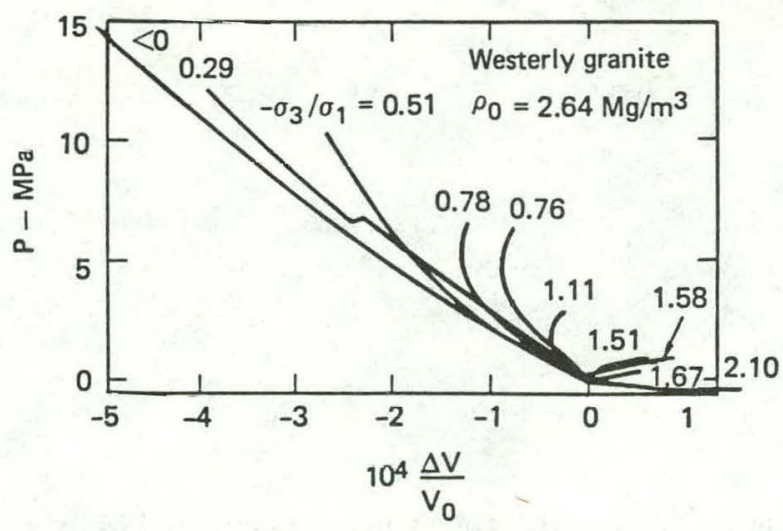

Figure 11. Mean stress vs volume strain for Westerly granite tested in uniaxial stress loading in extension. 
accommodate samples $25.4 \mathrm{~mm}$ in diameter by $80 \mathrm{~mm}$ long. The vessel is heated externally using band heaters. Temperature is monitored internally and can be controlled to within $1.5 \mathrm{~K}$. Axial force on the sample is determined using an internal load cell that is formed as part of the bottom-end closure. This vessel is shown schematically in Fig. 12. Axial force is determined by deflection of the load cell with reference to the base of the vessel. The sensing element is a displacement transducer. This vessel also allows for control of pore pressure up to $0.1 \mathrm{GPa}$. Pore pressure is generated by using a screw press and is monitored using pressure transducers and Heise gauges. This system can be used to determine the failure envelope of rocks as a function of temperature and effective pressure. An example of measurements on an oil shale sample (Blair et al., 1987) is shown in Fig. 13.

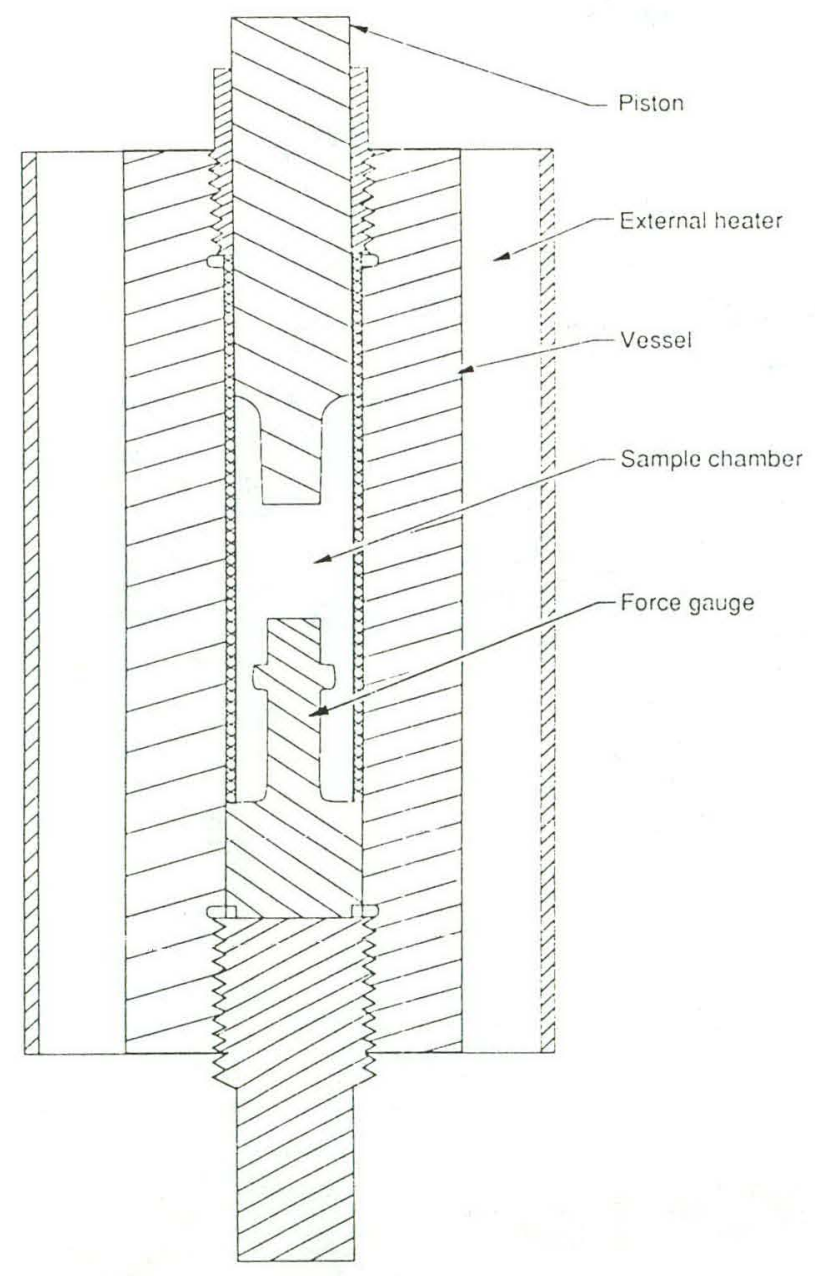

Figure 12. Assembly drawing of vessel used to measure mechanical properties while controlling confining and pore pressure at elevated temperatures.

\section{5-GPa Creep Apparatus}

The time-dependent mechanical properties of very weak to very strong materials can be determined at moderate temperature and confining pressures in the versatile $0.5-\mathrm{GPa}$ creep apparatus shown schematically in Fig. 14. Two identical screw-driven units are used for either compression or extension testing at strain rates $10^{-1}$ to $10^{-8} \mathrm{~s}^{-1}$. Operation in the creep (constant stress) mode is also possible. The screw-driven loading configuration allows precise displacement control at high loads with a very stiff loading system. Varied strain rates are possible by interchanging the electrical-drive motors and the transmissions that rotate the main screw shaft. A thrust bearing in the shaft-vessel coupling removes the rotational components from the screw motion; thus, the sample loading piston that enters the pressure vessel moves only linearly. Similar drive systems are used for the 1.0- and 1.5-GPa creep apparatuses and for the ice creep apparatus.

The pressure vessels are constructed of a hotworked tool steel. External heating limits operation to about $775 \mathrm{~K}$ and necessitates use of an inert fluid (carbon dioxide or argon) to generate the confining pressure. Loads applied to the sample are sensed internally at pressure and temperature but are measured externally. This is accomplished with a force gauge that is simply a dog-bone shaped extension of the high-pressure end plug (Fig. 14; a similar gauge appears in Fig. 19). The elastic distortion of the gauge under load is independent of packing friction, so it is directly proportional to the end load on the sample. The distortion of the gauge can be sensed through an axial passageway, which is on the room pressure side of the gauge (plug). Hence, all electrical connections are outside the vessel.

Two different sizes of pressure vessels may be used on each loading frame. Except for the level of confining pressure, testing conditions and operations are identical in all cases. The smaller vessel accepts test samples up to $10 \mathrm{~mm}$ in diameter by $20 \mathrm{~mm}$ long for moderate to strong materials and has a pressure capability of 0.5 $\mathrm{GPa}$. The larger vessel is designed for moderate to weak samples from 13 to $25 \mathrm{~mm}$ in diameter by 24 to $50 \mathrm{~mm}$ long. Maximum pressure at $300 \mathrm{~K}$ is $0.4 \mathrm{GPa}$; at maximum temperature it is $0.3 \mathrm{GPa}$. The loading frame with this vessel attached is shown in Fig. 15. Pore fluid pressure up to that of the confining pressure can be introduced to the jacketed sample through the hollow loading piston. Sample jacketing is 0.2 -mm-thick copper, aluminum, or lead tubing. Accuracies in stress difference are about $0.1 \mathrm{MPa}$ for $10-\mathrm{mm}$ samples.

Thermal gradients over the length of the test samples vary from 1 to $4 \mathrm{~K}$, depending somewhat on temperature and length of the sample. Temperatures for 


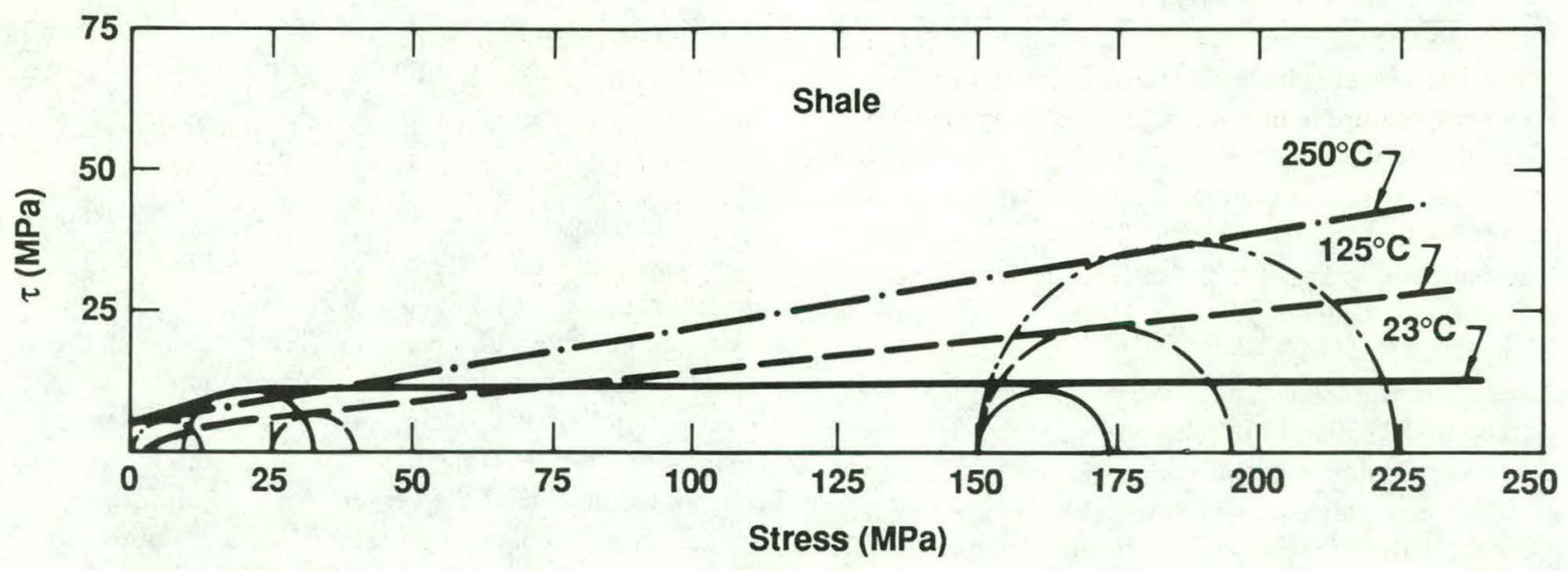

Figure 13. Mohr circles for shale at 23,125 , and $250^{\circ} \mathrm{C}$.

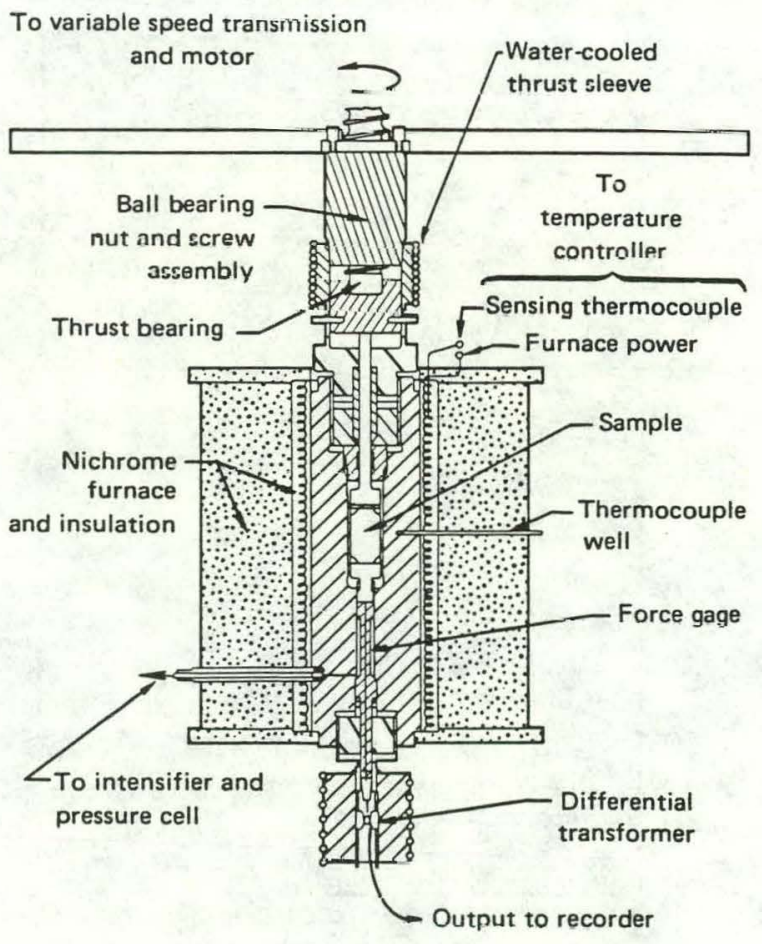

Figure 14. 0.5-GPa creep apparatus with external heater. The system is capable of measuring the strength of materials at $T \leq 773 \mathrm{~K}$.

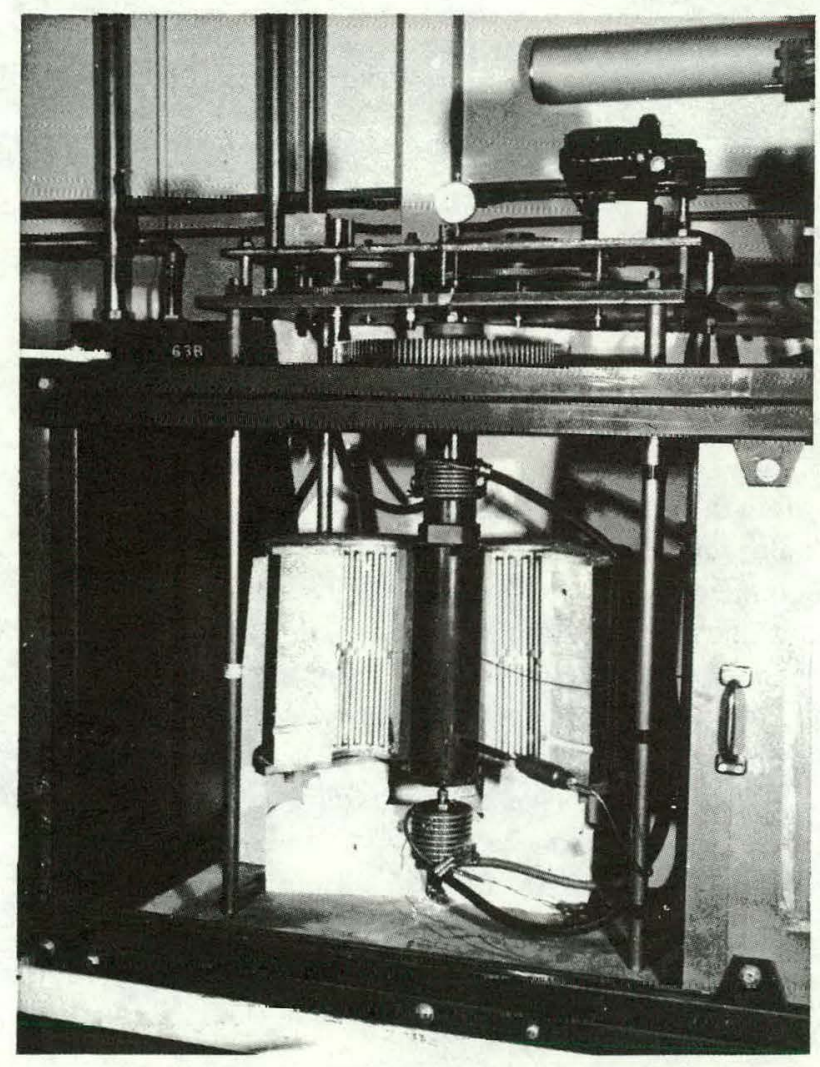

Figure 15. A photograph of the system shown schematically in Fig. 14. 


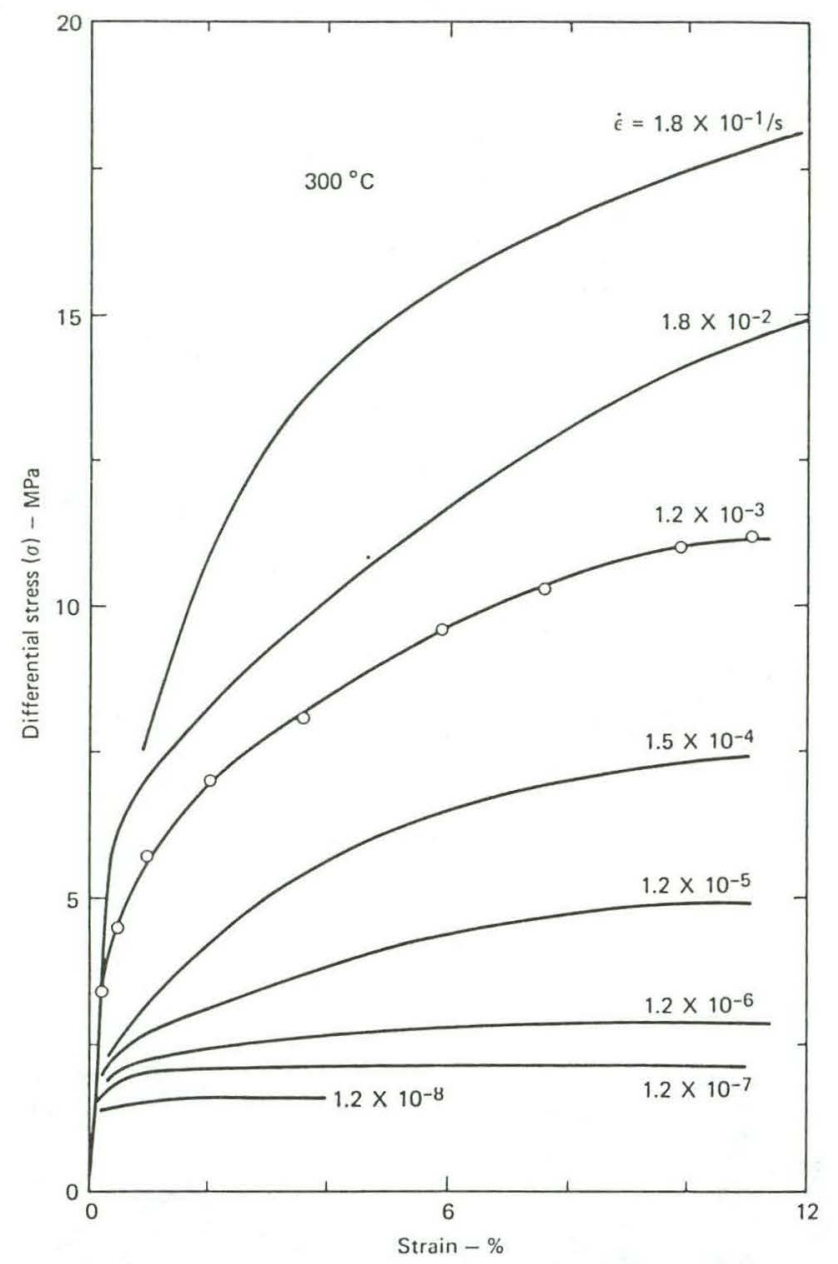

Figure 16. $\sigma_{1}-\sigma_{3}$ vs axial strain, polycrystalline salt, $573 \mathrm{~K}$, strain rates $10^{-1}$ to $10^{-8} \mathrm{~s}^{-1}$.

either vessel are accurate within about $2 \mathrm{~K}$. Confining pressures are generated by external intensifiers and measured by a manganin cell. These pressures are accurate within $0.5 \%$ or $1 \mathrm{MPa}$, whichever is greater. Axial strains and strain rates are known to be about $0.1 \%$. Complete descriptions of the operation of this apparatus as well as representative data on marble and halite flow can be found in Heard (1963), Carter and Heard (1970), and Heard (1972). Figure 16 illustrates typical stressstrain curves for halite (Heard, 1972).

This apparatus has been modified for acoustic emission experiments to $773 \mathrm{~K}$ by adding high-temperature electrical feedthroughs to fixed closure plug (Wang et al., 1989). Another modification to measure thermal diffusivity is described in Section A.4.

\section{7-GPa Creep Apparatus}

Constant displacement rate or creep testing in either compression or extension can be conducted at high temperatures and high confining pressures in a screwdriven apparatus that is internally heated. Most of the experimental data that have been generated by this apparatus describe the strength or steady-state flow behavior of earth materials. Figure 17 illustrates typical data acquired with this apparatus (Heard and Raleigh, 1972).

The $0.7 \mathrm{GPa}$ creep apparatus is similar to that described in the previous section. The pressure vessel is mounted horizontally. Temperatures of 300 to $1473 \mathrm{~K}$ are attained in the sample area with a resistance furnace residing in the bore of the vessel. Temperatures in the sample area are measured with a thermocouple inserted in a small hole in the loading piston assembly. Heat dissipation in the wall of the vessel is optimized by water cooling the outside of the vessel. An internal force gauge similar to the one described in the previous section is used to measure load on the sample during experiments. Sample strain rates from $10^{-2}$ to $10^{-8} \mathrm{~s}^{-1}$ are selected by drive gears and/or drive motors in the drive train to the screw. A thrust bearing placed in the

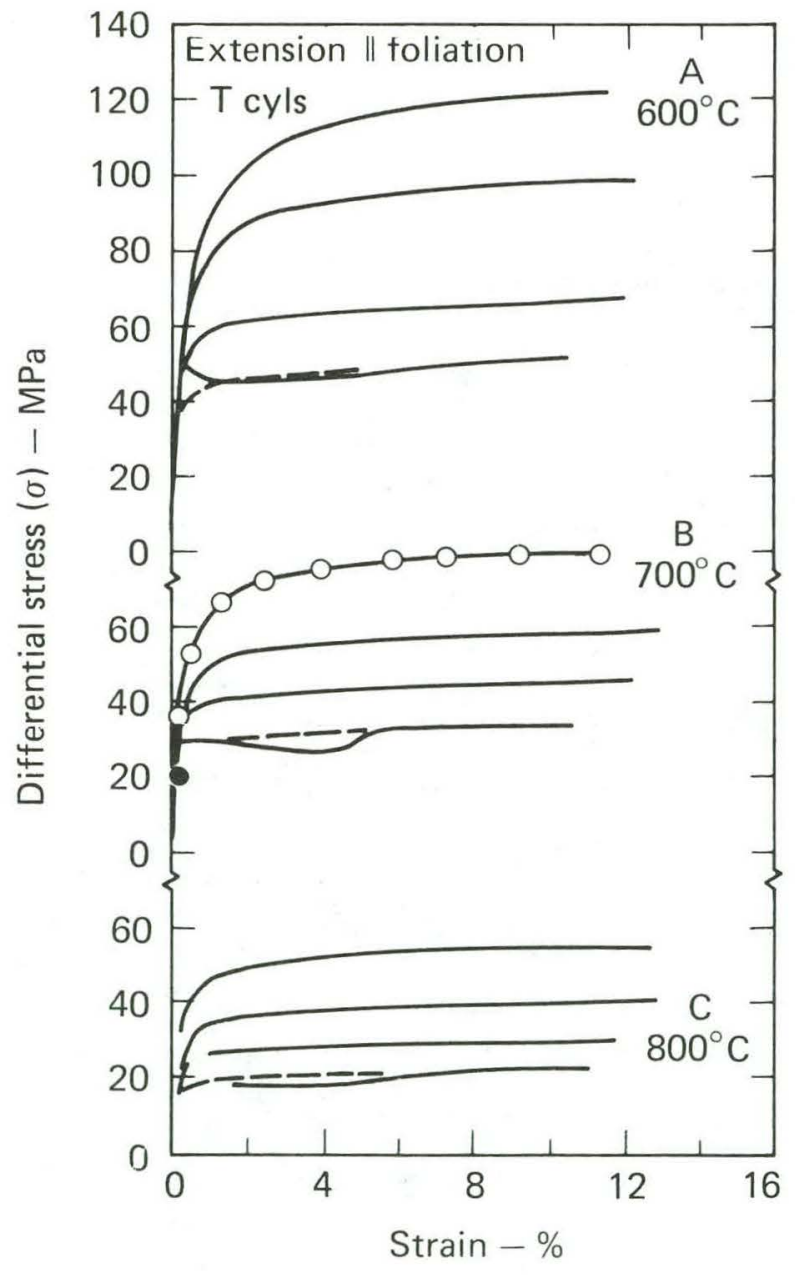

Figure 17. $\sigma_{1}-\sigma_{3}$ vs axial strain, Yule marble, 600 to $800^{\circ} \mathrm{C}$, extensional strain rates $10^{-3}$ to $10^{-6} \mathrm{~s}^{-1}$. 
coupling between the screw-drive mechanism and the loading piston ensures that only axial displacement of the screw is translated to the sample.

Confining pressure for the system is provided by pressurization of argon gas. High-pressure argon is generated by a gas booster and two hydraulically driven gas intensifiers. Automatic control of the confining pressure is accomplished by a feedback/control loop consisting of a manganin cell, millivolt comparator, and solenoid valves in the air line that drives the hydraulic pump. Pressure control is accurate to about $0.5 \mathrm{MPa}$ at $300 \mathrm{MPa}$.

The pressure vessel described here has suffered internal damage due to extensive use over its productive 20-year lifetime, and its pressure capability has been downgraded to $0.4 \mathrm{MPa}$. A replacement vessel is now being built. It has been conservatively designed so that creep experiments can be performed routinely up to 0.7 $\mathrm{GPa}$ and $1573 \mathrm{~K}$. This vessel will incorporate features such as a pressure-compensated loading piston and a 50 -mm-diameter bore that will accommodate a larger sample size and a more efficient furnace design.

\section{5-GPa Creep Apparatus}

Figure 18 shows a specialized creep apparatus used to determine uniaxial stress-strain behavior in compression. This unit consists of a 5.4-MN-capacity screw-driven loading system mounted horizontally and coupled to a multiwalled pressure vessel through a quick-disconnect coupling. The 44-mm-diameter tungsten-carbide loading piston is designed for a 25-mm-diameter by 50 -mm-long test sample with strength $\left(\sigma_{1}-\sigma_{3}\right)$ to $5.0 \mathrm{GPa}$. The piston can be altered slightly to accommodate samples of more moderatestrength materials up to about $35 \mathrm{~mm}$ in diameter. Test sample jackets may be 0.1 - to 0.2 -mm-thick copper, lead, aluminum, or polymeric material.

The pressure vessel is fitted with a tungsten-carbide load cell and manganin pressure-sensing coil. The pressure seal around the loading piston is controlledclearance Newhall packing (Johnson and Newhall, 1953; Griggs et al., 1960). Isopentane is the pressure fluid for work to $1.5 \mathrm{GPa}$; thus, only measurements near room temperature are possible. The main vessel could be fitted with an internal furnace for high-temperature use with silicone fluids or inert gases.

Confining pressure is accurate to $\pm 0.5 \%$ or $2 \mathrm{MPa}$, whichever is greater. Displacement of the loading pistor is accurate to about $0.02 \mathrm{~mm}$; axial sample strains and strain rates are accurate to about $0.1 \%$. Sensitivity in stress difference on the sample is about $1 \mathrm{MPa}$, but accuracy is only about $4 \mathrm{MPa}$.

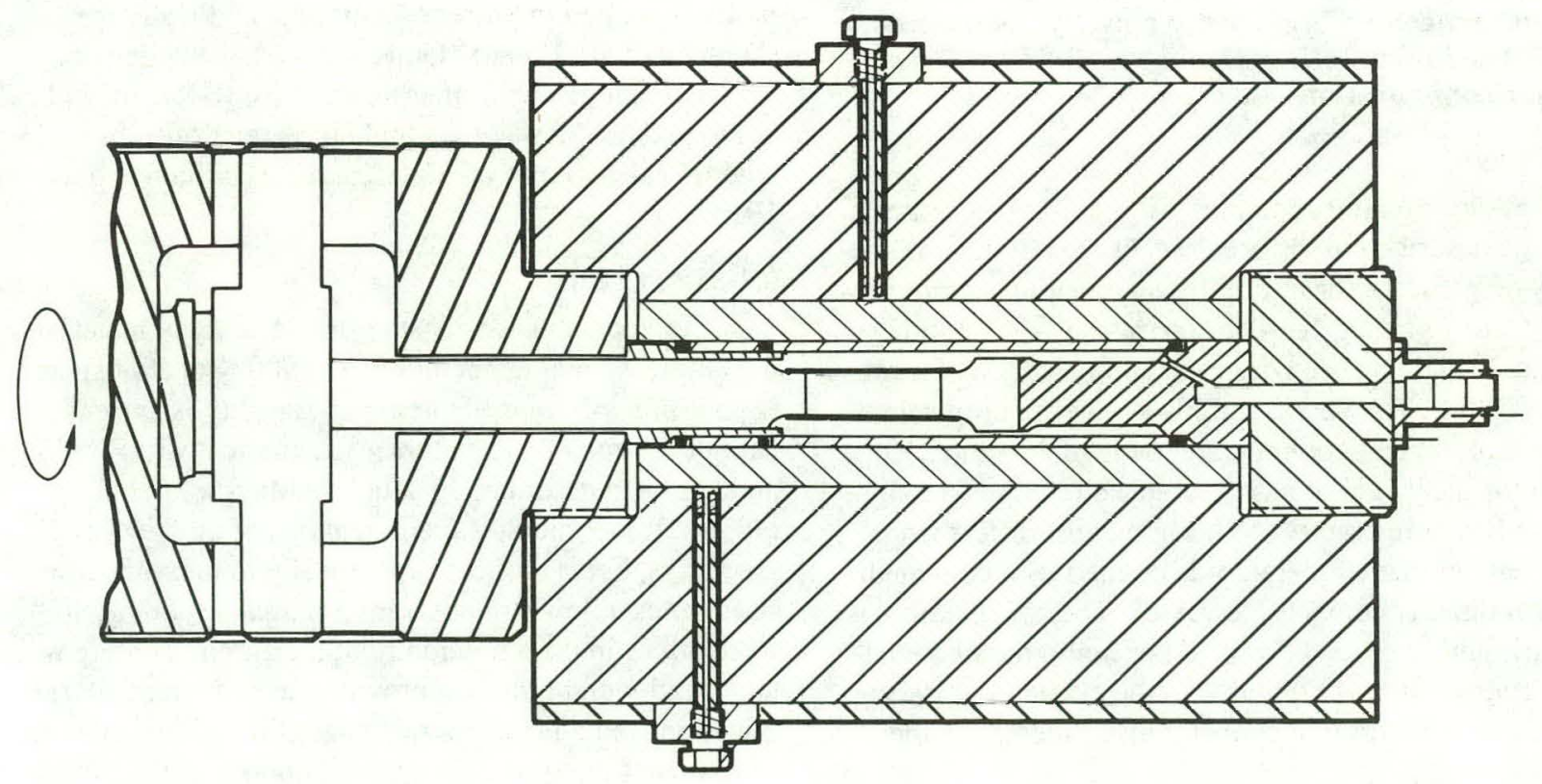

Figure 18. 1.5-GPa creep apparatus. 


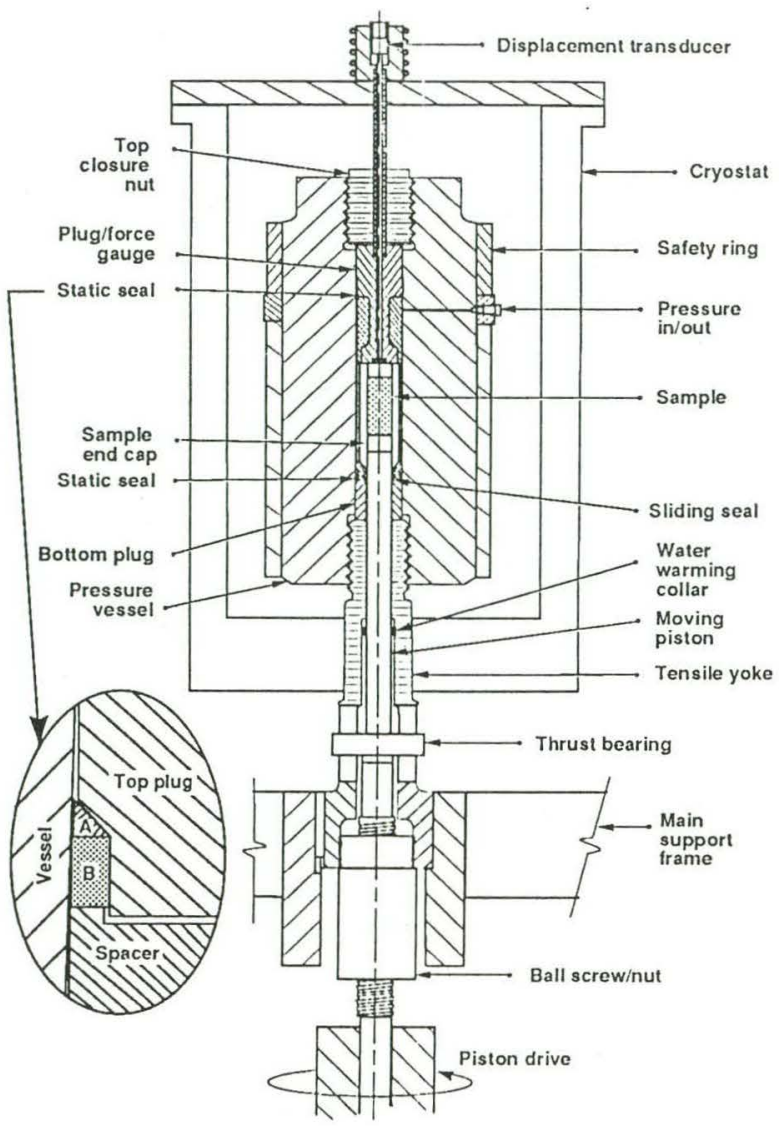

Figure 19. Assembly drawing of the ice creep apparatus. Inset: detail of the upper static seal. " $A$ " is the indium-coated brass mitre ring, " $\mathrm{B}$ " is the teflon ring. The lower static seal and the sliding seal have similar configurations.

\section{Ice Creep}

A deformation apparatus similar in most respects to those described in the previous two sections was specially constructed for testing frozen volatiles at temperatures from 77 to $273 \mathrm{~K}$. The apparatus is shown in Figs. 19 and 20 and has been described more fully by Heard et al. (1990). The vessel and load-bearing components of the experimental column are made of 300 and 350 maraging steel, which has favorable strength and toughness at low temperatures. This apparatus differs from the others in that temperature is defined by a cold medium that directly contacts the vessel. The cold medium is either liquid nitrogen $(T=77 \mathrm{~K})$ or liquid or solid ethanol. Temperature is regulated in the ethanol by passing liquid nitrogen through copper coils immersed in the ethanol.

The confining medium can be argon, nitrogen, or helium, depending on pressure and temperature conditions. Normal sample size is $25 \mathrm{~mm}$ in diameter by $63 \mathrm{~mm}$ long. Sample jackets are $0.5-\mathrm{mm}$ tubes of indium welded with a soldering iron to indium-coated steel

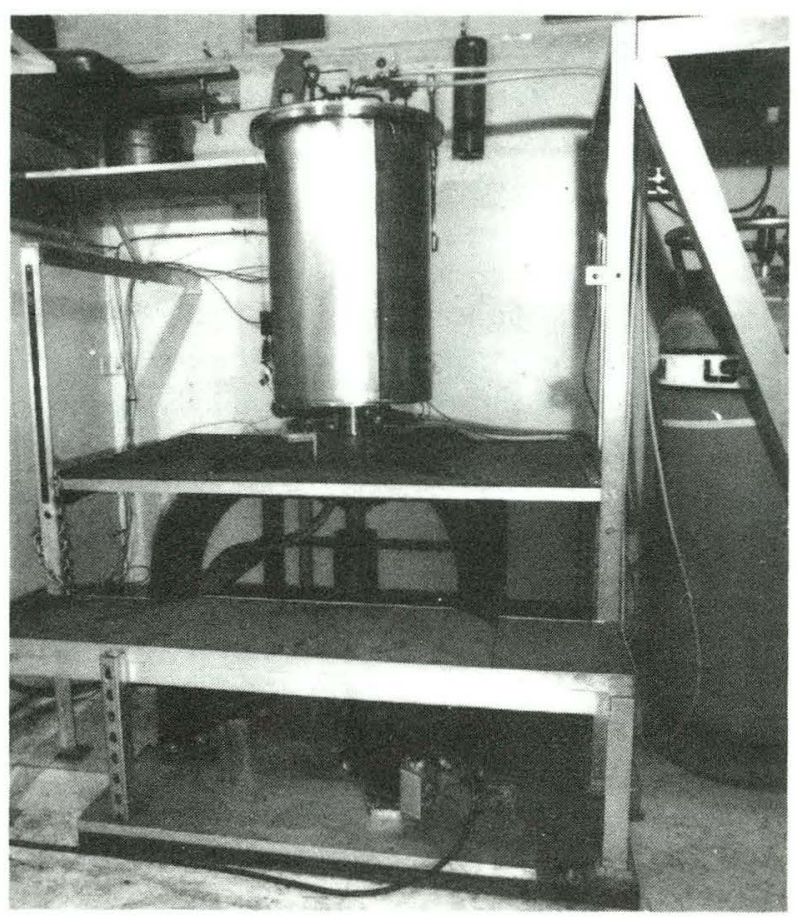

Figure 20. Photograph of the ice creep apparatus. The assembly stands approximately $2 \mathrm{~m}$ tall.

end caps. Because the end caps are not sealed to the piston, samples can only be loaded in compression.

Experiments have been done in this apparatus on the brittle and ductile flow of pure water ice (Durham et al., 1983c; Kirby et al., 1987), of mixtures of ice and rock particles (Durham et al., 1989), and of solid and partially molten mixtures of ammonia and water ice (Durham et al., 1988a). Other work has been done on the frictional behavior of sawcuts in ice (Beeman et al., 1988) and on the rheology and phase relationships among water ice phases II, III, and V (Durham et al., 1988b).

\section{1-MPa Creep}

An apparatus for constant-load testing of materials in compression at temperatures to $1900 \mathrm{~K}$ at atmospheric pressure and controlled oxygen fugacity is currently being constructed. It is shown schematically in Fig. 21, and has been described in detail by Mackwell et al. (1990). It incorporates many features of other 0.1-MPa creep rigs, but is designed specifically to measure slow strain rates at low stresses with minimal sensitivity to fluctuations in the temperature of the air and cooling water. Dead-weight loading provides accurate load determination, and an in situ strain cage (Fig. 22), consisting of four rods that sense the top and bottom of the sample provides a direct measure of sample shortening. The apparatus also features a double-frame assembly for ease of sample loading. The apparatus will be used to measure the strength of refractory earth materials as well as to deform unjacketed samples of fine-grained 


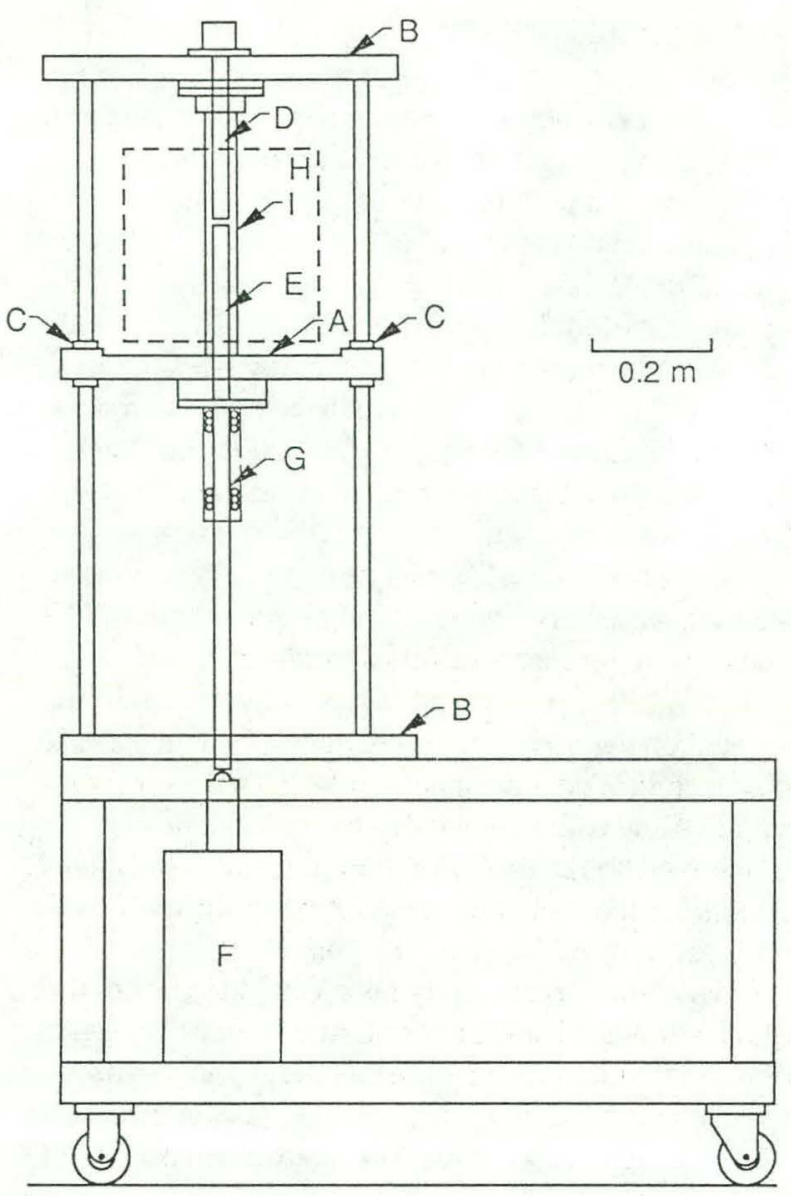

Figure 21. Schematic diagram of the 0.1-MPa creep apparatus. The ball bushings on the inner plate allow it to move vertically with respect to the outer frame, for access to the sample and strain cage shown in Fig. 22.

aggregates where low differential stresses $(<1 \mathrm{MPa})$ may be neressary to prevent cavitation and brittle failure.

\section{Intermediate Strain-Rate Apparatus}

One-dimensional stress and strain loading presents difficult machine-design and data acquisition prohlems. especially at high pressures and strain rates. Figure 23 shows a loading system with its associated highpressure vessel that operates at strain rates of $10^{-2}$ to $10^{2} \mathrm{~s}^{-1}$. Pressure vessels with $63-$ and $162-\mathrm{mm}$ bores may be used in this apparatus with pressure limits of 1.0 $\mathrm{GPa}$ and $70 \mathrm{MPa}$, respectively. Different velocities at the sample loading piston are achieved by coupling one of several electrical motors to the main flywheel. At the desired speed, the flywheel is engaged to the main horizontal drive shaft that has a cam to drive the sample loading piston. This cam is decoupled from the main

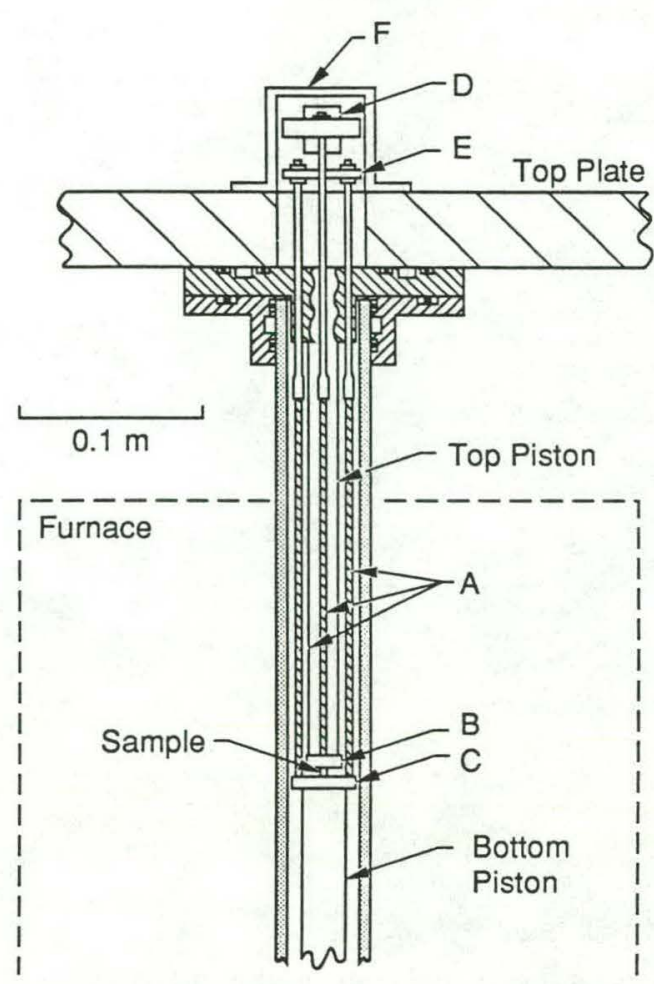

Figure 22. Schematic drawing of the strain measurement assembly for the 0.1-MPa creep apparatus.

shaft at about 15 degrees rotation after striking the loading piston; thus, the piston gives only a single impulse to the sample. A brake slows the flywheel-shaft assembly after a test. A schematic drawing of the vessel-sample assembly is shown in Fig. 24.

A maximum stress difference of about $2.5 \mathrm{GPa}$ can be applied to a $25-\mathrm{mm}$-diameter sample. The sample $75-\mathrm{mm}$ in diameter by $150-\mathrm{mm}$ long (typical of the

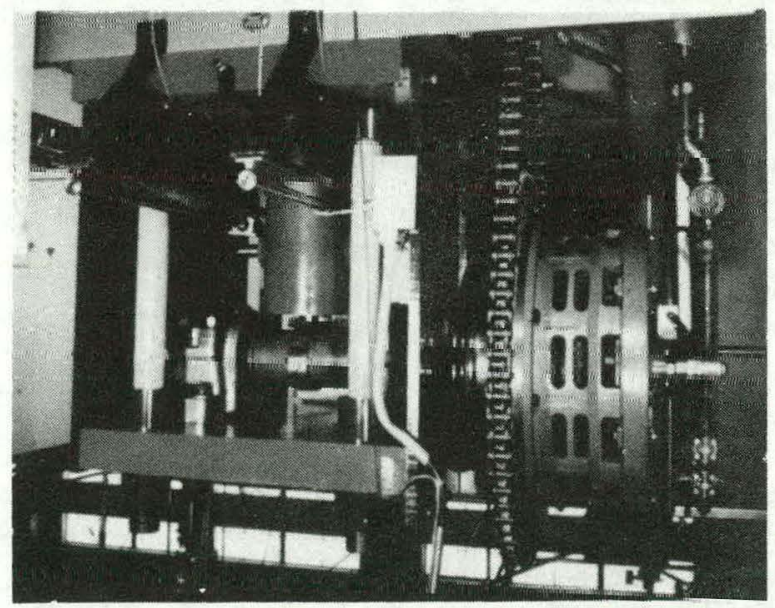

Figure 23. Intermediate strain-rate apparatus configured for testing at $10^{-2} \mathrm{~s}^{-1}$. The vessel is shown anchored in place prior to testing. For higher rates the chain is removed and the flywheel is driven with belts. 


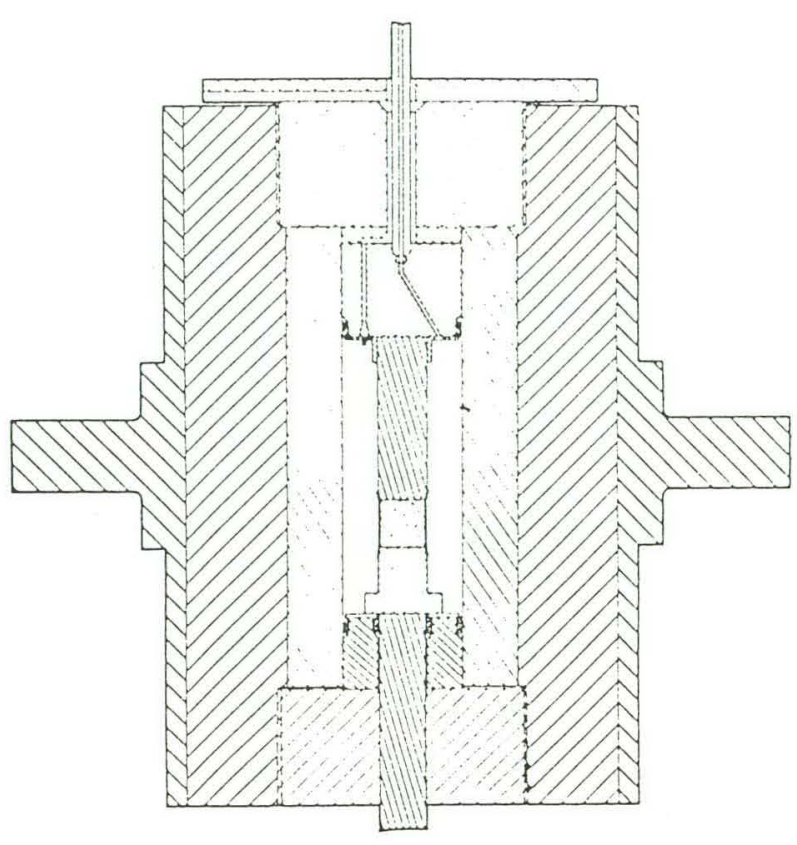

Figure 24. 1.0-GPa pressure vessel, intermediate strain-rate apparatus.

70-MPa vessel) limits the possible stress differences here to about $0.20 \mathrm{GPa}$. Gas is used as the confining medium. Pressure is measured with a manganin cell and a Heise bourdon-tube gauge. The stress pulse applied to the sample under pressure is determined by an internal load cell in series with the jacketed sample. Foil strain gauges are used on the load cell and on certain samples with low porosity and low strain at failure. Estimated accuracies of the stress determination are about $1 \%$ or $5 \mathrm{MPa}$, whichever is larger (Abey and Dibley, 1977).

For compressible and low moduli materials, special eddy-current displacement indicators are used. During a test, the velocity of the top sample end cap is monitored using a linear velocity transducer. A high-speed digitizing recorder digitizes and records velocity data and data from other sensing elements. Axial displacement vs time is then calculated by integrating the velocity as a function of time. Test temperatures are usually near room temperature. However, a cooling jacket has been made to fit the vessels, and tests have been performed on ice at temperatures of 253 and $263 \mathrm{~K}$ (Blair et al., 1986; Blair, 1987). The apparatus has also been used to produce multiple (more than two) fractures in liquid-filled boreholes by pressurizing the liquid at intermediate rates (Swift and Kusubov, 1982). The strength of weathered sandstone at intermediate rates has also been measured (Blair et al., 1989).

\section{Rotating-Cup Viscometer}

Stress-strain rate relationships for molten and partially molten silicates (and potentially other molten systems) can be measured for viscosities between 1 and $10^{6} \mathrm{~Pa} \cdot \mathrm{s}$ with a rotating-cup viscometer (Figs. 25 and 26). The viscometer assembly is housed within a threezone platinum-rhodium alloy resistance furnace. The viscometer assembly consists of a Pt30\%Rh "cup and bob," with the molten sample occupying the annulus (Fig. 25). The cup, attached to a drive motor and gear train, can be rotated between 0.1 and $200 \mathrm{rpm}$. The stress exerted on the bob by the rotating liquid is measured by one of two sensors. The sensors are in the form of torsion bars in which the angle of twist is measured by strain gauges arranged as a Wheatstone bridge. The combination of sensors covers a torque range of $7 \times 10^{-4}$ to $7 \mathrm{~N} \cdot \mathrm{m}$. Labyrinth-type rotatable seals are mounted on the drive and torque measurement tubes to allow a controlled atmosphere to be passed over the sample. Hence, the fugacity of oxygen can be controlled, which is critically important for iron-bearing systems. A more detailed description of the basic system is given by Weed et al. (1978).

The system has recently been used to measure the non-Newtonian viscosities of picritic compositions from Kilauea Iki at temperatures below the liquidus with crystal contents as high as 45 vol\% (Ryerson et al., 1988). Sample flow curves (shear stress vs strain rate) are shown in Fig. 27.

\section{4-GPa Attenuation Apparatus}

Figures 28 and 29 show an apparatus for measuring the frequency-dependent complex modulus of materials at elevated temperature and pressure. Material stiffness and damping of vibrations (also called seismic attenuation or internal friction) can be computed from this quantity. The apparatus is a torsional oscillator that twists a sample about an equilibrium position at driving frequencies ranging from $10^{-2}$ to $10^{+2} \mathrm{~Hz}$. Eddy-current proximity detectors monitor equilibrium-positions at two locations along the torsion bar, which transmit torque from the electromechanical assembly at the left to the sample and the elastic member that serves as a load cell. Measurements at average torsional strains ranging from $10^{-7}$ to $10^{-4}$ are currently possible. This apparatus has been used to show the effect of thermal microfracturing on shear attenuation in granites (Wanamaker and Bonner, 1988) and to show that the nonlinear component of attenuation increases with fatigue damage in crystalline rock (Bonner et al., 1989). The experimental assembly is designed to be inserted into the pressure vessel shown in Fig. 30, which has been successfully proof- tested to $550 \mathrm{MPa}$. The pressure 


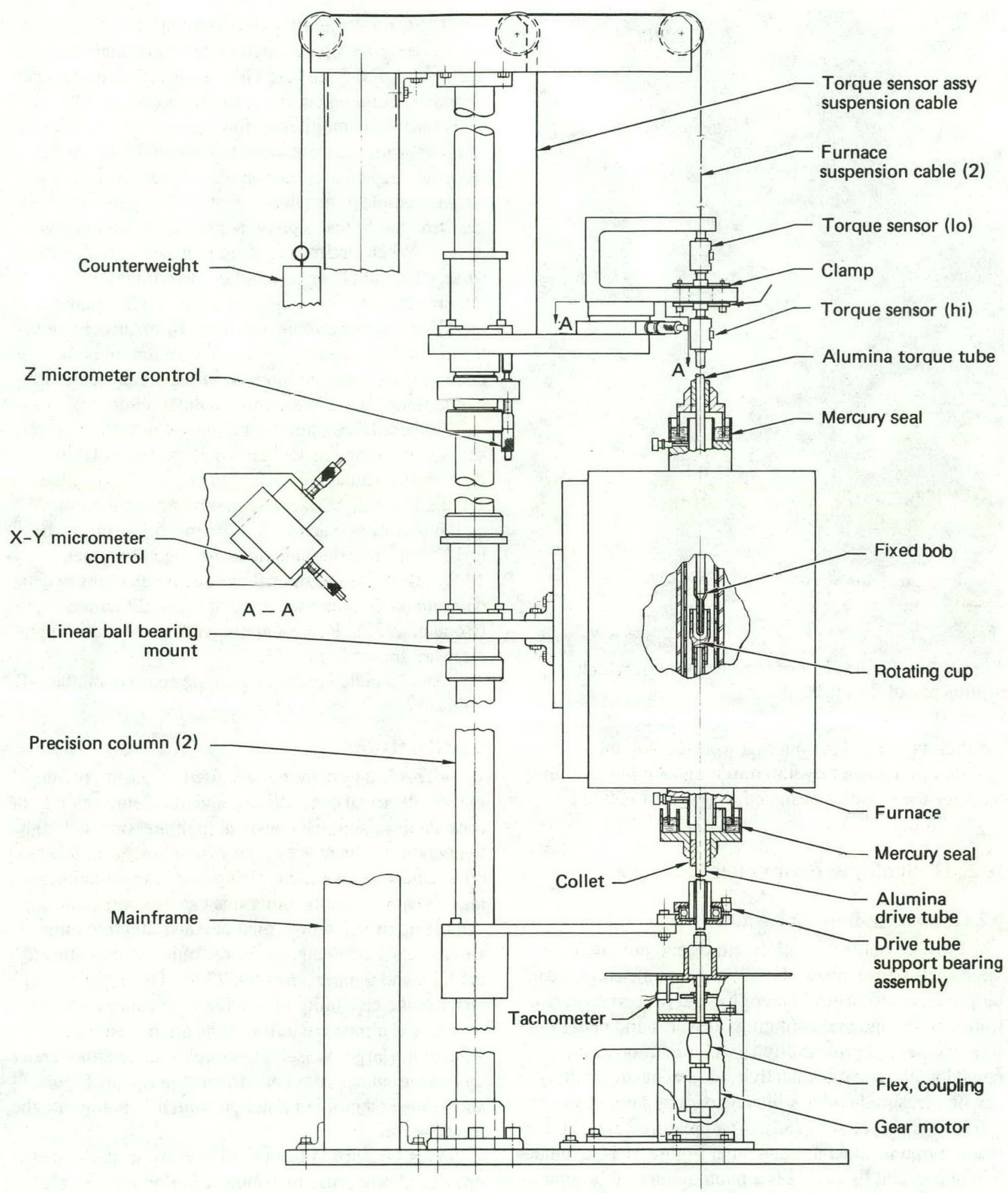

Figure 25. Automated high-temperature rotational Couette-type viscometer. The sample is sheared between the rotating cup and the fixed bob, which are made of $\mathrm{Pt} / 30 \mathrm{Rh}$ for operation up to $2000 \mathrm{~K}$. Liquid end seals allow for gas flow around the sample to control $f_{\mathrm{O}_{2}}$ during experiments. 


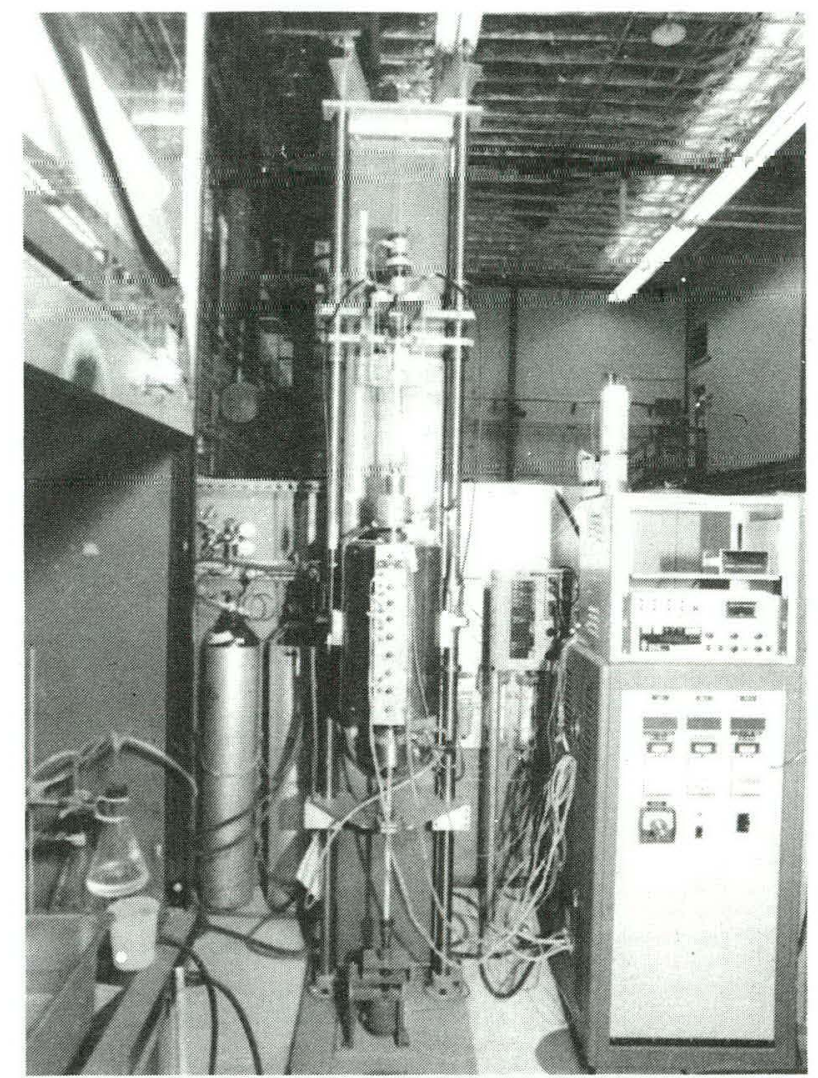

Figure 26. Front view of the viscometer, which stands about $3 \mathrm{~m}$ tall.

medium is gas and the internal working volume is $100 \mathrm{~mm}$ in diameter by $450 \mathrm{~mm}$ long. An internal furnace for the vessel is designed to operate to $1500 \mathrm{~K}$.

\section{A.2. Hydrologic Properties}

\section{2-GPa Large-Bore Apparatus}

Flow of fluids through fractures and bulk rock on large (150-mm-diameter by 300 -mm-long) samples can be correlated to several other physical properties at controlled pore fluid and confining pressures and under differential load. Permeability as well as stress-strain behavior, electrical conductivity, and acoustic velocity can be measured under arbitrary loading paths (Bonner, 1975; Trimmer et al., 1980). The pressure vessel and loading ram form an integral unit. Figure 31 is schematic diagram and Figure 32 is a photograph of this apparatus. It has a working bore of $200 \mathrm{~mm}$ and is especially well suited for mechanical property measurements on large samples of coarse-grained, inhomogeneous, and relatively weak materials such as certain tuffs, shales, or alluvia.
The force capacity of the loading ram in the base of this vessel is $18 \mathrm{MN}$, enough to generate axial stress differences of 0.55 to $0.75 \mathrm{GPa}$ on an 180 -mm-diameter sample, depending un the contining pressure. The vessel is fitted with an internal force gauge. Accuracies in stress measurement are generally abuut 0.1 to $1.0 \%$. Accuracy depends mostly on the difficulties in determining sample dimensions. Test sample jackets may be lead, copper, rubber, epoxy, or plastic of variable thicknesses. When strain gauges are attached to the jacket surface for radial and axial strain determination, 0.5 - to 1.5-mm-thick lead or copper is used. Axial displacement (strain) can also be measured by externally monitoring loading ram movement. Hydraulic oil is the confining pressure medium, and tests are presently limited to temperatures near room temperature.

In these large samples, permeabilities can be measured in the range of $10^{-11}$ to $10^{-24} \mathrm{~m}^{2}$ (10 to $10^{-11}$ darcy). For values from $10^{-11}$ to about $10^{-16} \mathrm{~m}^{2}$, the standard technique of pressure drop across the sample and fluid flow rate are used; at permeabilities from $10^{-16}$ to $10^{-24} \mathrm{~m}^{2}$, transient methods are used (Trimmer, 1981). Both compressional and shear velocities may be determined, in either the axial or radial directions (Bonner, 1975). Representative results from this apparatus are shown in Fig. 33.

An associated piece of analytic equipment, the 3-D profilometer is described below.

\section{1-GPa Hydrology}

This is a system that we use to measure permeability, electrical conductivity, and ultrasonic velocity of rock samples simultaneously at high pressure and high temperature. There are two pressure vesseis in this system. One can take a sample up to $25 \mathrm{~mm}$ in diameter and $100 \mathrm{~mm}$ long; the other one can accommodate a sample up to $100 \mathrm{~mm}$ in diameter and $200 \mathrm{~mm}$ long. Both vessels are designed for operation at pressures to $0.1 \mathrm{GPa}$ and temperatures to $573 \mathrm{~K}$. The larger vessei also has the capability of making impedance tomographs and ultrasonic tomographs on the same sample. Also in the larger vessel, the sample can be either under an isothermal condition or a thermal gradient. Figure 34 shows the assembly of a sample which is going into the larger vessel.

This system has been used primary to study the hydrological properties of Topopah Spring tuff samples (Lin and Daily, 1984; Daily et al., 1987; Lin and Daily, 1988a). Cores from the Salton Sea Scientific Drilling project were also studied in this system (Lin and Daily, 1988b). Figure 35 shows a typical variation of permeability of a fractured Topopah Spring tuff sample 


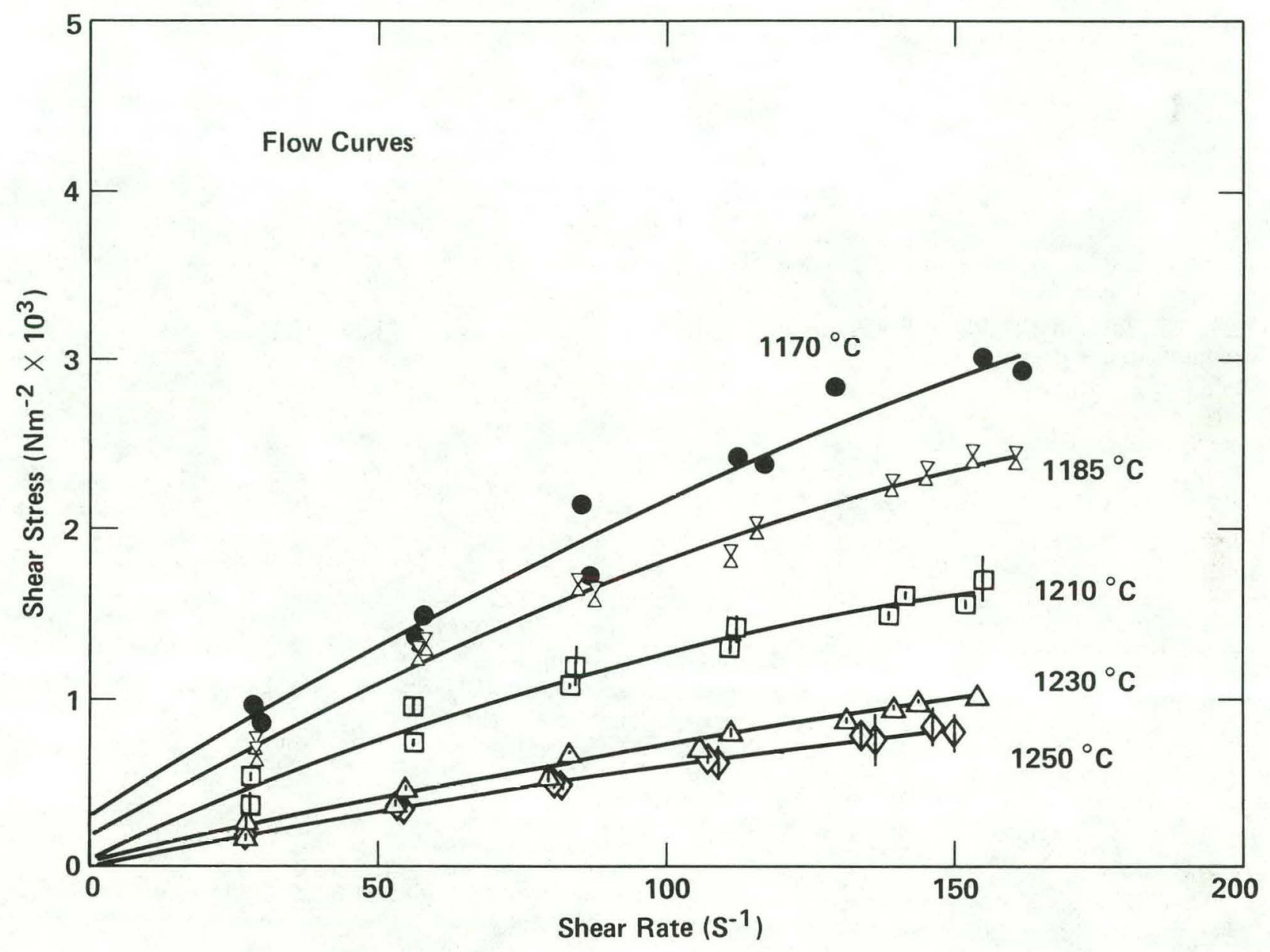

Figure 27. Shear stress vs shear rate for Kilauea Iki basalt as a function of temperature. Note that the behavior is approximately Newtonian at $1250^{\circ} \mathrm{C}$, but deviates increasingly from Newtonian behavior as temperature decreases. 


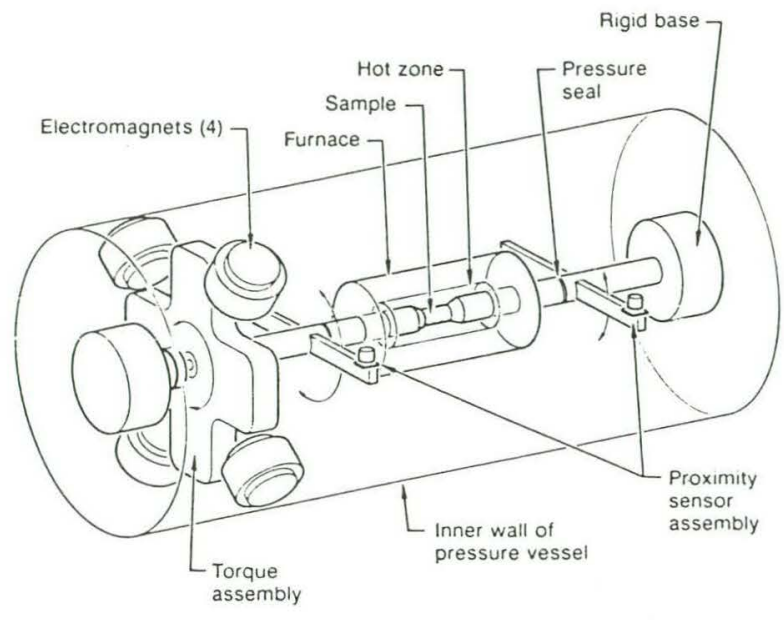

Figure 28. Torsional oscillator for attenuation measurements under pressure.

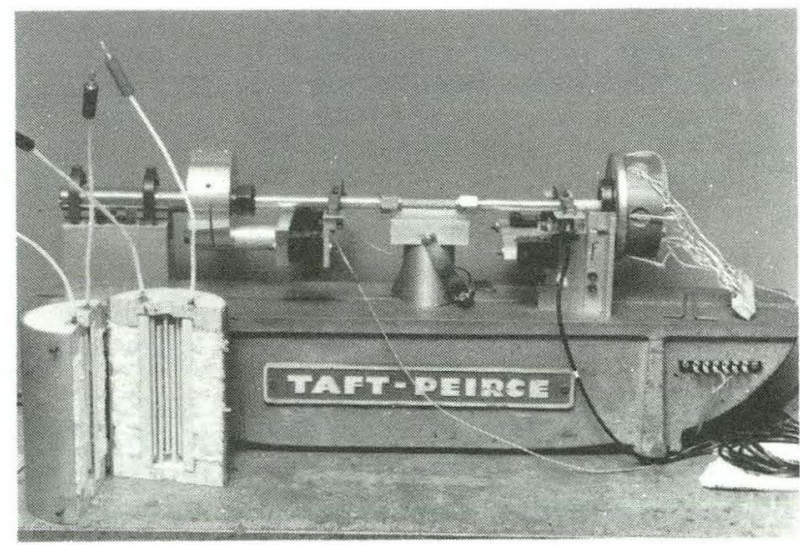

Figure 29. Photograph of sample assembly showing proximity detectors, granite sample, and furnace. With the furnace in place, bench-top measurements to $725 \mathrm{~K}$ are possible.

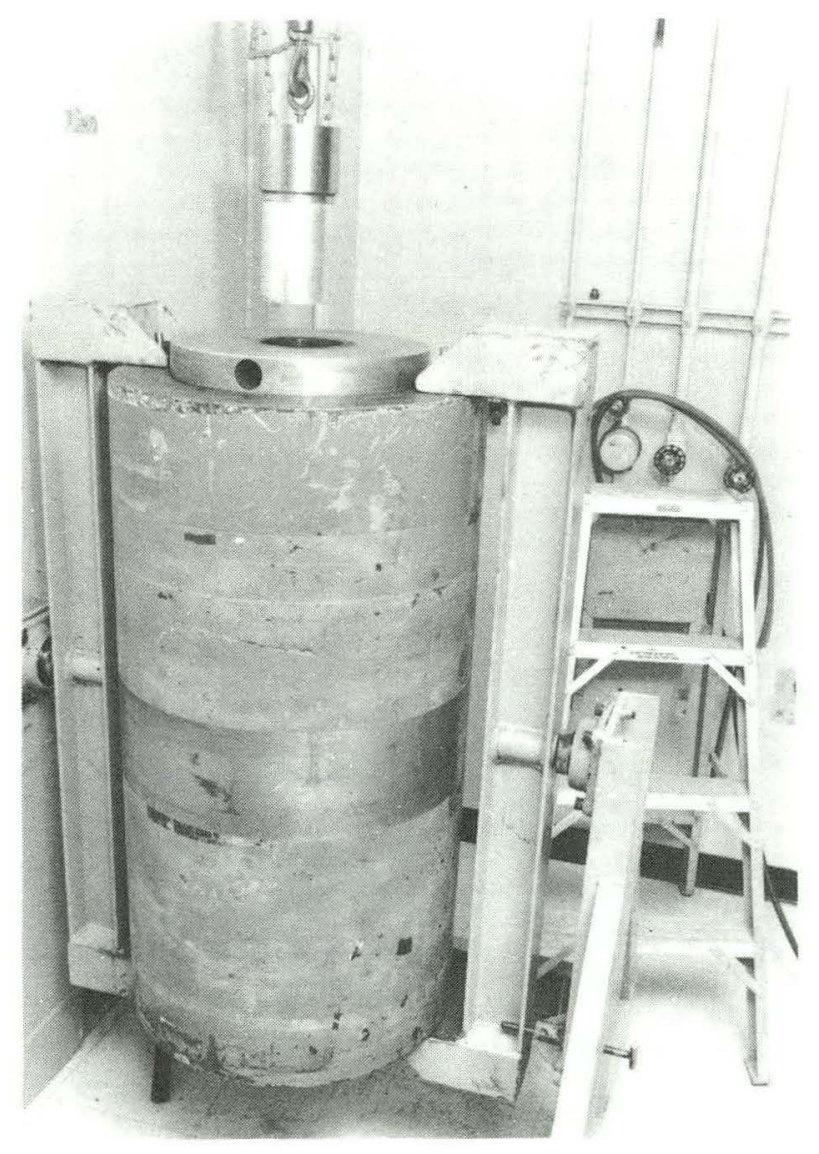

Figure 30. Photograph of 0.4-GPa pressure vessel used primarily for attenuation measurements. 


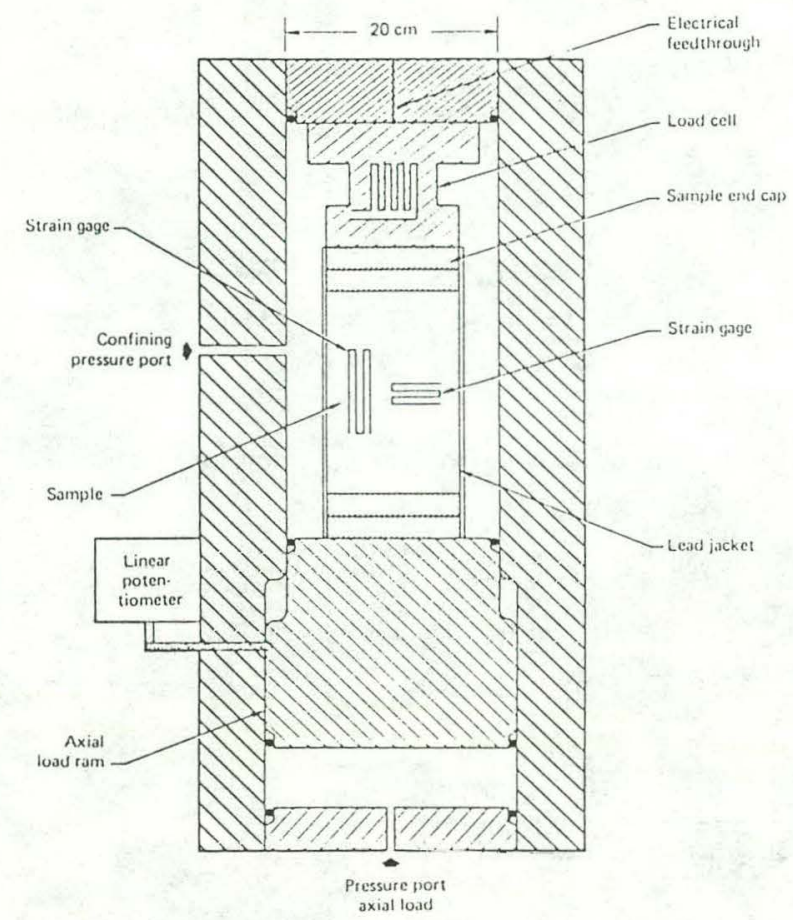

Figure 31. Schematic drawing of the 0.2-GPa largebore vessel and loading ram.

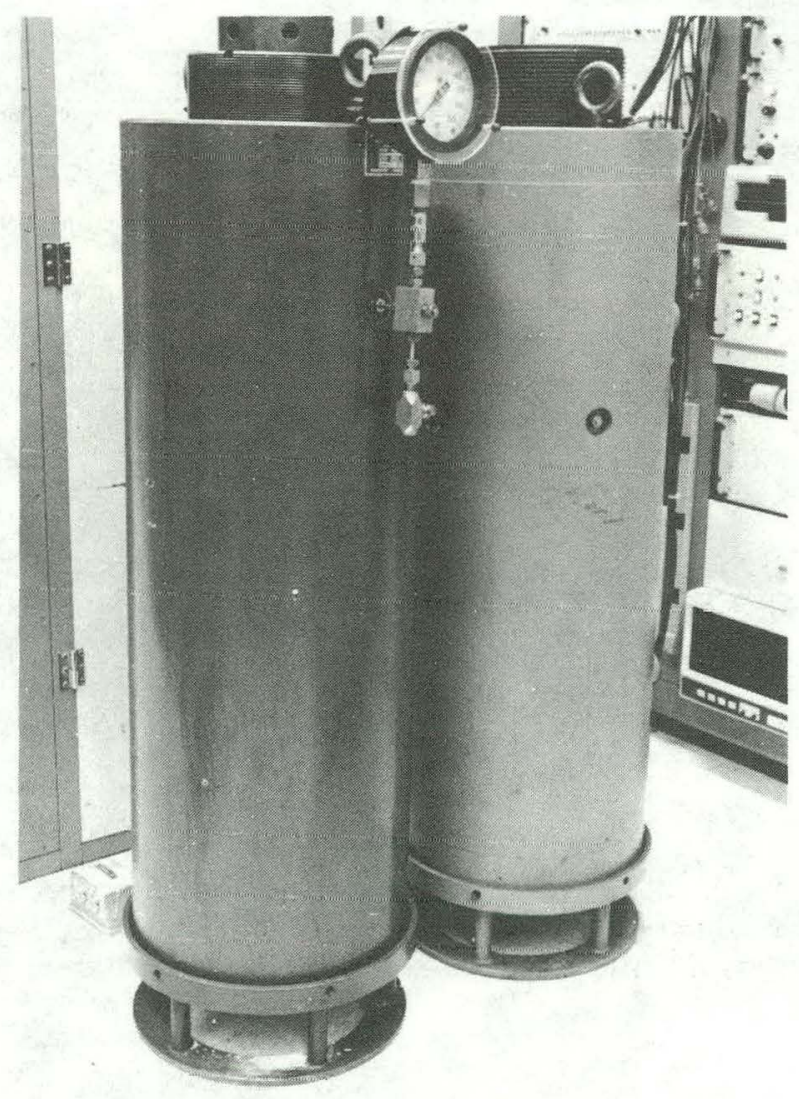

Figure 32. The two 0.2-GPa large-bore vessels. 


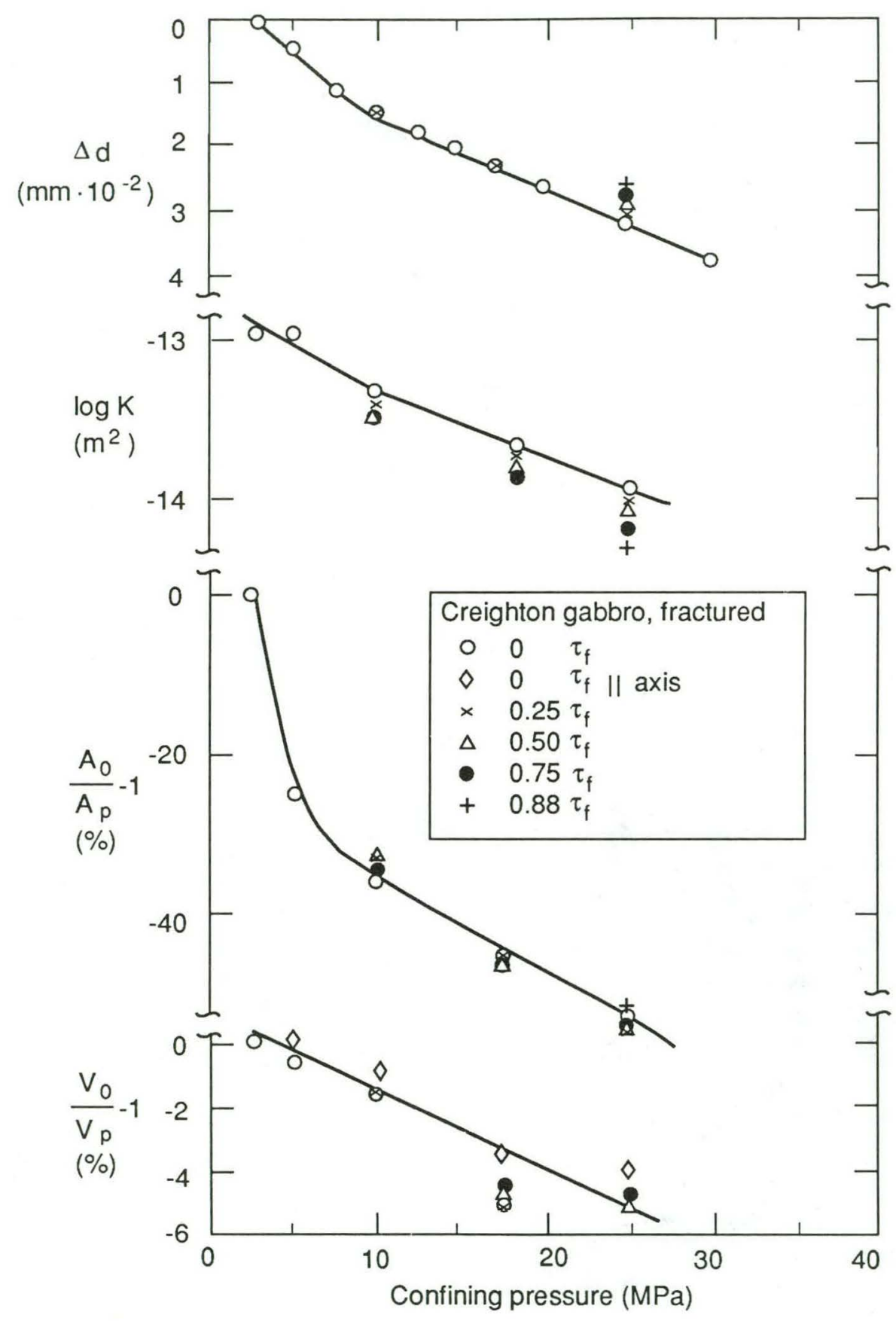

Figure 33. Compressional velocity $V$, pulse amplitude $A$, permeability $K$, and crack closure $\Delta d$ as a function of confining pressure and differential stress for fractured Creighton gabbro. The symbols are keyed to the differential stress applied to the ends of the sample, stated in terms of a fraction of the expected failure strength $\tau_{f}$ of Creighton gabbro. 


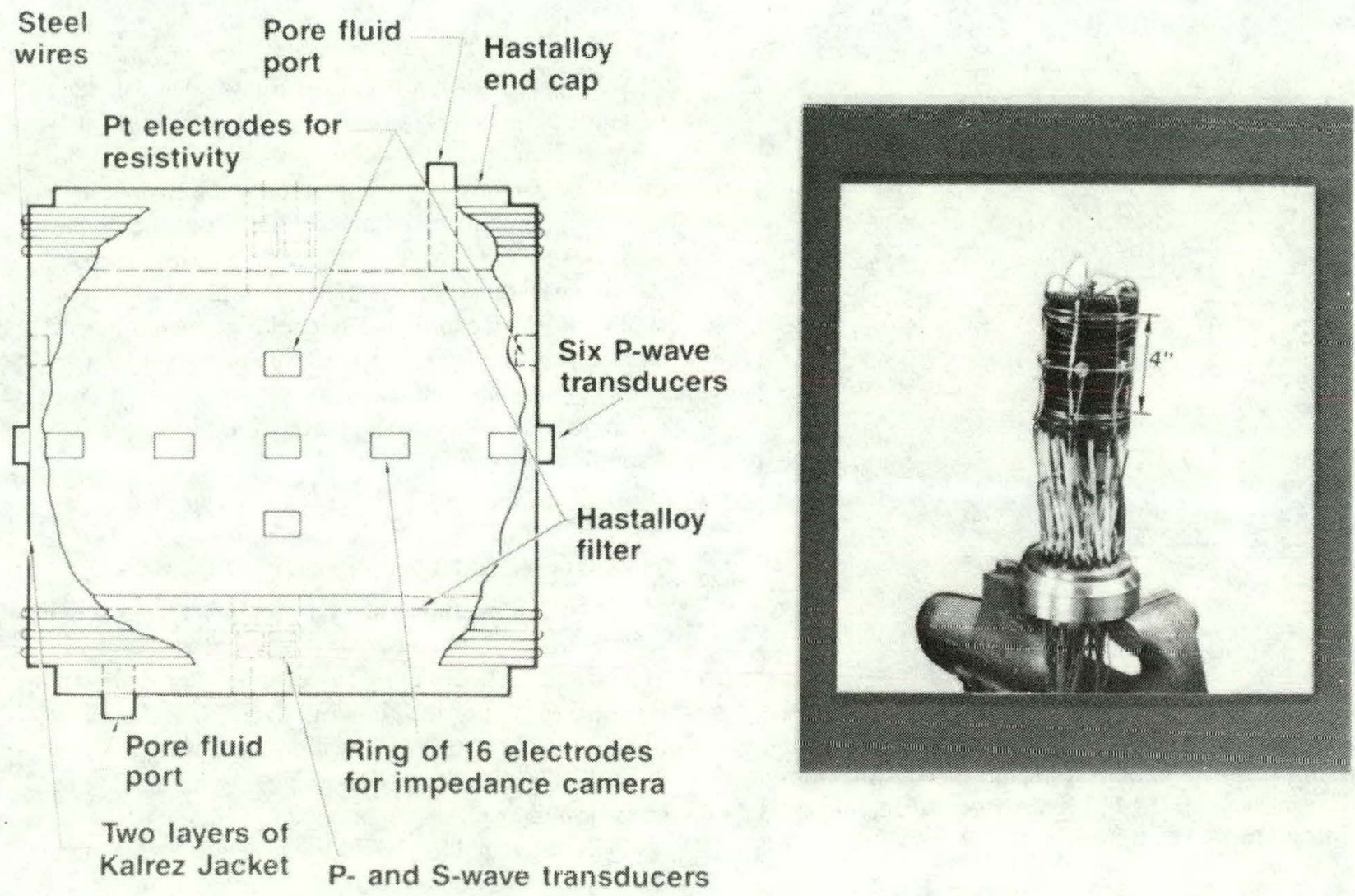

Figure 34. Sample assembly for the study of transport properties using the 0.1-GPa hydrology system. 


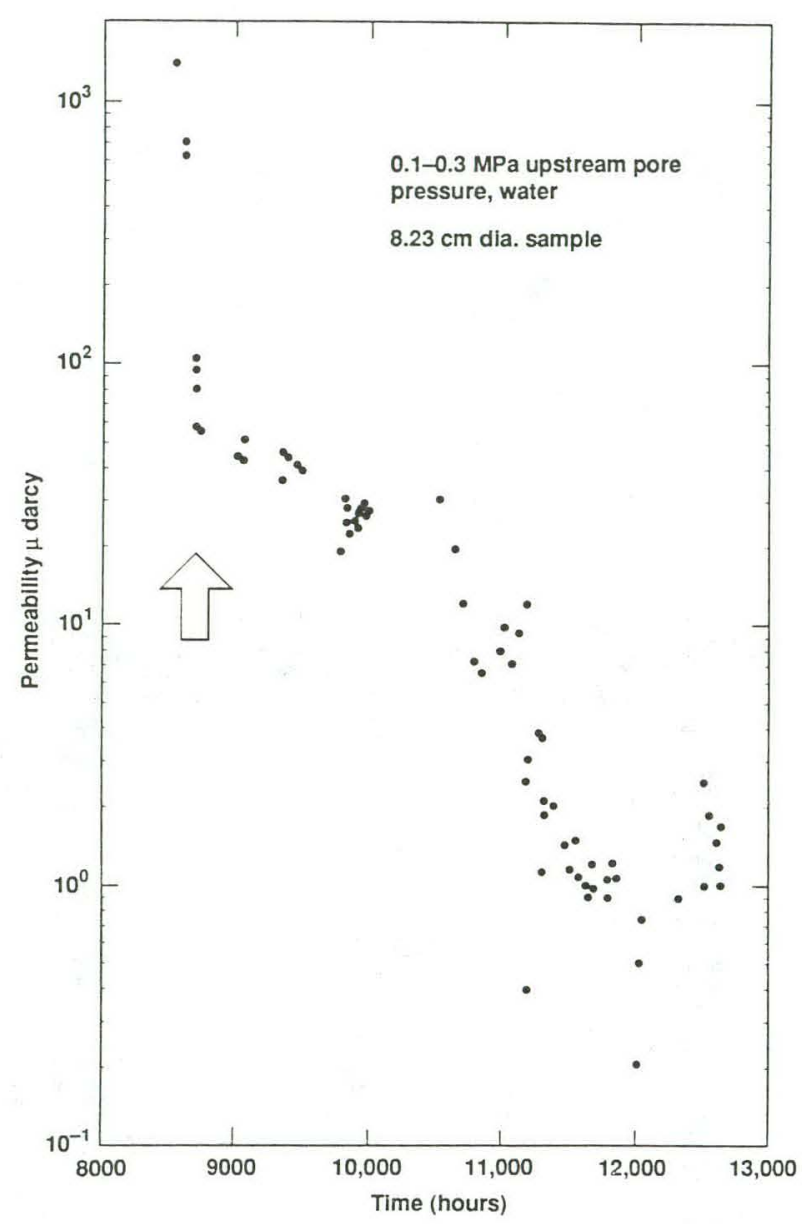

Figure 35. Fluid permeability of a fractured Topopah Spring tuff sample as a function of time. During this experimental period the sample has gone through heating (to $422 \mathrm{~K}$ ), dehydration, and rehydration (Daily et al., 1987).

as a function of temperature and time. Ultrasonic and impedance tomographs of a Salton Sea Scientific Drilling Project sample are compared with an x-ray tomograph in Fig. 36.

Figure 37 shows the plumbing of a system being developed to measure two-phase flow at high pressure and temperature in the same 0.1-GPa hydrology vessel. Two fluid phases, normally gas and water, are independently forced into a sample in the pressure vessel by the two displacement pumps. The two phases will both flow through the sample. At the downstream end, the two phases are separated and the flow rate of each phase is measured by a corresponding flowmeter. The degree of water saturation in the sample will be monitored by measuring electrical resistance and by impedance tomography. The amount of water in the sample will be controlled by varying the motor speed of either the gas displacement pump or the water displacement pump. Relative permeability of both gas and water phases in the sample will be measured as a function of degree of water saturation in the sample.

\section{1-GPa Hot Permeability Apparatus}

An apparatus has been constructed that can determine the permeability of four samples simultaneously. Samples are typically 44-mm-diameter and 76-mm-long cylinders. Environmental parameters are temperatures to $625 \mathrm{~K}$, confining pressures to $100 \mathrm{MPa}$, and pore pressures to $50 \mathrm{MPa}$. Two identical systems are used, one to measure gas permeability and the other to measure liquid permeability. The confining medium is oil and the pressure vessels are externally heated. Permeability is measured either by the steady-state or pulse techniques described in the section entitled, "0.2-GPa Large-Bore Apparatus."

\section{Three-Dimensional Profilometer}

Our 3-D profilometer is an analytical device built specifically to characterize the shapes of fractures in jointed and faulted rocks. The profilometer is shown in Fig. 38 and is described in more detail by Keller and Bonner (1985). Surface elevation is measured with a fine-tipped probe attached to a linear-voltage differential transformer. Rather than being dragged, the probe is repeatedly lifted and lowered as the surface in question is translated beneath the probe. The feature that distinguishes this instrument is its ability to reproduce exactly the position in the plane of the surface being profiled. Thus, not only does it produce line profiles in a standard fashion, it can digitize on a 2-D grid effectively making a series of parallel line profiles that are accurately $( \pm 1 \mu \mathrm{m})$ indexed to each other. This ability allows us to index the two faces of a fracture to one another, giving us the shape of the void space itself (Brown et al., 1986). Knowledge of this shape is critical to understanding the hydrologic characteristics of the fracture (Durham and Bonner, 1987). 
(a)

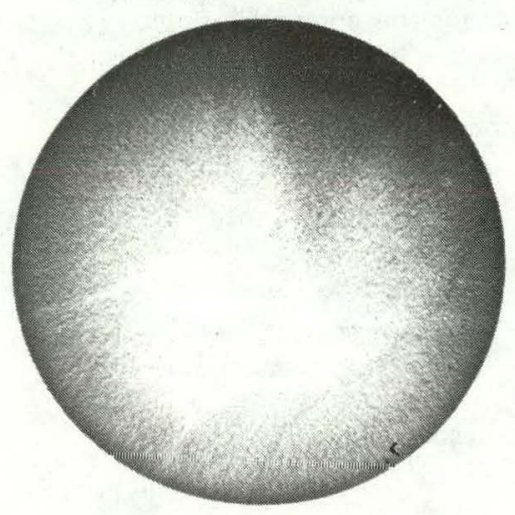

X-ray tomography

CT scan

before experiment (b)

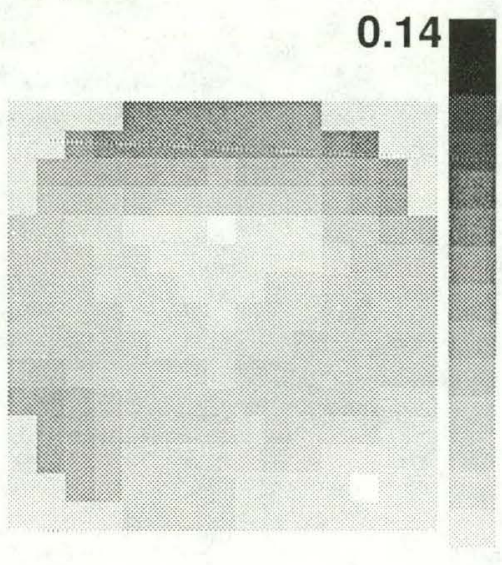

$-0.02$ (c)

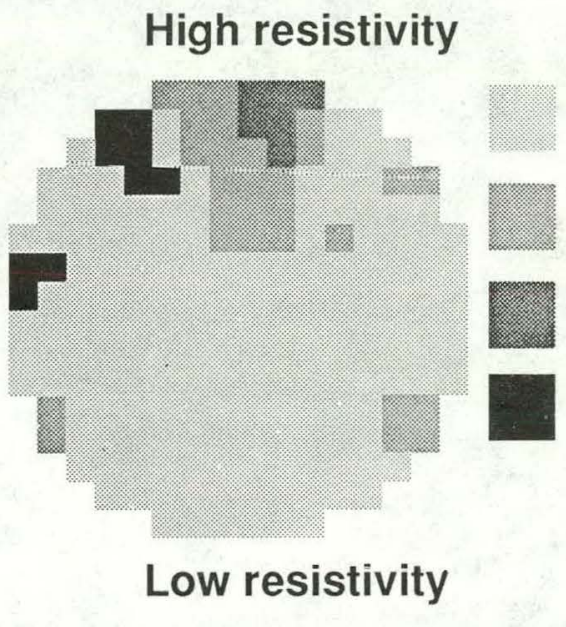

Ultrasonic tomograph Impedance tomography

Figure 36. Tomographic imaging of a Salton Sea Scientific Drilling Project sample, from a depth of $\mathbf{1 1 5 8} \mathbf{~ m}$. (a) X-ray tomograph near the midplane before the experiment. Darker shades represent higher density. The azimuthally symmetric pattern is probably an artifact of the high density contrast between the sample and air. (b) Ultrasonic P-wave velocity tomograph. The tomograph is an image of changes in inverse velocity between when the sample was at near-surface conditions and at about 300-m depth. (c) Electrical impedance tomograph. This is a tomograph, as in (b) above, of electrical resistivity change at $1 \mathrm{kHz}$. The lightest shade represents no change in resistivity. 

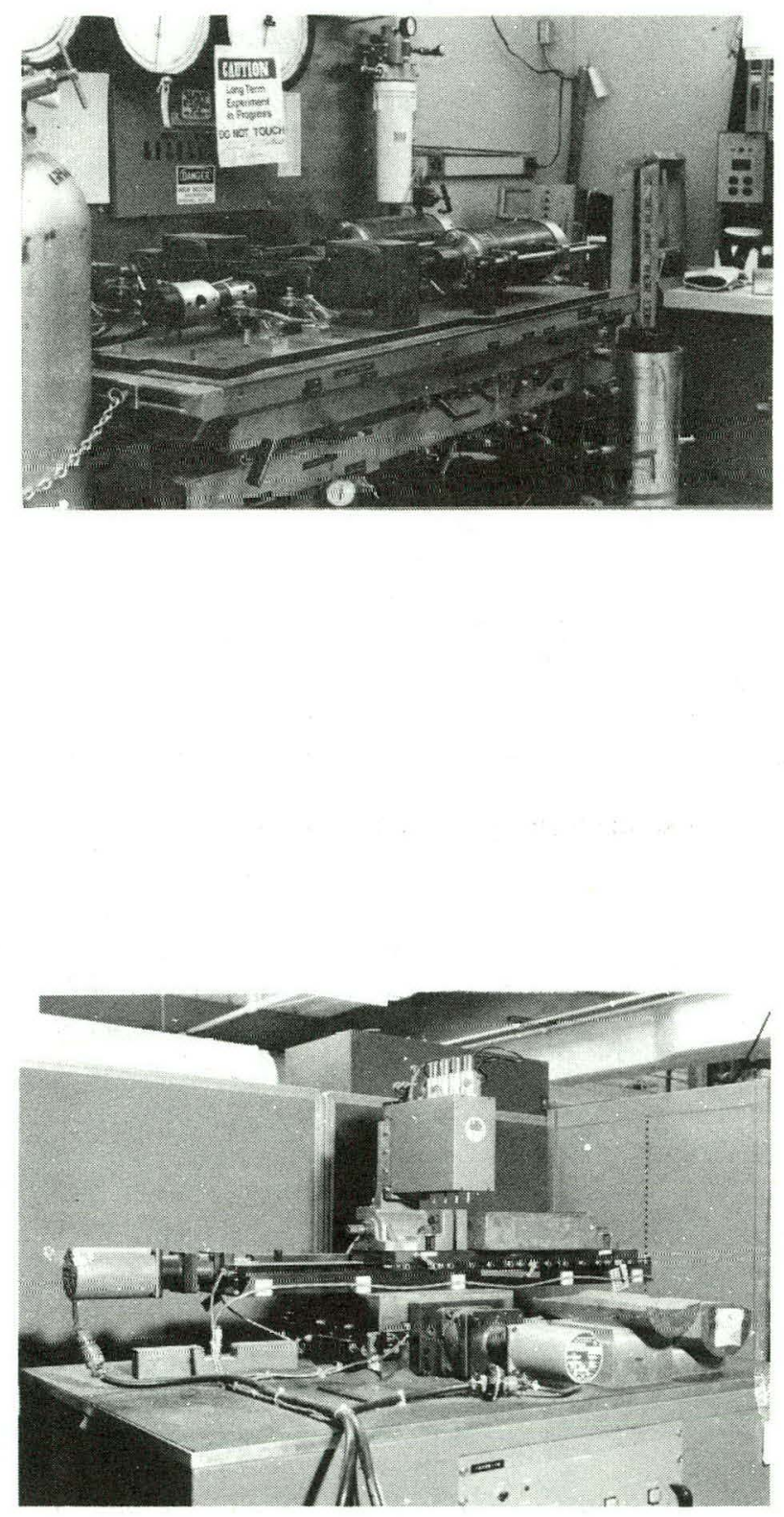

Figure 37. A photograph of the two-phase system. The vertical cylinder is the pressure vessel. The two horizontal cylinders are the displacement pumps.

Figure 38. Three-dimensional profilometer. The rock surface to be digitized (here, a flat surface is in place for a calibration run) moves, while the digitizing head (housing the four digitizing tips seen above and just to the left of the reference flat) remains fixed. The tips retract while the surface translates to a new position. Also visible are the stepping motors that drive the table in the $\boldsymbol{x}$ and $\boldsymbol{y}$ directions, and a fractured cylindrical rock, laid open and readied for digitization. 


\section{A.3. Electrical Properties}

\section{1-MPa Conductivity Apparatus}

The electrical conductivity $\sigma$ of materials can be measured over a practically unlimited size range at ambient conditions, either in the fluid-saturated or evacuated state. These data are used to study near-surface properties of rocks and help interpret field geophysical surveys. They can also aid in sorting schemes based on physical property variation and are used to calibrate measurements inside a complicated mechanical device, such as the pressure-temperature systems described in this report. Figure 39 illustrates a typical application of these techniques to saturated Kemmerer coal drying in air (Duba and Ho, 1977).

Measurements of electrical conductivity and Seebeck coefficient at temperatures to $2000 \mathrm{~K}$ under controlled oxygen fugacity $f_{\mathrm{O}_{2}}$ are also possible

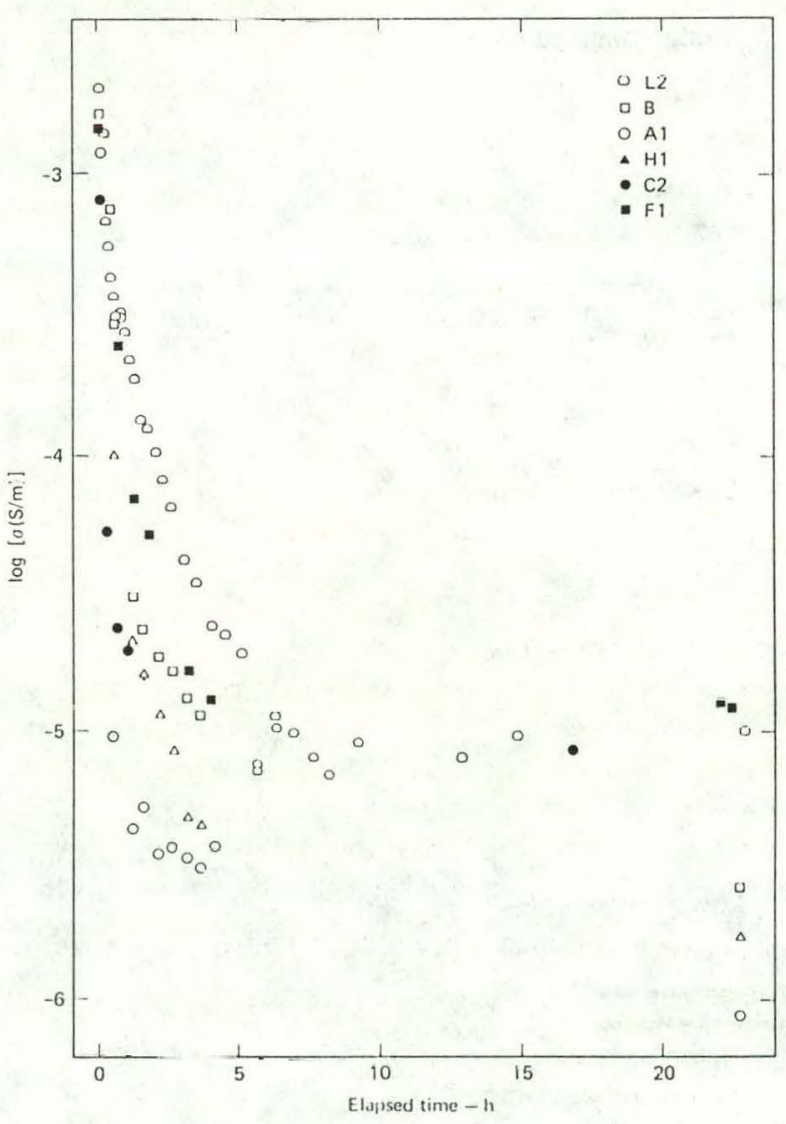

Figure 39. Log conductivity vs time, Kemmerer coal. Samples L2, C2, and F1 were dried at $25 \pm 5^{\circ} \mathrm{C}$; others were dried under a heat lamp at $35 \pm 5^{\circ} \mathrm{C}$.

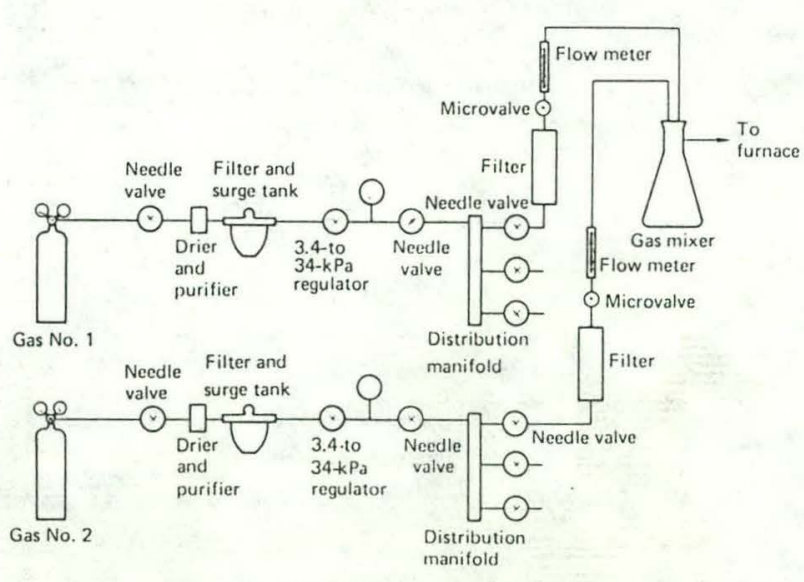

Figure 40. Gas mixing system for oxygen fugacity control.

(Duba et al., 1990). The system mixes $\mathrm{CO}_{2}$ and $\mathrm{CO}$ to control fugacity $f_{\mathrm{O}_{2}}$ while $\sigma$ is being measured (Fig. 40). Figure 41 is a sketch of the apparatus. Such $f_{\mathrm{O}_{2}}$ control is necessary if meaningful data are to be collected at elevated temperatures for iron-bearing silicates (Duba and Nichols, 1973; Duba et al., 1974; Nitsan, 1974; Schock et al., 1989).

A solid electrolyte $\left(\mathrm{CaO}\right.$-doped $\left.\mathrm{ZrO}_{2}\right)$ allows simultaneous determination of $f_{\mathrm{O}_{2}}$ and $\sigma$ as a function of temperature for a given gas mixture (Netherton and Duba, 1978). Sample size in this apparatus can vary from plates $0.3 \mathrm{~mm}$ thick by $2 \mathrm{~mm}$ wide up to $10 \mathrm{~mm}$ in any dimension. Figure 42 shows the electrical conductivity of oil shale as a function of grade at $1.0 \mathrm{kHz}$ (Duba, 1983).

\section{0-GPa Conductivity Apparatus}

Figure 43 shows one assembly to determine electrical conductivity $\sigma$ to $1950 \mathrm{~K}$ in argon to $1 \mathrm{GPa}$. This assembly in inserted into a $38-\mathrm{mm}$-diameter by 250 mm-long water-cooled pressure vessel (Fig. 44). The internal furnace limits sample size to a rectangular plate $1 \mathrm{~mm}$ thick and up to $5 \mathrm{~mm}$ on a side. The furnace can be redesigned to allow measurement of samples up to $15 \mathrm{~mm}$ in any dimension, but such a design would limit the maximum temperature to about $1300 \mathrm{~K}$. The addition of about $1 \%$ of a CO $\mathrm{CO}_{2} / \mathrm{CO}$ mixture to the argon is necessary to control $f_{\mathrm{O}_{2}}$ when $\sigma$ of iron-bearing silicates is measured. See Fig. 45 for data on the electrical conductivity of single crystals of pyroxene at $0.5 \mathrm{GPa}$ up to $1825 \mathrm{~K}$ (Duba et al., 1976). 


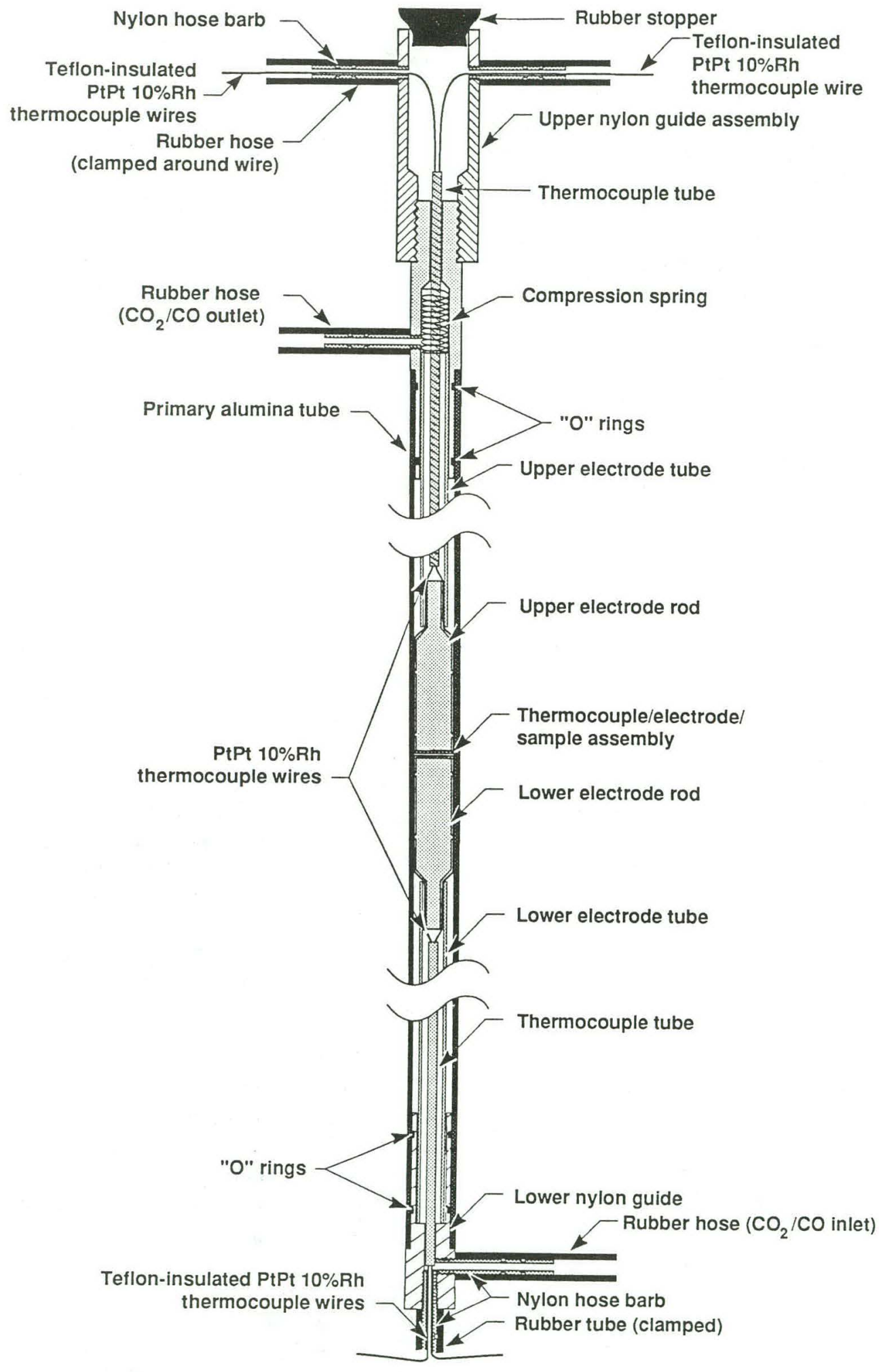

Figure 41. Cross section of the 0.1-MPa conductivity cell. Drawing is to scale, with the outer diameter of the primary alumina tube being $18 \mathrm{~mm}$. The total length of the primary tube is $508 \mathrm{~mm}$. In order to show the interior parts of the cell the figure has been interrupted on either side of the center, with no loss of information. Not shown in the figure are the platinum foil-silver paint electrical shield and cooling jackets that are on the outside of the primary alumina tube. 


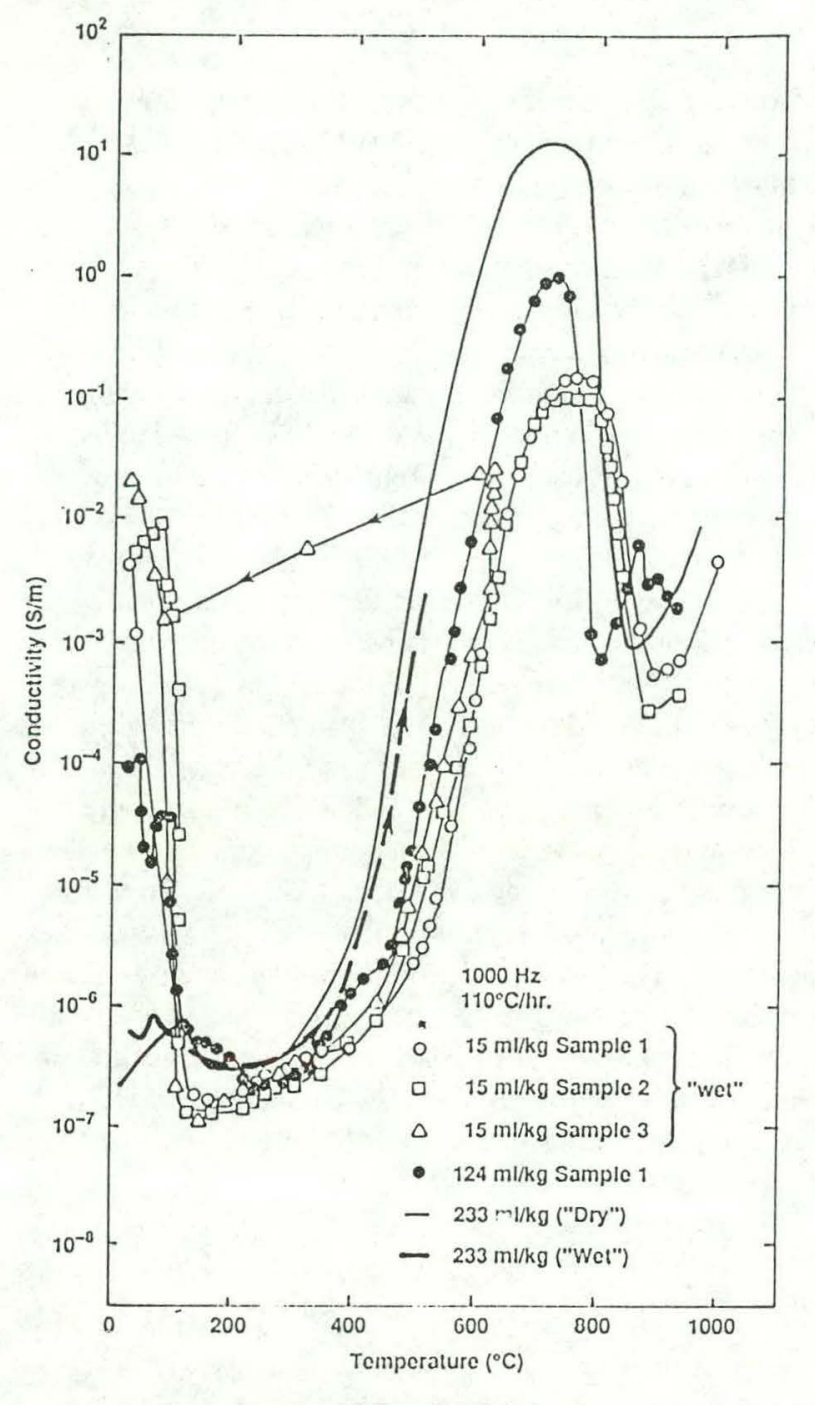

Figure 42. The electrical conductivity of oil shale at $1000 \mathrm{~Hz}$ and at a heating rate of $110^{\circ} \mathrm{C} \mathrm{h}^{-1}$.

Figure 43. Internal conductivity cell used in 1.0-GPa vessel.

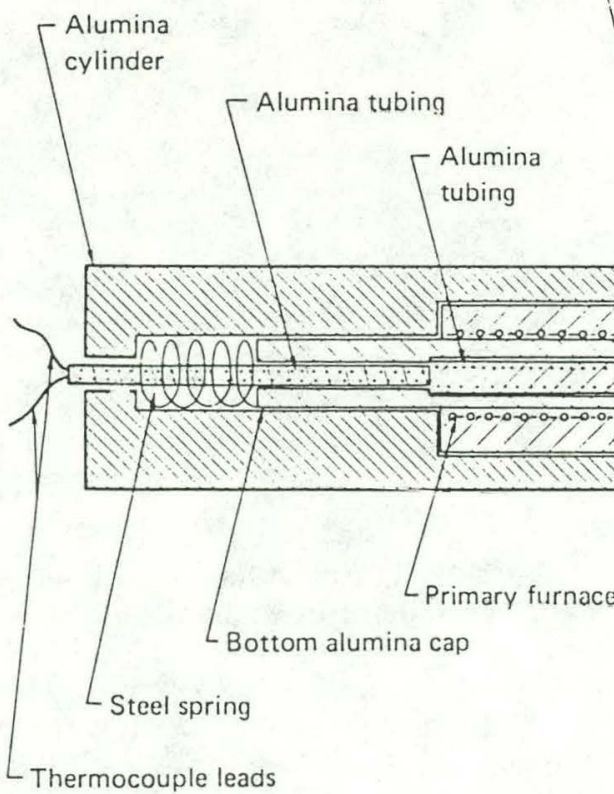

Alumina
crystal
holder

Olivine

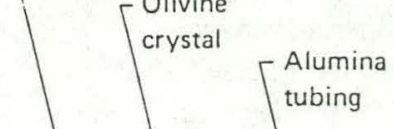




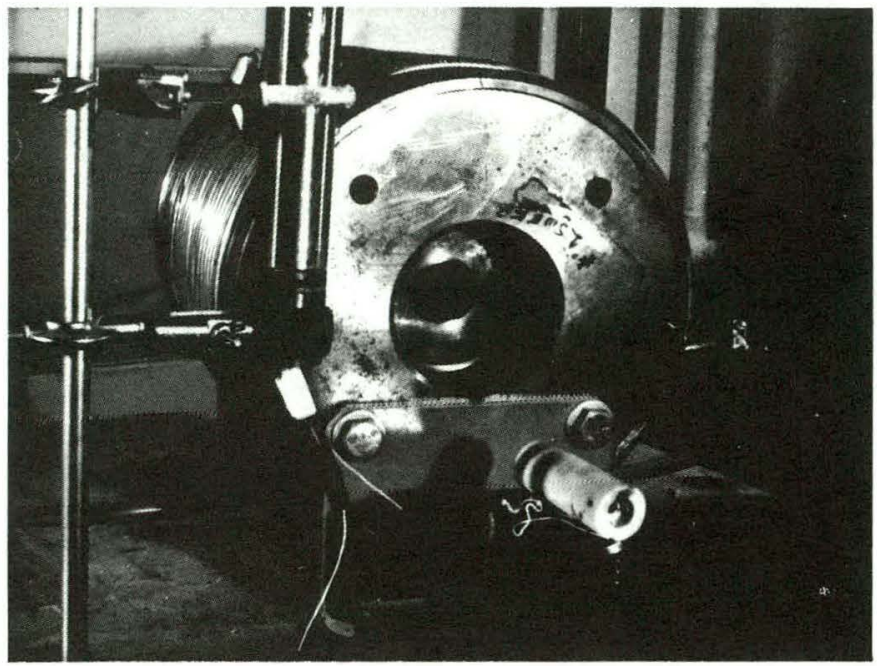

Figure 44. 1.0-GPa vessel used for conductivity measurements. Conductivity cell (Fig. 43) shown in foreground; complete assembly with end closure is shown at left.

\section{Girdle-Anvil Systems}

Figure 46 shows the assembly of the girdle-anvil apparatus, which is used to determine conductivity. It is used in conjunction with the wide-platen 9.1-MN press frame and can be operated to quasi-hydrostatic pressures of about $7 \mathrm{GPa}$ and up to $1700 \mathrm{~K}$. The design is unique both for the 0.05 -mm-thick $\mathrm{Pt} / 10 \% \mathrm{Rh}$ foil heater and the opposing Pt-Pt/10\% Rh thermocouples that contact the specimen and serve as both thermocouples and electrodes. The heater can produce $1700 \mathrm{~K}$ for brief durations and $1500 \mathrm{~K}$ for several temperature cycles. Electrode-thermocouple wires are fed through alumina tubing in the $1.5-\mathrm{mm}$ holes in the carbide pistons. Samples can be up to $1 \mathrm{~mm}$ thick and about $3 \mathrm{~mm}$ diameter. Figure 47 compares some typical data on the electrical conduciivity of pyroxene (Schock et al, 1977; Heard et al., 1975) with literature data. The girdle-anvil system has also been used to measure electrical conductivity to higher pressures at room temperature. Figure 48 shows the electrical conductivity of dysprosium to $15 \mathrm{GPa}$ as measured in this system (Stromberg and Stephens, 1964).

The wide-platen 9.1-MN press accommodates other girdle-anvil assemblies. Maximum pressures of $15 \mathrm{GPa}$ are possible for small samples $1 \mathrm{~mm}$ thick by $5 \mathrm{~mm}$ in diameter. The use of this press for ultrasonic measurements has already been mentioned (Section A.1.1.). In addition to measuring ultrasonic transmission, linearvoltage differential transformers are used to measure piston displacement as a function of pressure. Thus, velocity data may be converted to include changes in sample length caused by pressure. Correction for compressibility of the tungsten carbide pistons can also be made. Samples up to $6.5 \mathrm{~mm}$ diameter by $4 \mathrm{~mm}$ long can be measured in this assembly. Temperatures up to $1300 \mathrm{~K}$ on smaller samples can be achieved at reduced pressures (5 to $6 \mathrm{GPa}$ ).

The possibility also exists for performing phase equilibrium studies using this press, although they are more commonly pursued using the piston-cylinder, cubic-anvil, and diamond-anvil systems described in Section B. We have three sizes of girdle-anvil combinations, with inner diameters of $6.3,12.7$, and $25 \mathrm{~mm}$. These may be operated at simultaneous pressures and temperatures as high as $15 \mathrm{GPa}$ and $2250 \mathrm{~K}$. Figure 49 is a schematic of the girdle-anvil assembly that was used to sinter polycrystalline diamond samples at $2200 \mathrm{~K}$ and 6.5 GPa (Stromberg and Stephens, 1970). A larger volume "belt" assembly, a variation on the girdle-anvil configuration, is capable of about $16 \mathrm{GPa}$ and $2250 \mathrm{~K}$. It has been fully described by Hall (1960).

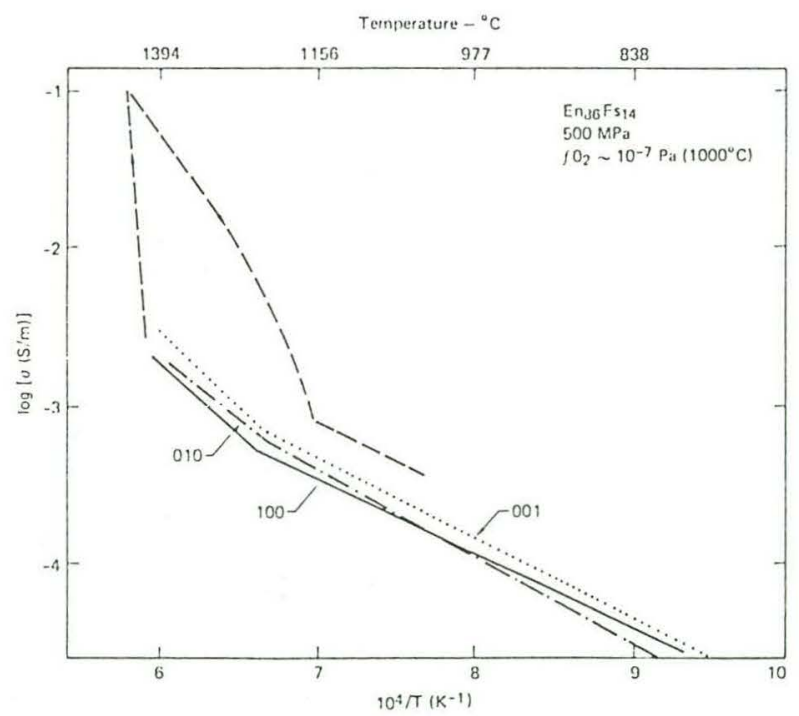

Figure 45. Log conductivity of Bamble orthopyroxene vs temperature at $0.5 \mathrm{GPa}$. 


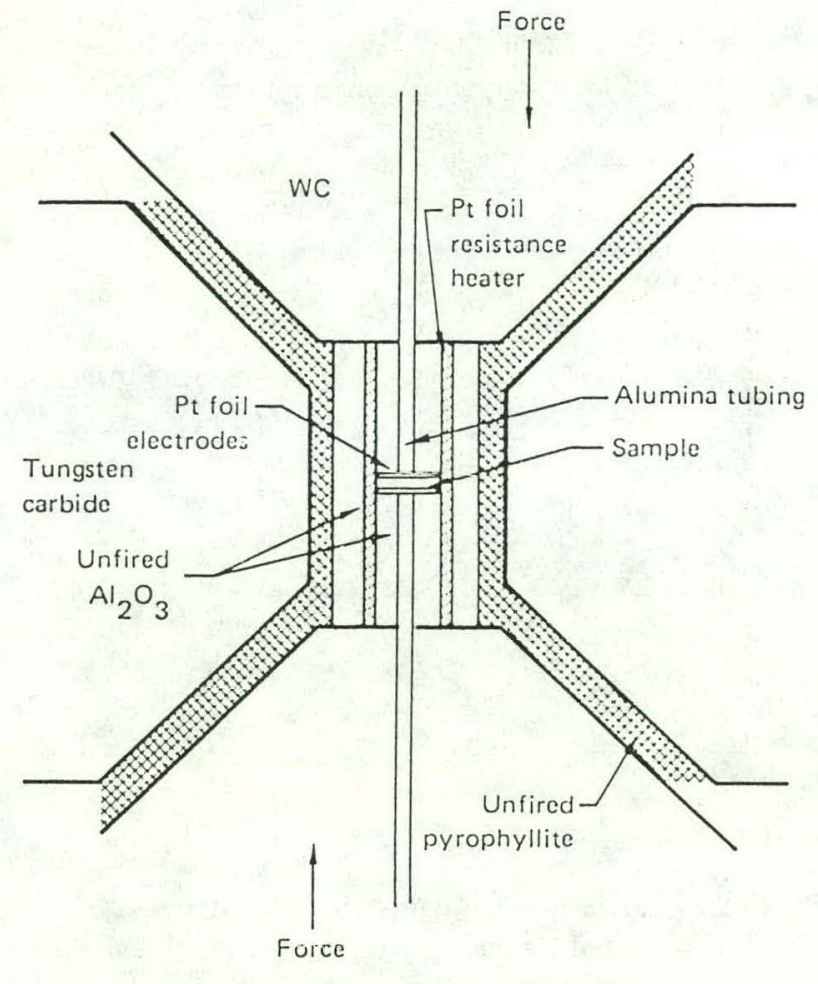

Figure 46. Sample assembly for conductivity measurements in the girdle-anvil system.

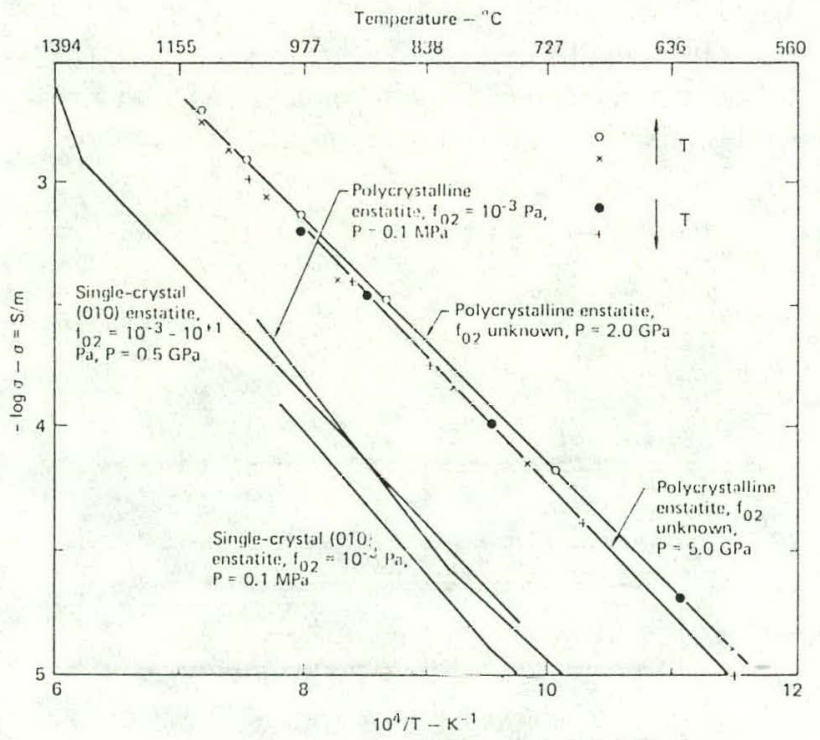

Figure 47. Log conductivity vs temperature for several materials at various pressures.

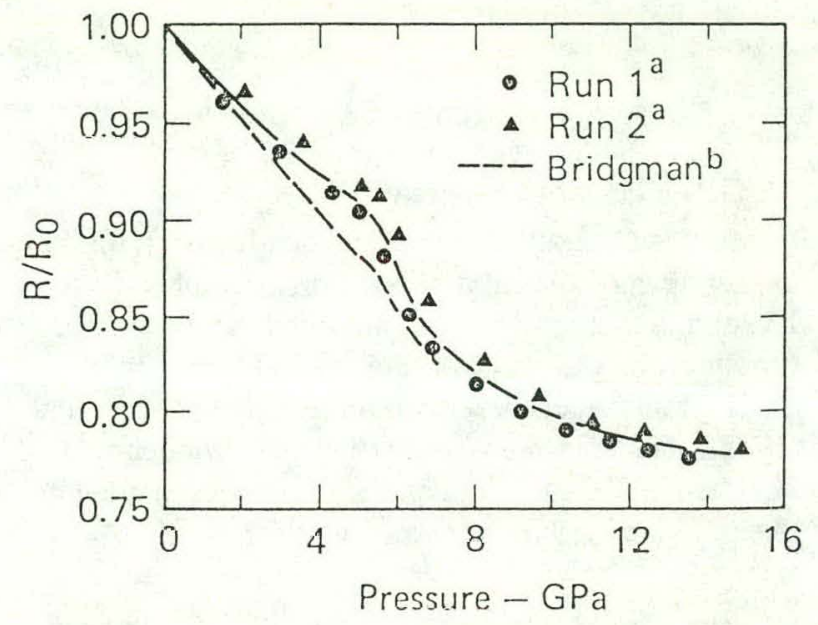

Figure 48. Normalized resistance vs pressure for dysprosium. Data points are from Stromberg and Stephens (1964). Dashed line is from Bridgman (1954). 

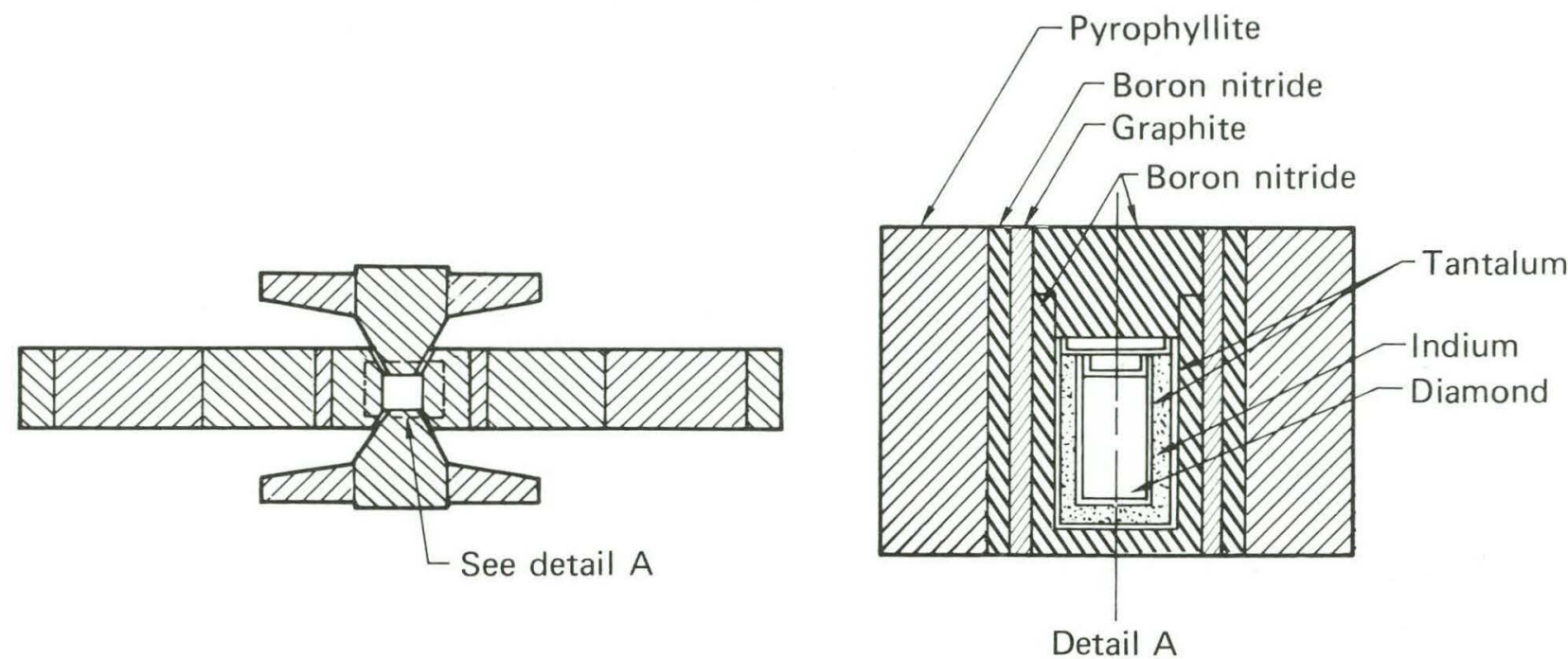

Figure 49. Girdle-anvil configuration for diamond aggregate sintering.

\section{A.4. Thermal Transport Properties}

\section{2-GPa Thermal Properties Vessel}

In this apparatus, the thermal conductivity, diffusivity, and linear expansion of large rock samples (up to $125 \mathrm{~mm}$ in diameter by $250 \mathrm{~mm}$ long) can be measured simultaneously at temperatures to $750 \mathrm{~K}$ and pressures to $0.2 \mathrm{GPa}$. This is described more fully by Abey et al. (1982). The pressure vessel is a single cylinder of H-13 steel with a $200-\mathrm{mm}$ bore and $350-\mathrm{mm}$ working length. The pressure medium is argon and the heating is external.

The sample is a thick-walled cylinder jacketed in a combination of copper, stainless steel, and lead

(Fig. 50). An internal heater (with guard heaters) in the axial hole approximates an infinite line source, and several $1.5-\mathrm{mm}$ sheathed thermocouples entering through the ends of the sample measure the temperature gradient imposed by the heater. Conductivity is determined by achieving a steady-state heat flow, then measuring electrical power to the internal heater and temperature in the sample as a function of radial distance from the axis. Diffusivity is measured by pulsing the internal heater and measuring temperature as a function of time and radius. The experiment must be numerically simulated in order to reduce both conductivity and diffusivity data. Thermal linear expansion is measured by attaching position sensors to the front and back plates of the sample. The measurement techniques are detailed in Durham et al. (1983a).

The apparatus has been used to measure the thermal properties of rock salt and granites as a function of pressure and temperature (Durham and Abey, 1981, 1983;
Durham et al., 1985; Durham et al., 1987a). As a historical note, the capability for measuring linear expansion was used only in early work with the apparatus (Durham et al., 1983b). It added a great deal of complexity to the experiment and was replaced by a simpler technique using small samples in the 0.5-GPa creep apparatus described previously (Page and Heard, 1981; Heard and Page, 1982).

\section{Thermal Diffusivity Apparatus}

Thermal diffusivity of rock at pressures to $200 \mathrm{MPa}$ and temperatures to $675 \mathrm{~K}$ can be measured with an assembly adapted to the externally heated vessel of the

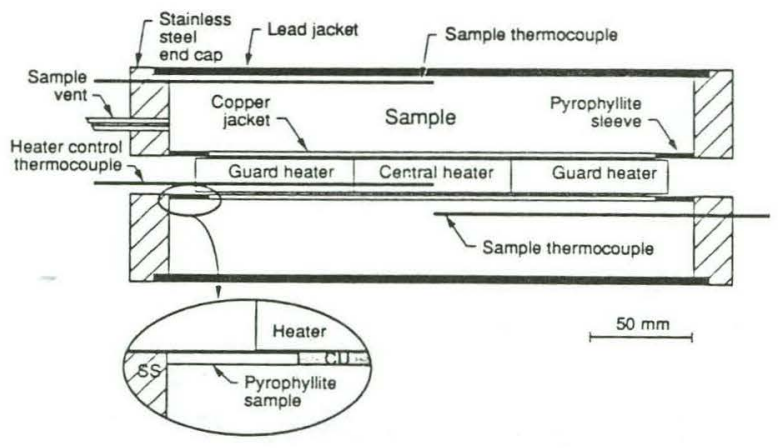

Figure 50. Scale drawing of the sample assembly for measuring thermal properties of rocks in the 0.2 GPa vessel. 


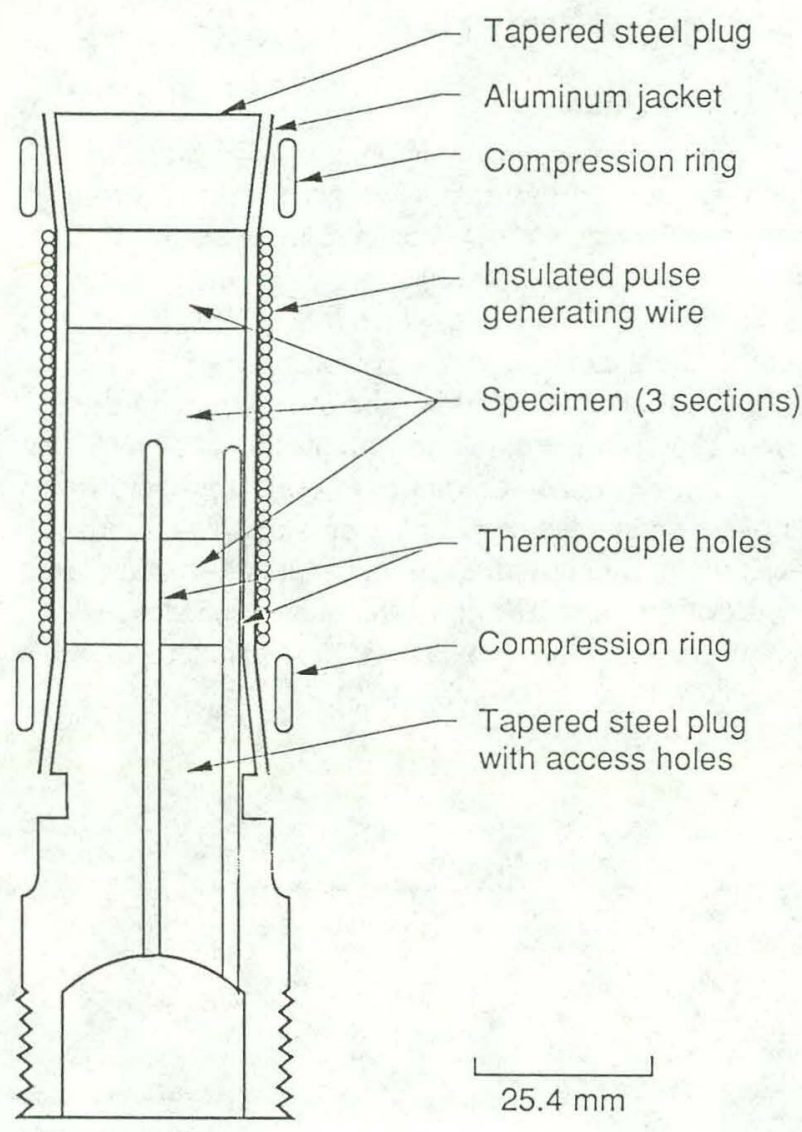

Figure 51. Schematic drawing of the sample assembly for the diffusivity apparatus with approximate scale.

0.5-GPa creep apparatus described above in Section A.1.2. The adaptation is shown in Fig. 51; the assembly and measurement principle are described more fully by Mirkovich (1977) and Durham et al. (1987b). The sample is a cylinder $25 \mathrm{~mm}$ in diameter and $63 \mathrm{~mm}$ long, jacketed in 0.25-thick aluminum and sealed to a specialized vessel plug (Fig. 51). A sinusoidal heat wave is applied to the outside of the sample using a low-power resistance furnace wound tightly against the sample jacket, and temperatures are measured as a function of time at two points within the sample, along the axis and just below the outer surface. Diffusivity is a function of the period of the heat wave and the phase delay of the wave between the two measured points in the sample.
The apparatus is suitable for characterizing rocks that are homogeneous on a scale above a few millimeters. Because it uses smaller samples, it has the advantage of better measurement resolution and much faster equilibration times than for the thermal properties apparatus described above. Sample results are shown in Fig. 52. The apparatus has been used to measure diffusivity of fine-grained evaporites (Durham et al., 1987a) and of several igneous rocks (Durham et al., 1987b).

\section{Line-Probe Thermal Conductivity Apparatus}

A simplified measurement of thermal conductivity (compared to the measurement technique used in the thermal properties apparatus) can be made to pressures of $0.1 \mathrm{GPa}$ and temperatures to $625 \mathrm{~K}$ using an assembly adapted to the $0.1-\mathrm{GPa}$ hot permeability apparatus. The measurement is based on the lineprobe technique, wherein the conductivity of a medium is determined by the rate of temperature increase under conditions of constant power input of a line heat source within that medium. The geometry is again axisymmetric. The typical sample is a thick-walled, leadjacketed cylinder with outer and inner diameters of 83 and $3.2 \mathrm{~mm}$ and a length of $150 \mathrm{~mm}$. The assembly is shown in Fig. 53 and an example of output is shown in Fig. 54. The apparatus, technique, and measurements made on Permian Basin evaporites are described in Durham et al. (1987a).

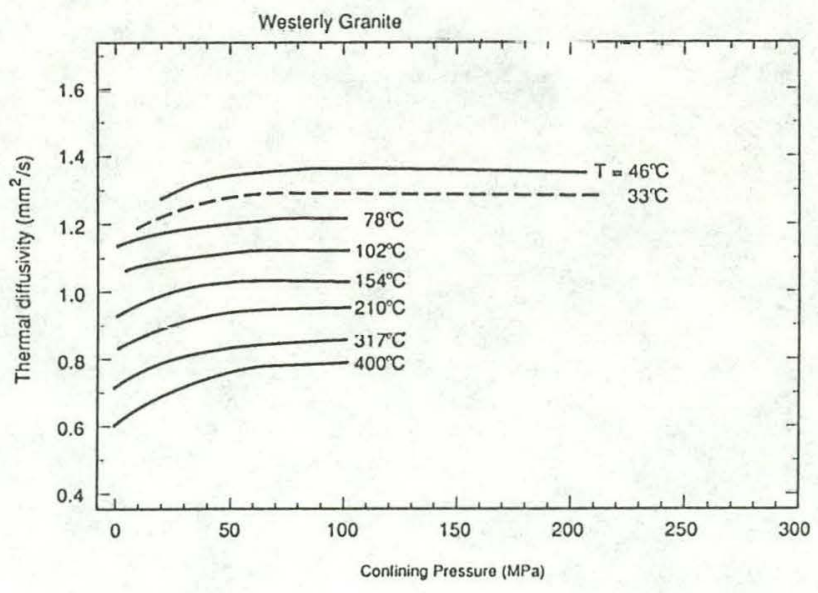

Figure $\mathbf{5 2}$. Thermal diffusivity of Westerly granite vs pressure and temperature. 


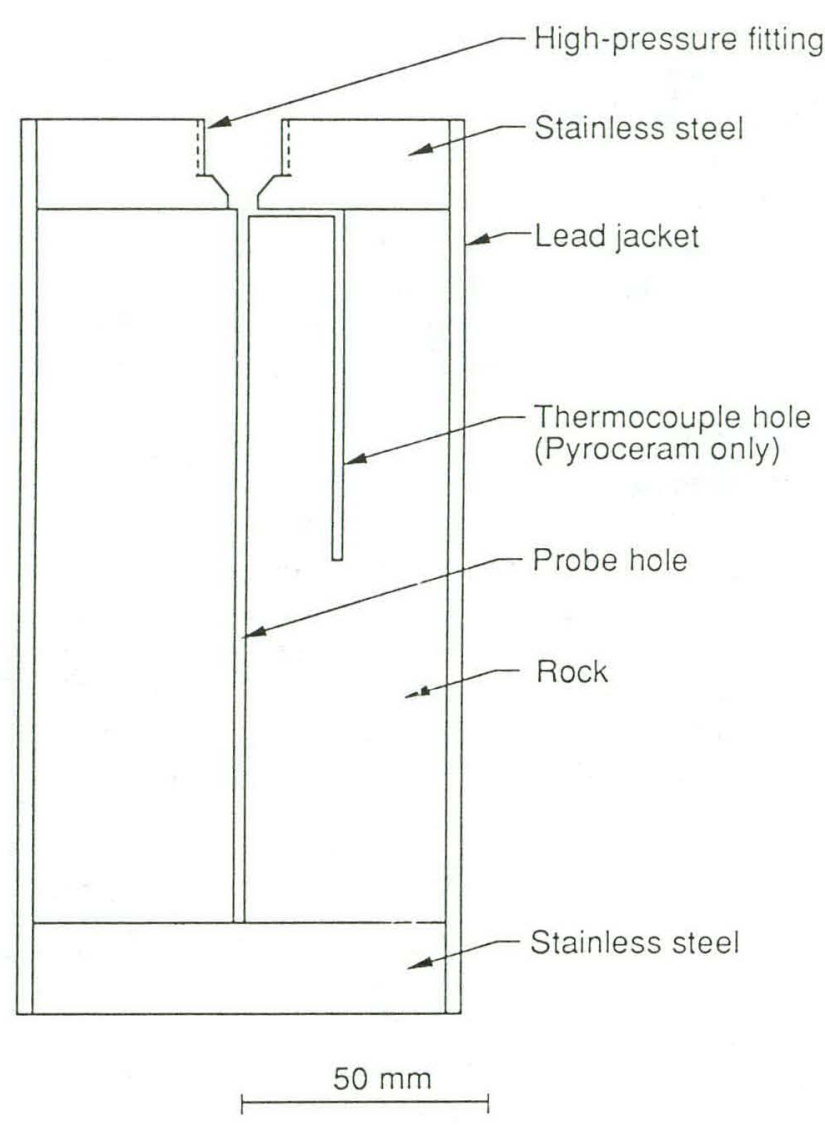

Figure 53. Cross section of sample assembly for the measurement of thermal conductivity under pressure using the line-probe technique.

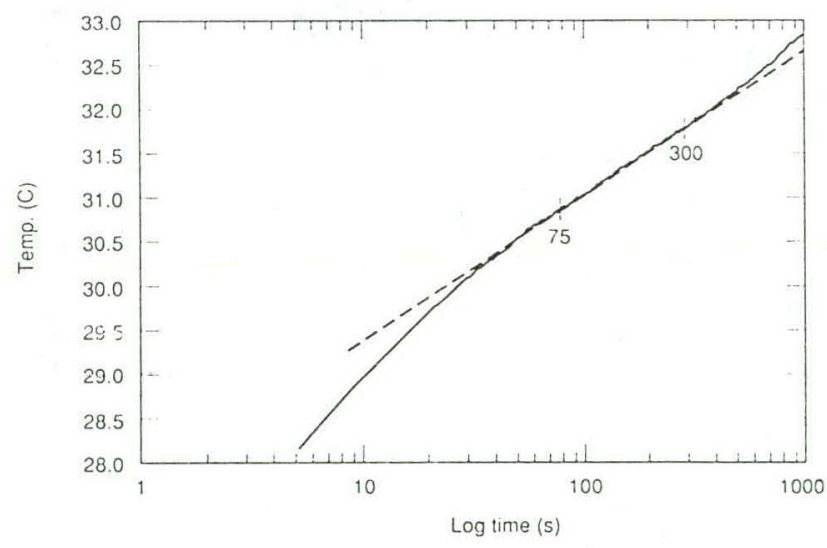

Figure 54. An example of a run record for the lineprobe thermal conductivity measurement. The record traces the temperature increase of a heater in the axial probe hole (Fig. 54) under constant power input. For this sample of Corning Glass Pyroceram code 9606 , the linear portion of the curve (between $\mathbf{7 5}$ and $300 \mathrm{~s}$ ) indicates a thermal conductivity of $\mathbf{3 . 8 2}$ $\mathrm{W} / \mathrm{m} \cdot \mathrm{K}$ at $300 \mathrm{~K}$.

\section{A.5 Optical Properties}

\section{2-GPa Sapphire Window}

Figure 55 is a schematic diagram of a vessel that allows optical studies through a 6-mm aperture (Stromberg and Schock, 1970). The aperture is a conical sapphire window supported by a pyrophyllite gasket against the steel cone into which it is seated. The pressure medium can be either a hydrocarbon or silicone fluid, or a gas such as argon or nitrogen. Temperatures to about $1500 \mathrm{~K}$ are possible for samples up to $10 \mathrm{~mm}$ long by $10 \mathrm{~mm}$ in diameter. Studies of optical properties at pressure and temperature or viewing of phase-synthesis experiments are possible with this apparatus. Measurements of the pressure and temperature dependence of single crystal elastic constants at moderate temperatures have been made (Liu et al., 1975).

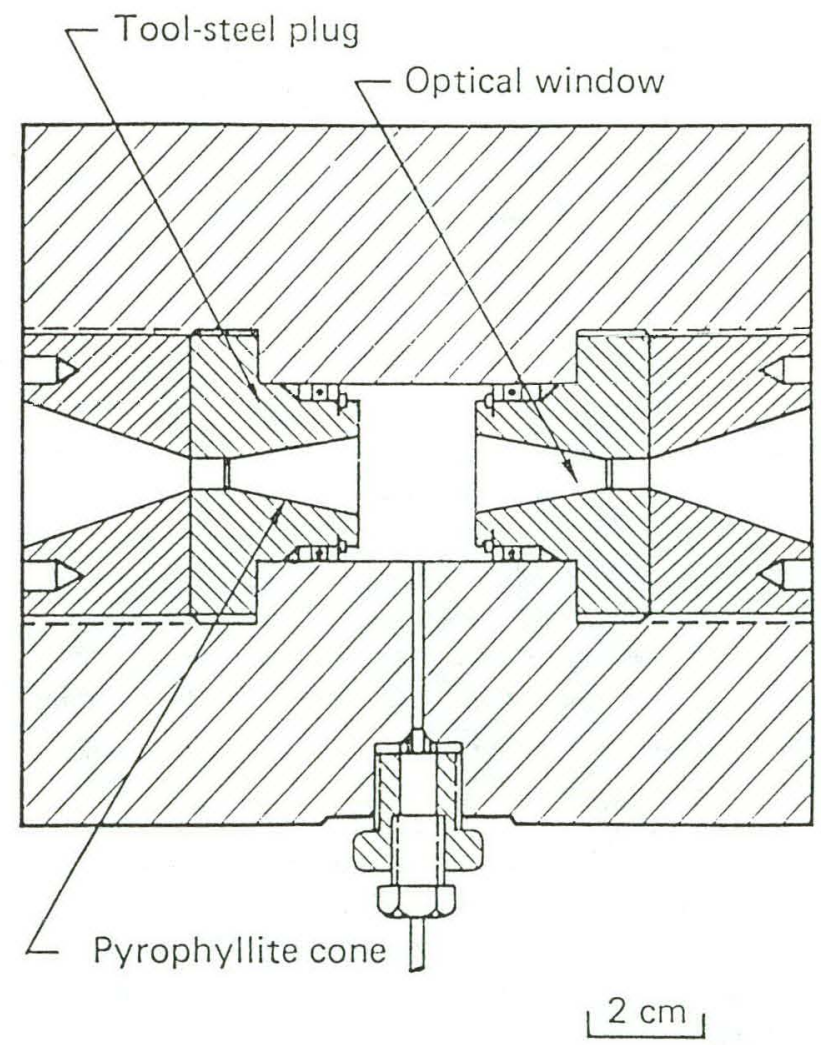

Figure 55. 1.2-GPa optical vessel. 


\section{B. Phase Equilibria and Kinetics Measurements}

\section{Diamond-Anvil Cells}

We use the diamond-anvil cell (DAC) to investigate the high-pressure behavior of various materials including gases, both to extend our knowledge of their highpressure properties and to experimentally test current solid-state and condensed matter theories. The cell consists of two flawless, gem-quality diamonds (typically 0.3 carat) mounted culet (tip) to culet in a fitted steel piston and cylinder (Fig. 56). Between the culets of the diamonds is a thin metal gasket with a hole in its center that forms the sample chamber and confines the sample radially. The design achieves tremendous sustained pressures ( $460 \mathrm{GPa}$, Moss et al., 1986) by concentrating a moderate force on a tiny area, namely the culet faces of the anvils. Ethanol, methanol, rare gases, hydrogen, etc., can all be used as the hydrostatic pressure medium around the sample. Sophisticated computer-aided finiteelement codes are used to design the shape of the anvils for generating still higher pressures. The transparency of the diamonds to most of the electromagnetic spectrum makes the DAC uniquely suited for $\mathrm{x}$-ray, spectroscopic, and optical studies.

Samples can be heated in the DAC to about $1000 \mathrm{~K}$ for longer periods of time by using a resistance heater. A pulsed YAG laser can be used for generating temperatures to $2800 \mathrm{~K}$ for shorter periods. Under these hightemperature conditions, materials properties can be investigated to 25 and $200 \mathrm{GPa}$, respectively, and accurate measurements on phase equilibria, reaction kinetics, and melting can be made.

We have DACs for measuring optical and electrical properties of condensed matter at ultra-high pressure. Pressure is measured from the fluorescence of ruby powder (calibrated to $200 \mathrm{GPa}$ ) or from the equation of state (EOS) of marker materials (using $\mathrm{x}$-ray diffraction techniques) placed in the sample chamber. We have achieved a maximum pressure of $230 \mathrm{GPa}$ in DAC

(a)

(b)

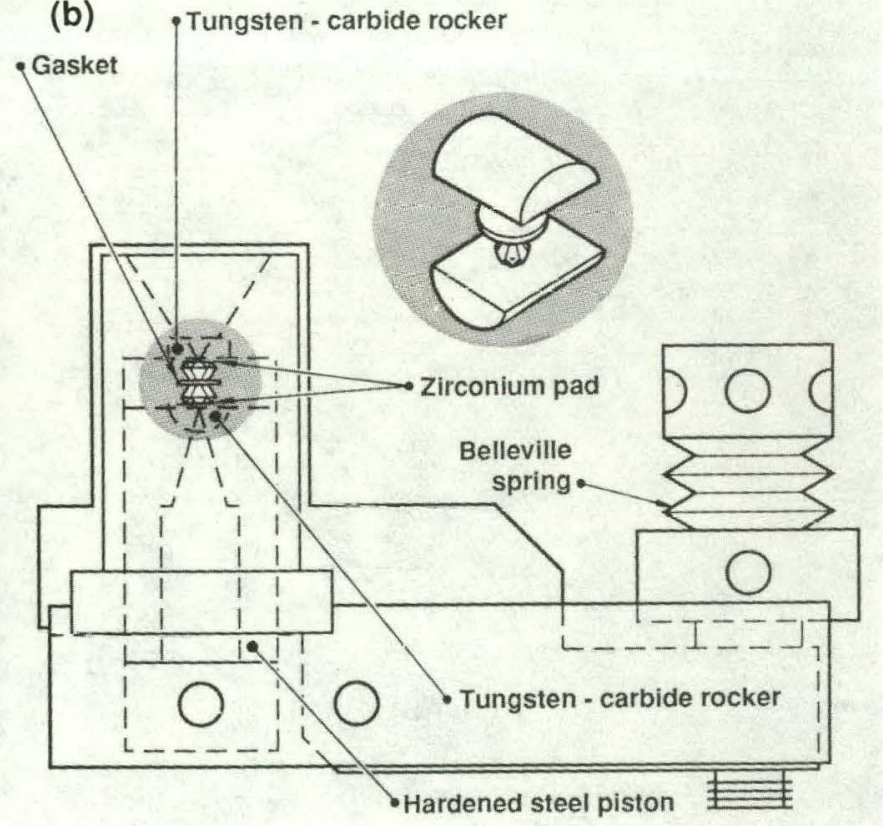

Figure 56. The mechanical and optical components of the diamond-anvil cell (DAC) for high-pressure studies. (a) Disassembled to show various components that make up the DAC, with collimator and $\mathrm{x}$-ray film cassette used for pressure-volume work. (b) Cutaway view showing how the various components fit together. 
experiments on contained samples (Williams et al., 1987, 1989). Our experimental capabilities in DAC research include reflection and absorption spectroscopy from the near UV to the far infrared, emission spectroscopy in the visible and near infrared, and lectrical resistance measurements (four- and two-probe) at room temperature and low temperature (10 to $300 \mathrm{~K})$. We have collaborated with others to measure Raman spectra of $\mathrm{H}_{2}$ and $\mathrm{N}_{2}$ between 100 and $200 \mathrm{GPa}$ (Reichlin et al., 1985 ) and now have Raman capability in our own laboratory. We are currently using Mössbauer spectroscopy techniques to study the spin state of $\mathrm{Fe}^{2+}$ in iron-rich silicates at high pressure (Reichlin et al., 1989a).

Optical absorption techniques allow us to measure directly the electron band gap of an insulating material

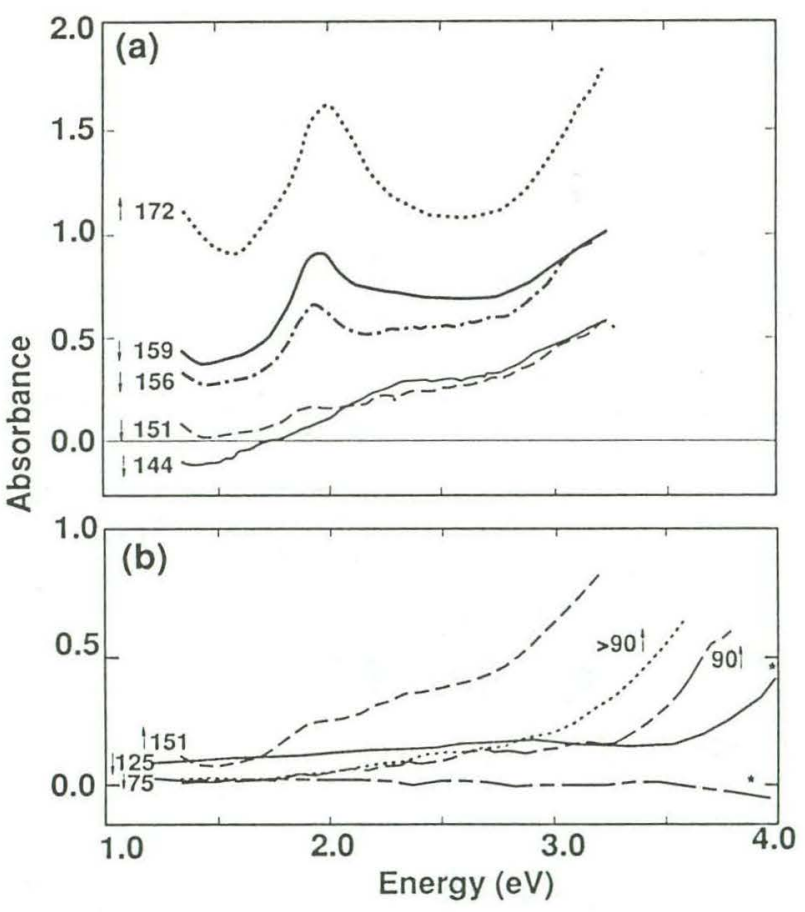

Figure 57. (a) Xenon absorbance vs energy as measured in the cell (DAC). Pressures are indicated for each spectrum in GPa. Up and down arrows indicate spectra collected on loading and unloading, respectively. (b) Low-pressure spectra plotted on an expanded vertical scale.

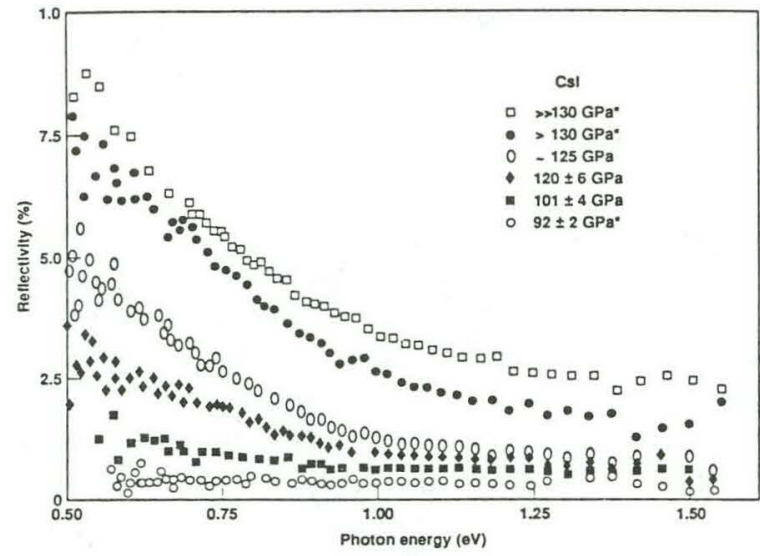

Figure 58. High-pressure infrared reflectivity spectra of CsI at the diamond-sample interface as a function of photon energy.

(between valence and conduction states) as a function of pressure. Spectra are collected through the diamond anvils plus sample and are corrected for absorption and reflection in the diamonds. Figure 57 shows absorption spectra of condensed xenon to $172 \mathrm{GPa}$. These data, combined with electron band calculations, were used to demonstrate the onset of an insulator-metal transition in xenon at $150 \mathrm{GPa}$ (Reichlin et al., 1989b).

Reflection spectroscopy is used to document the presence of free-electron behavior, and thus, metallic character, in materials at high pressure. Figure 58 shows infrared reflection spectra for CsI up to $170 \mathrm{GPa}$. Reflection spectra were collected at the sample/diamond interface and were corrected for absorption in the diamond anvils. The increase in reflectivity at low energies indicates that CsI is metallic at pressures above $110 \mathrm{GPa}$ (Reichlin et al., 1986).

Electrical properties are also directly measured in the DAC using a four-probe technique. The electrical resistance of iron vs pressure is shown in Fig. 59. The $\alpha$ to $\varepsilon$ transition is indicated by a discontinuity in resistance at $15 \mathrm{GPa}$ (Reichlin, 1983).

The DAC is a very important tool for studying the properties of materials at ultra-high pressures, as well as temperatures. X-ray diffraction is used with the DAC to obtain the crystal structural and volume changes under high pressures (Akella, 1983). Pressure-volume data obtained with the DAC are more precise than the dynamic shock-wave data. We discovered structural changes in uranium and plutonium that were never reported in shock-wave work (Akella et al., 1985). With the improvements in DAC technology, high-pressure 


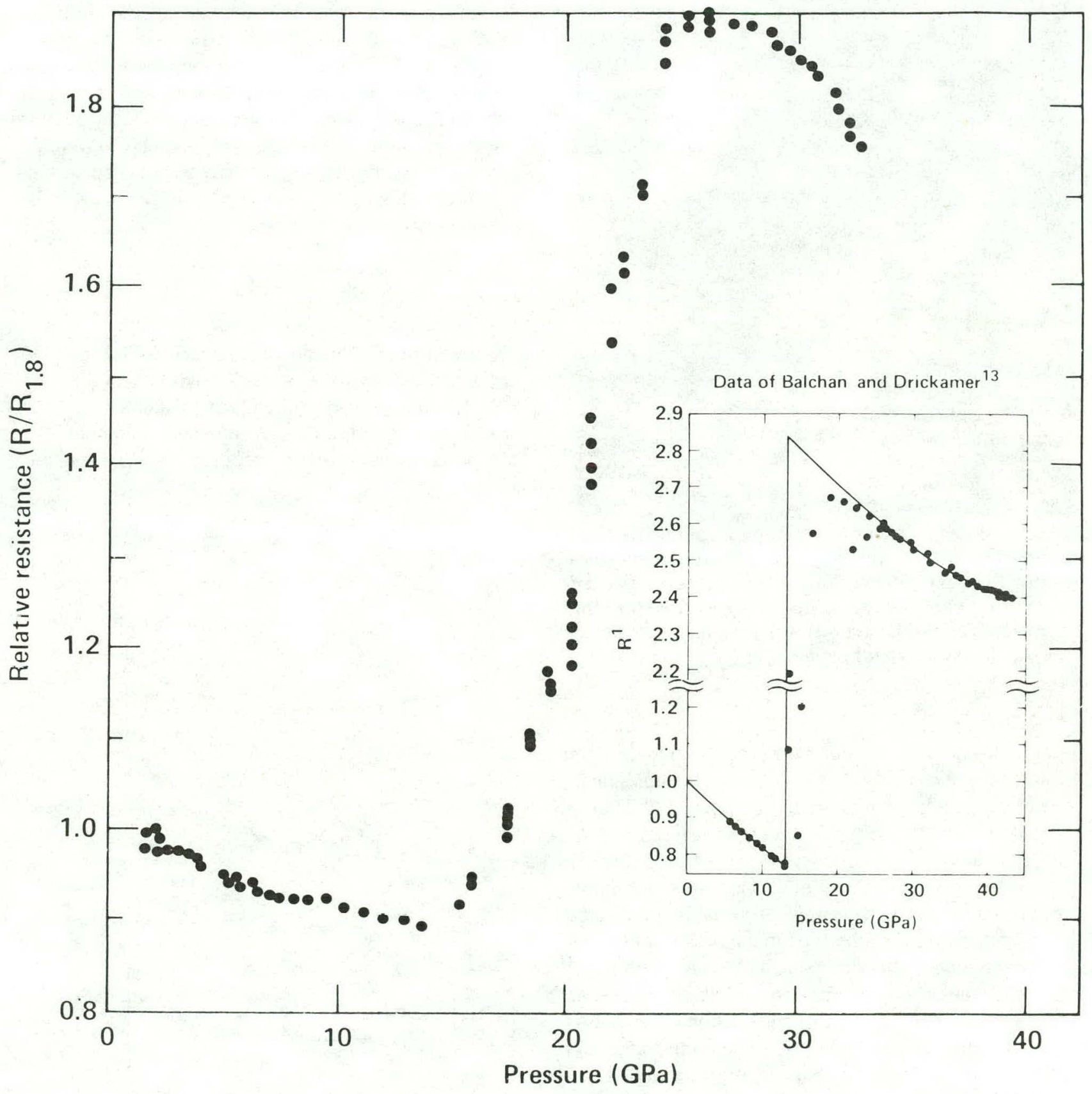

Figure 59. Relative resistance of iron vs pressure as measured in the DAC.. 


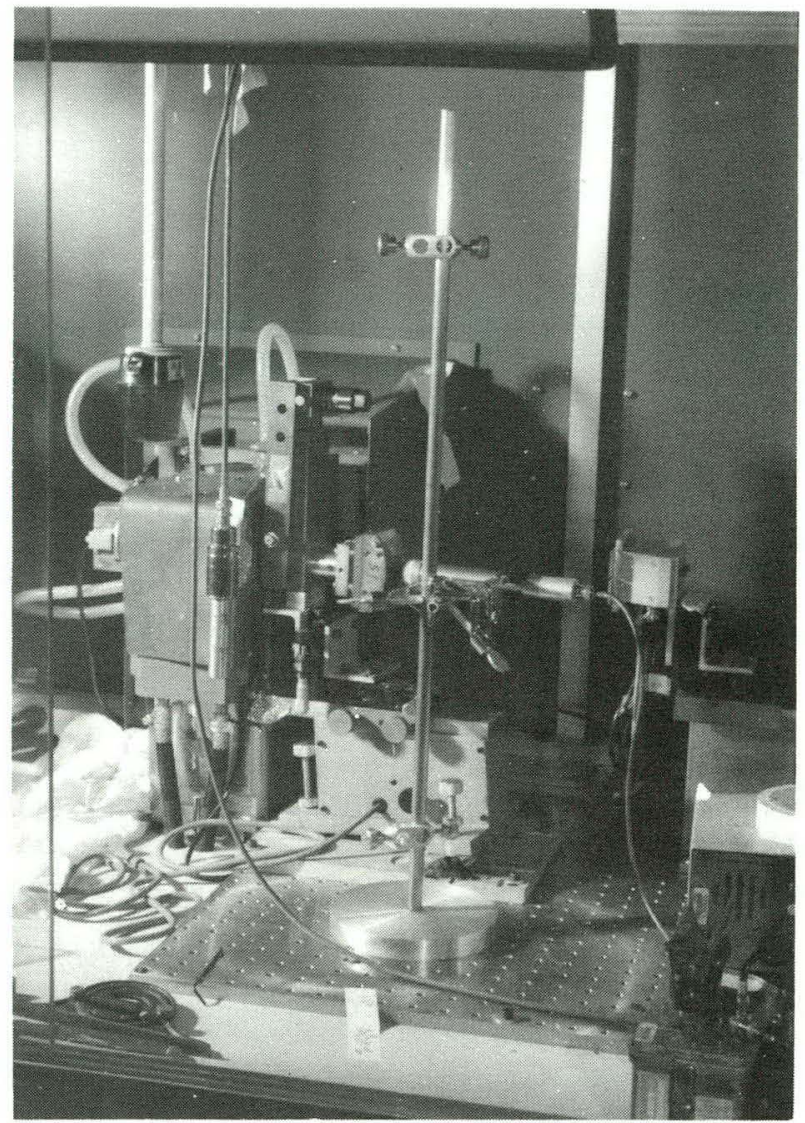

Figure 60. Equipment for making $x$-ray diffraction measurements. $X$ rays from the rotating anode generator (left) pass through the DAC (center). The diffracted $x$ rays from the sample are recorded on film in the curved holder (right) or by a solid-state detector (at the back or right side).

studies using this apparatus have progressed to the point where they even complement shock-wave studies and overlap over a large pressure region (up to $300 \mathrm{GPa}$ ).

DACs are uniquely suited to investigate hazardous and radioactive materials because the sample required for cutaining x-ray diffraction data is very small (milligram quantities) and the sample material is completely recoverable. We are interested in the behavior of f-electron metals under pressure and temperature and also any similarities between the lanthanide (4f) and actinide (5f) metals. Using $x$-ray diffraction techniques to pressures greater than $150 \mathrm{GPa}$, we determined the crystal structures and volume changes for some rare-earth elements (Akella and Smith, 1986; Akella et al., 1986; Akella et al., 1988a; Smith and Akella, 1982, 1984, 1986) and actinides (Akella et al., 1979, 1980, 1988b, Akella and Smith, 1990; Smith et al., 1981).

To achieve higher pressures in the DAC, the diamond facets between which the sample is pressed (flat of the culet) and the sample itself must be made smaller
( $25 \mu \mathrm{m}$ across). This configuration produces enormous pressure gradients across the sample. Also, the small size of the samples makes it very difficult to $x$ ray it in a reasonable time using a conventional $\mathrm{x}$-ray generator (Fig. 60). We use synchrotron $x$-radiation to obtain crystallographic data (Smith and Akella, 1987) because this type of radiation is highly collimated and many orders of magnitude more brilliant than any conventional, rotating, anode $\mathrm{x}$-ray generator. Using a collimated $\mathrm{x}$-ray beam of $10 \mu \mathrm{m}$ from such a source, we are able to avoid the pressure gradient (because we are $\mathrm{x}$ raying a very small sample area) and obtain accurate data within one or two hours. We are currently working to develop a system with which $\mathrm{x}$-ray data can be obtained on samples at ultra-high pressures while being simultaneously heated to very high temperatures.

\section{Cubic-Anvil System}

Quasi-hydrostatic pressures up to $25 \mathrm{GPa}$ are generated with a two-stage cubic anvil system, USCA-1200 (Uniaxial Split Cone Apparatus with a 1200 ton capacity), used in conjunction with the 11$\mathrm{MN}$ press frame. This apparatus can be used for phase

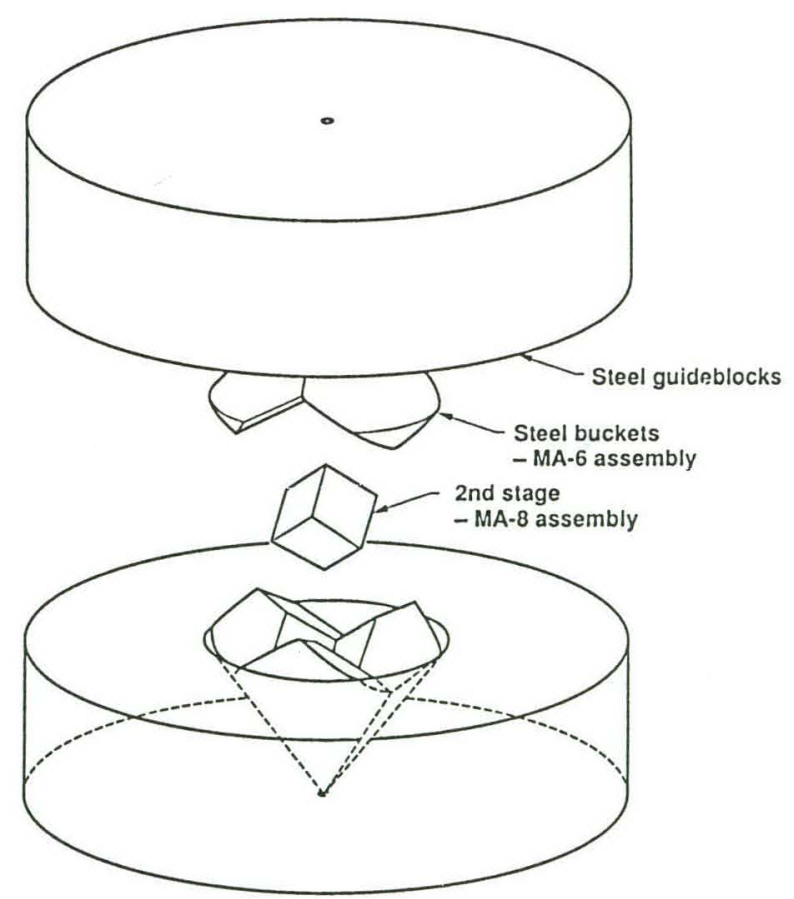

Figure 61. Schematic drawing of the cascading pressure system used in USCA-1200. Steel guideblocks contain the MA-8 assembly of steel anvils, which in turn contain the WC MA-8 sample assembly. 
(a)
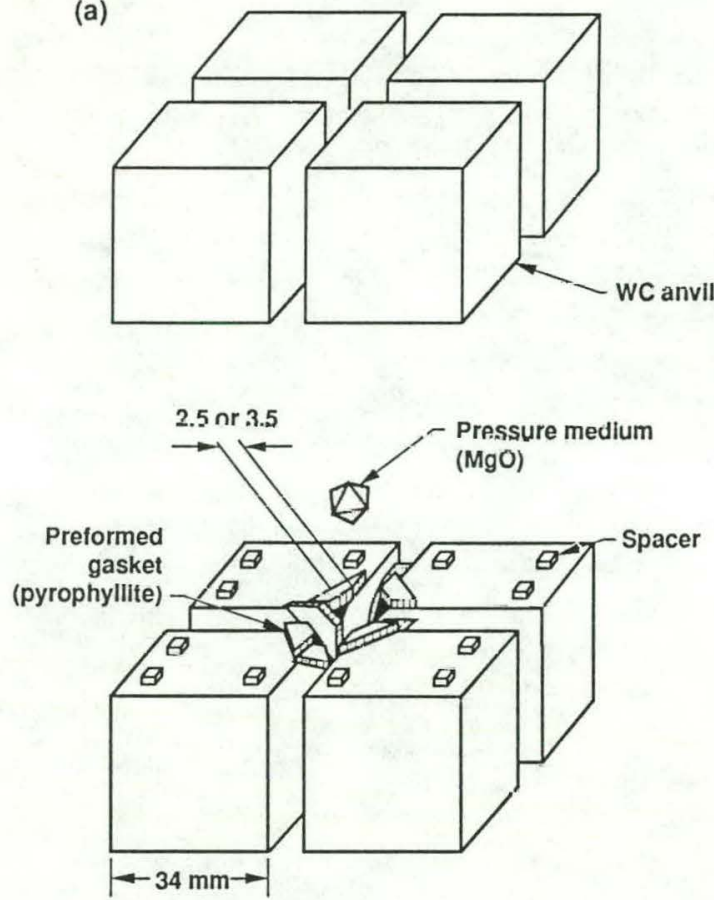

(b)

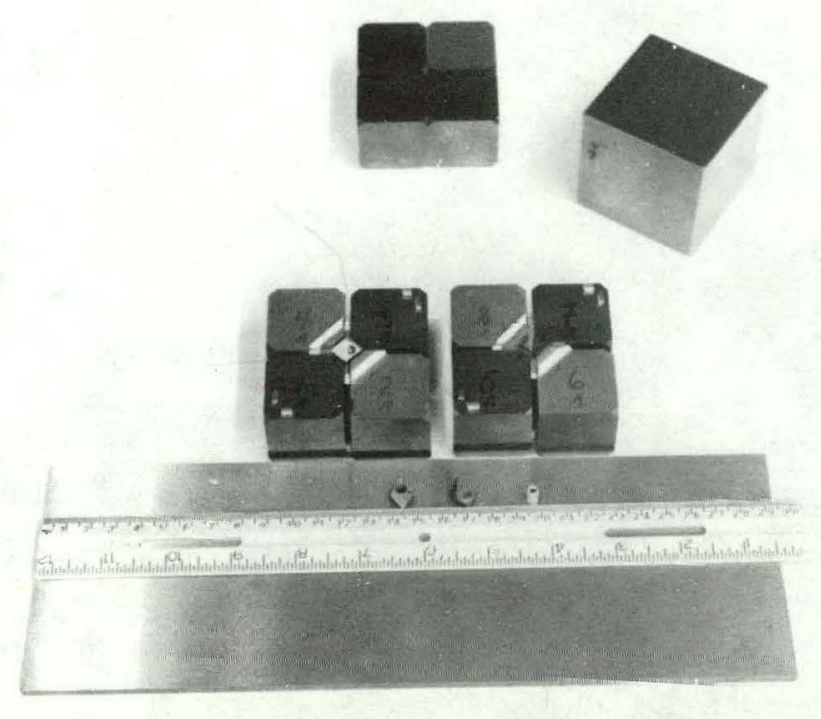

Figure 62. (a) Schematic drawing and (b) photograph of the MA-8 assembly. The MA-8 assembly is comprised of 8 WC blocks (numbered in the photo) that are truncated at each corner. When fully assembled, the cubes leave an octahedral volume at the center of the assembly where the pressure medium, a sintered $\mathrm{MgO}$ octahedra. The cylindrical hole through the center of the octahedra contains the furnace assembly.

equilibrium measurements, and measurements of diffusion kinetics and phase transformations, as well as for synthesis experiments. A schematic of the cascading pressure system is shown in Fig. 61. An octahedral sample assembly is contained within a set of eight tungsten-carbide (WC) cubes that are truncated at each corner to form a triangular face (Fig. 62). This set of anvils is called the MA-8 assembly, and forms the secondstage of the system. The assembly within the central octahedral volume consists of an octahedral pressure medium, typically fabricated from $\mathrm{MgO}$ or unfired pyrophyllite. A cylindrical cavity projecting from opposed faces of the octahedron contains a resistance heater, thermal and electrical insulation, and the sample assembly. The sample volume depends on the desired pressure range; the size of the WC cube truncation is varied to optimize the generated pressures and sample volumes. At the highest pressures, samples of several cubic millimeters may be accommodated. The secondstage of the system is compressed by the six steel anvils or buckets in a "split-cone" configuration (Fig. 63), which form the first-stage of the system or MA-6 assembly. This, in turn, is compressed by the main press (Fig. 64).

Figure 63. View of the lower guideblock of USCA1200. The conical portion of the guideblock supports three steel anvils or buckets that form the lower portion of the MA-6 assembly. The steel cube is used to align the upper and lower bucket assemblies.

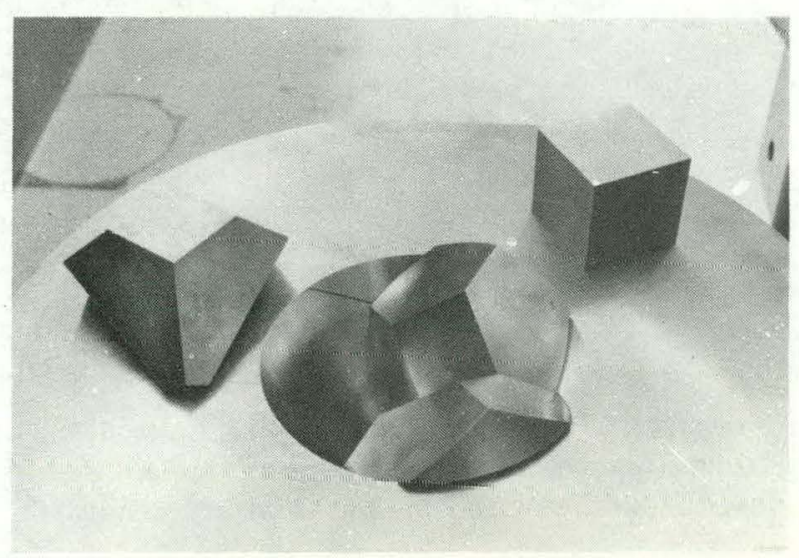




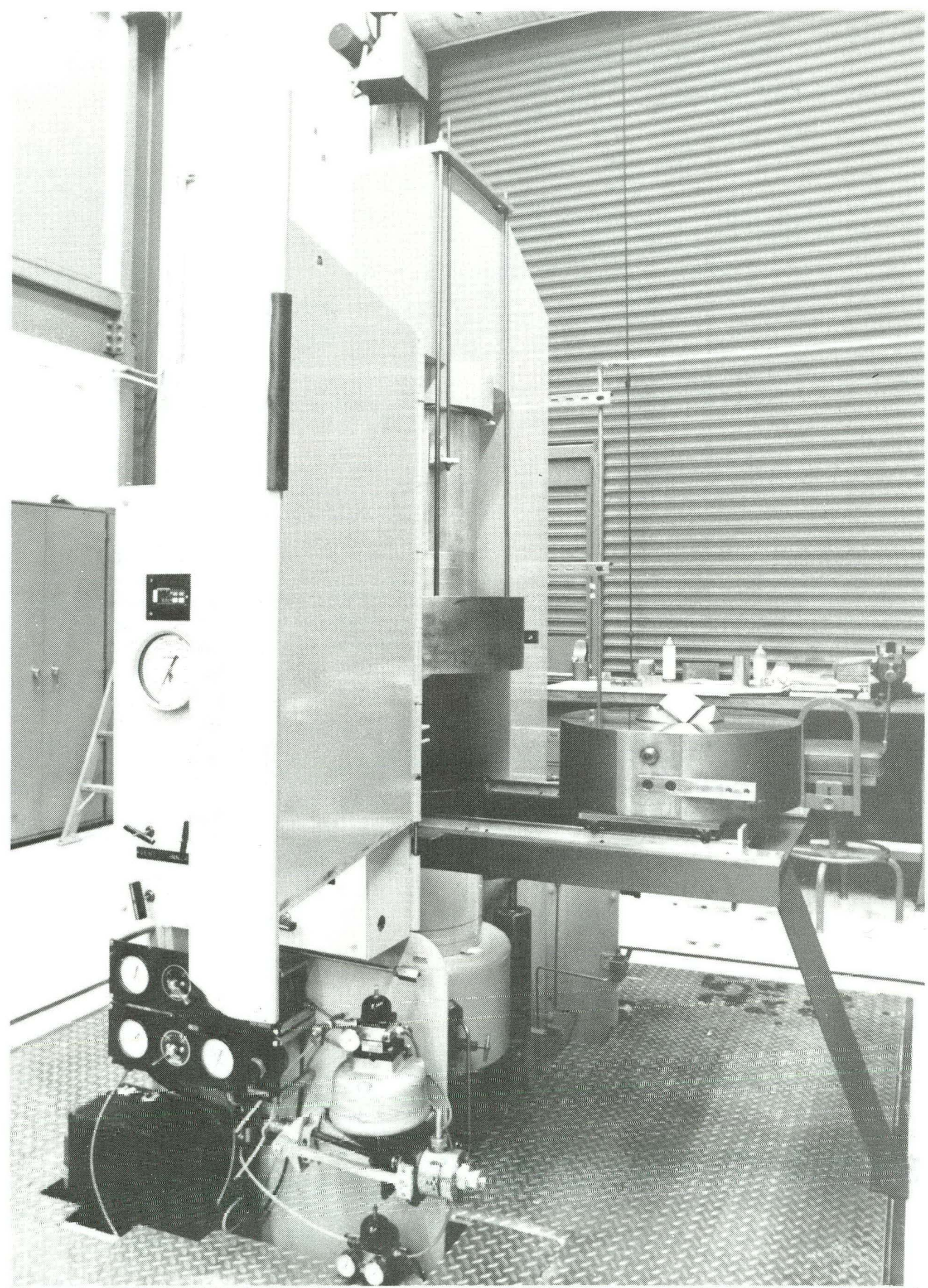

Figure 64. USCA-1200 (Uniaxial Split Cone Apparatus). Guideblocks to support the MA-6 assembly (which in turn supports the MA-8) are placed within a 11-MN press. The rails allow the lower guideblock to be removed from the press frame for sample loading. 


\section{Piston-Cylinder Cells}

Quasi-hydrostatic pressures for pressure-volume $(P-V)$ measurements are generated by displacing a tungsten-carbide piston within a short cylindrical die of similar material. The components of the piston die and sample assembly are shown in Fig. 65. The press used to achieve the highest end loads is a 6.8-MN frame designed specifically for piston-cylinder experiments (Fig. 66). It has a double-acting hydraulic ram that allows independent clamping of the die while the piston is forced against the sample. See Stephens et al. (1970) for a complete description of this system. The pistoncylinder cells can also be operated at lower pressures in the general-purpose $3.0-\mathrm{MN}$ frame, which also has a double-acting ram.

Multiple die sizes ranging from 10 to $51 \mathrm{~mm}$ in diameter may be used. One die is $100 \mathrm{~mm}$ long; the rest are $50 \mathrm{~mm}$ long. Samples up to $51 \mathrm{~mm}$ in diameter by $76 \mathrm{~mm}$ long can be accommodated. At low temperatures, lead, tin, or other soft metal may be used as the pressure medium; the only requirement is that the shear strength be negligible compared to the mean stress. Quasi-hydrostatic pressures slightly more than $4 \mathrm{GPa}$ may be generated in all except the largest size die (Table 1). Although most $P-V$ measurements have been made up to $4.0 \mathrm{GPa}$ at room temperature, associated external heaters are available for operation to about $675 \mathrm{~K}$

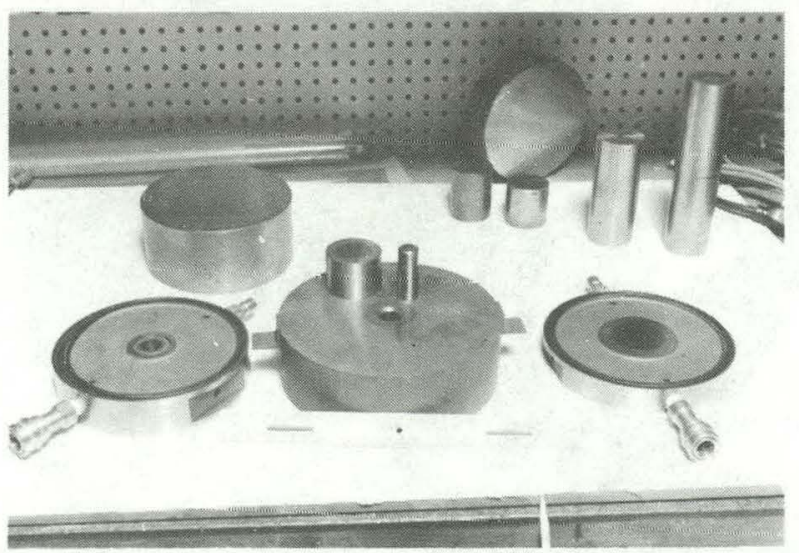

Figure 65. Piston and die assembly used for hightemperature piston-cylinder experiments. The center disk is the pressure vessel with a WC core. This core will accept a 19-mm sample assembly. The adjacent disks are the lower and upper platens containing annular segments for coolant, and connections for electrical leads. and perhaps $3 \mathrm{GPa}$. Usual loading rates are about $10^{-4} \mathrm{~s}^{-1}$; however, somewhat lower or higher rates may be accommodated. Pressures or volumes are accurate within about $\pm 5 \%$, depending somewhat on the test material.

On smaller samples and with internal-resistance heating (standard heaters are made of graphite), we can use this system to perform phase equilibrium and kinetic studies to temperatures in excess of $1800 \mathrm{~K}$ and 4.0 GPa. In this case, nonmetals such as salt, pyrex glass, and crushable alumina are used as the pressure medium. Other applications include high-pressure, high-temperature phase synthesis, diffusion kinetics, and solid-solution studies.

\section{Hydrothermal Vessels}

Eight externally heated pressure vessels exist in a high-confining-pressure, high-temperature apparatus suited for such geochemical studies as phase synthesis, diffusion, solid-fluid equilibria, or solubility determinations in chemical systems that may contain $\mathrm{H}_{2} \mathrm{O}$. All of the individual vessels are the Tuttle cold-seal type (Luth and Tuttle, 1963) and may be operated independently. Four may be operated to pressures of $0.4 \mathrm{GPa}$ and temperatures to $1200 \mathrm{~K}$ for short times; four have a capacity of $1.0 \mathrm{GPa}$ and $1000 \mathrm{~K}$. Sample materials in quantities of 10 to $20 \mathrm{mg}$ are liquid and/or powder and are encapsulated in noble metal tubing and welded shut. Single or multiple charges may be pressurized and heated in a single vessel. Figure 67 is an enlarged diagram of the vessel showing sample placement. The confining pressure surrounding each sample capsule is externally generated in an intensifier that uses argon as the working fluid. After an experiment, the vessel is cooled with a compressed-air jet. Temperatures are accurate within 1 to $5 \mathrm{~K}$, depending on the temperature selected. Pressures are known to about $0.5 \%$ or $1 \mathrm{MPa}$, whichever is larger. Some typical results are shown in Fig. 68 and have been published elsewhere (Piwinskii, 1973, 1975).

\section{1-MPa Diffusion Furnaces}

Resistance furnaces equipped with alumina muffle tubes for gas mixing are used for both phase equilibrium experiments and measurements of diffusion in melts and minerals. The systems use standard Deltech VT-31 furnaces with Eurotherm temperature controllers and SCR assemblies. The alumina muffle tubes are fit with water-cooled collars that allow sample feed-throughs at the top of the furnace, and accommodate zirconia $f_{\mathrm{O}_{2}}$ sensors and thermocouples through the 


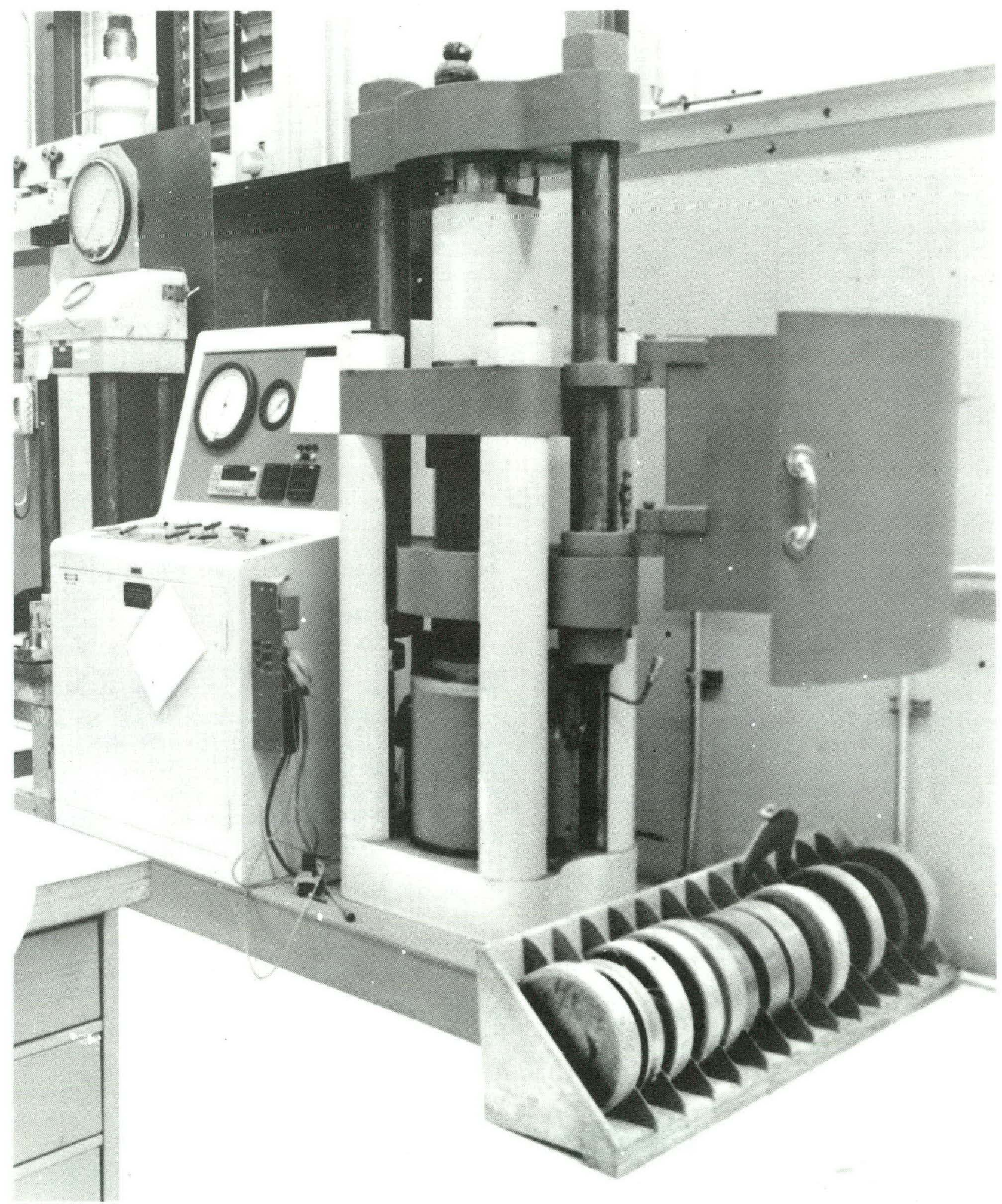

Figure 66. The 6.8-MN uniaxial press used for piston-cylinder experiments. The upper hydraulic ram raises a platen to compress the pressure vessel assembly. The lower ram controls the advance of the WC piston through the pressure vessel. The panel on the left contains the pressure- and temperature-control hardware. 
bottom. Oxygen fugacities can be controlled between that of pure oxygen and that equivalent to the $\mathrm{Fe}-\mathrm{FeO}$ buffer. One furnace has been adapted for use as a vacuum furnace for oxygen diffusion measurements

(Fig. 69). Using a sorption pump, this system allows the furnace to be evacuated to $1 \mathrm{~Pa}$ prior to filling with isotopically enriched gases for the diffusion anneals. The samples are suspended through a vacuum feedthrough, and can be held in a cold region of the furnace until the furnace atmosphere has equilibrated. After completion of the experiment, the isotopically enriched gases can be cryogenically pumped from the furnace
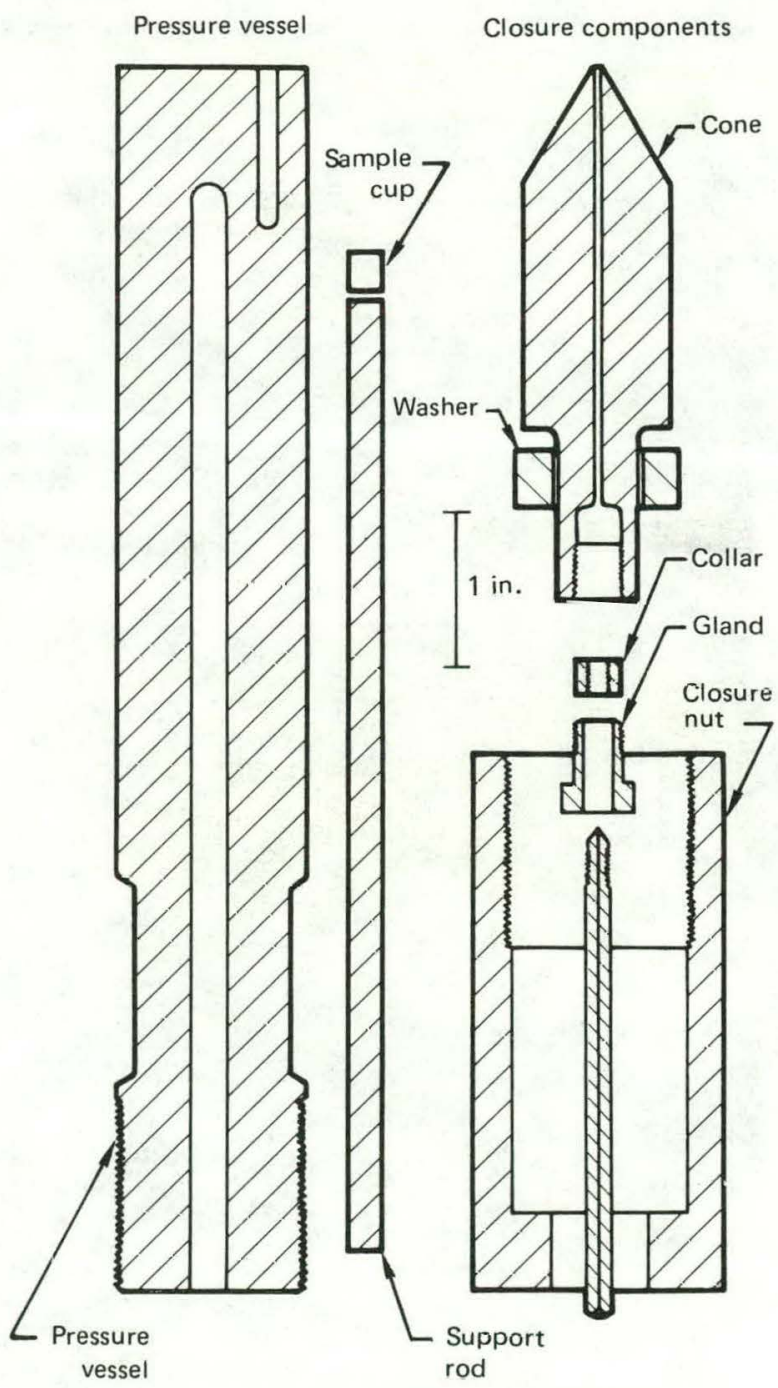

Figure 67. Cross section of 1.0-GPa vessel used for hydrothermal tests. and stored for later use. This system has been used to measure the diffusion of oxygen in San Carlos olivine as a function of oxygen fugacity [Ryerson et al., (1989), (see Fig. 70)].

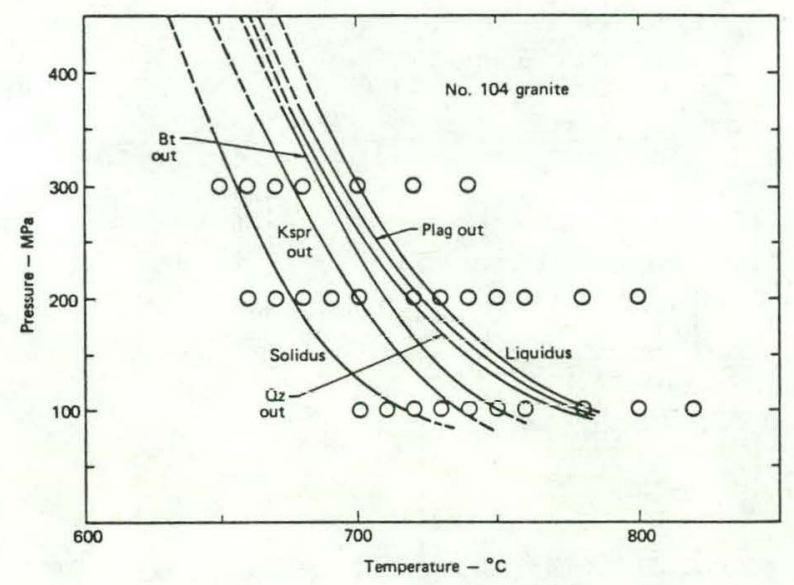

Figure 68. Solidus-liquidus boundaries for granite at pressure and temperature. 


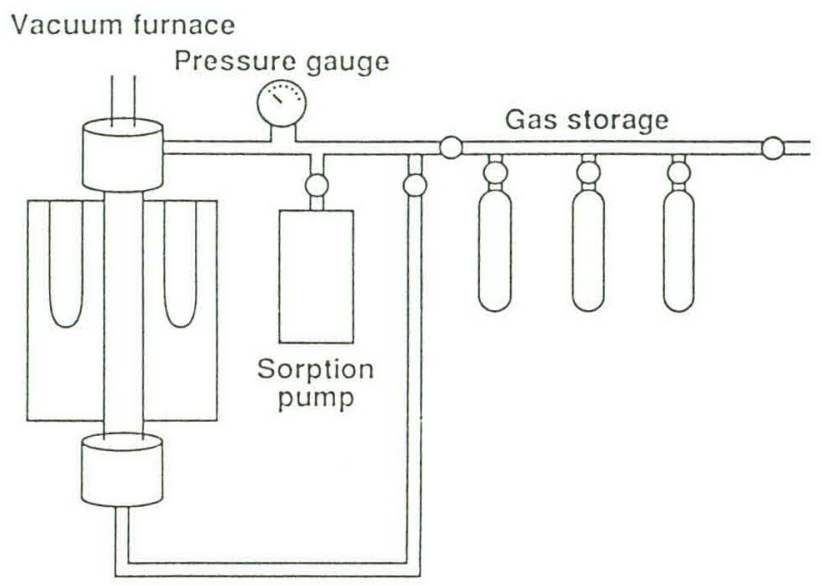

Figure 69. Schematic drawing of a vacuum furnace used for oxygen diffusion experiments. The sorption pump is used to evacuate the muffle tube that passes through the furnace. After evacuation the pump is isolated and isotopically "tagged" gases can be admitted from the rack of gas storage cylinders. After the experiment the gases can be cryogenically pumped back into the storage cylinders.

Figure 70. Results of oxygen diffusion experiments in single crystals of San Carlos peridot as a function of oxygen fugacity and temperature for the [100] direction.

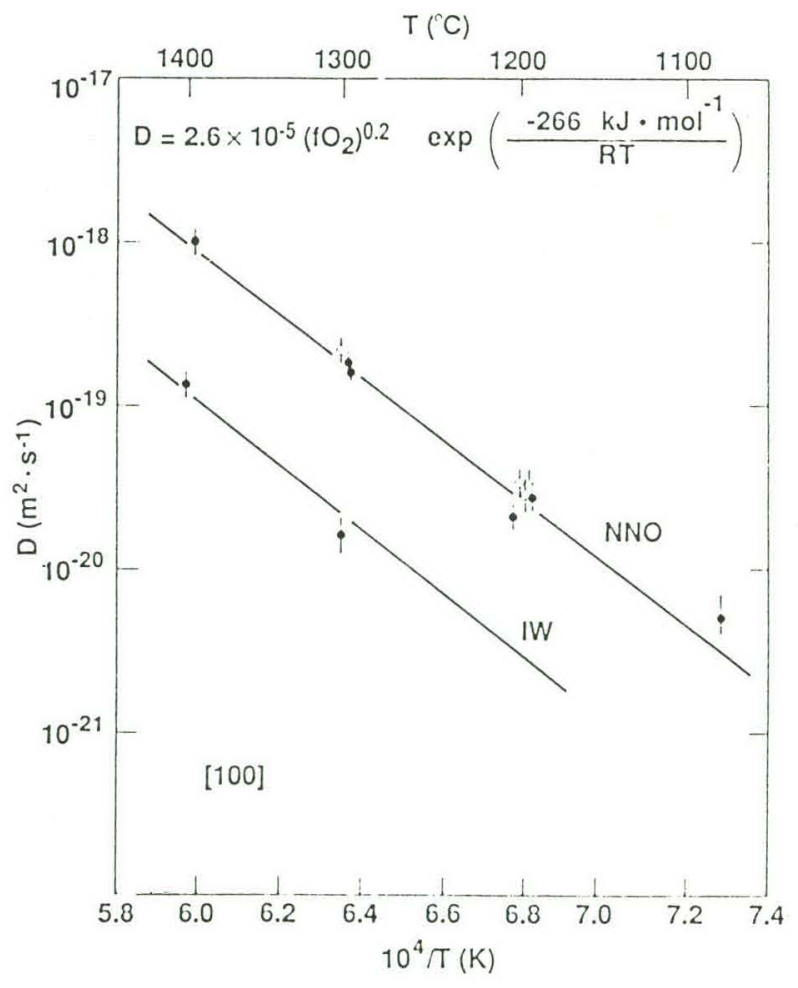




\section{Bibliography}

Abey, A. E., "Effect of hydrostatic pressure on torosional stress-strain curves of single-crystal copper," J. Appl. Phys. 44, 2087-2092 (1973).

Abey, A. E., and B. P. Bonner, "Elastic Constants of Polycrystalline $\alpha$-Uranium," J. Appl. Phys. 46, 1427 (1975).

Abey, A. E., and L. L. Dibley, Apparatus for deformation tests at intermediate strain rates, $10^{-2} \mathrm{sec}^{-1}$ to $10^{+2} \sec ^{-1}$ and at high pressure, Lawrence Livermore National Laboratory, Livermore, Calif., UCRL-79012 (1977).

Abey, A. E., and H. D. Stromberg, "70 Kilobar Shear Apparatus," Rev. Sci. Instrum. 40, 557-558 (1969).

Abey, A. E., B. P. Bonner, H. C. Heard, and R. N. Schock, Mechanical Properties of a Shale From Site U-2, Lawrrence Livermore National Laboratory, Livermore, Calif., UCID-16023 (1972).

Abey, A. E., W. B. Durham, D. A. Trimmer, and L. L. Dibley, "Apparatus for determining the thermal properties of large geologic samples at pressure to $0.2 \mathrm{GPa}$ and temperatures to $750 \mathrm{~K}$," Rev. Sci. Inst. 53, 876-879 (1982).

Akella, J., "Diamonds: Powerful tools for high pressure physics," Energy Technology Review, 11-19 (February, 1983).

Akella, J., and G. S. Smith, "High pressure diamond-anvil studies on neodymium to $40 \mathrm{GPa}$," J. Less. Comm. Metals. 116, 313-316 (1986).

Akella, J., and G. S. Smith, "High Pressure Studies on Curium," Defense Res. Rev. (in press) (1990).

Akella, J., Q. Johnson, W. Thayer, and R. N. Schock, "Crystal structure of the high pressure form of Am," J. Less. Comm. Metals 68, 95-97 (1979).

Akella, J., Q. Johnson, and R. N. Schock, "Phase transformations in Am at high pressure: Relation to rare-earth elements," J. Geophys. Res. 85, 7056-7058 (1980).

Akella, J., G. S. Smith, and H. C. Weed, "Static high pressure diamond-anvil studies on uranium to $50 \mathrm{GPa}$," J. Geophys. Res. 46, 399-400 (1985).

Akella, J., J. Xu, and G. S. Smith, "Static high pressure studies on Nd and Sc," Physics, 139-140B, 285-288, (1986).

Akclla, J., G. S. Smith, and A. P. Jephcoat, "High pressure phase transformation studies in gadolinium to $106 \mathrm{GPa}$," J. Phys. Chem. Solids 49, 573-576(1988a).

Akella, J., Q. Johnson, G. S. Smith, and L. C. Ming, "Diamond-anvil cell high pressure x-ray studies on thorium to 100 GPa," High Pr. Res. 1, 91-95 (1988).

Bassett, W, T. Takahashi, P. W. Stook, “ X-ray diffraction and optical observation on crystalline solids up to 300 kbar," Rev. Sci. Instrum. 38, 37-42 (1967).

Beeman, M. L., W. B. Durham, and S. H. Kirby, "Friction of Ice,"J. Geophys. Res. 93, 7625-7633 (1988).

Birch, F. J., "The velocity of compressional waves in rocks to 10 kilobars, part 2," J. Geophys. Res. 66, 2199-2224 (1961).

Blair, S. C., "Confined Compressive Strength of Saline Ice at Intermediate Strain Rates," U. S. Army Cold Regions Research and Engineering Laboratory Special Report 86-30, Hanover, N.H. (1986), Proc. Second Workshop on Ice Penetration Technology, Naval Post-Graduate School, Monterey, Calif.

Blair, S. C., "Mechanical Properties of First-Year Sea Ice at Intermediate Strain Rates," Proc. Ninth Internat. Conf. on Port and Ocean Engineering under Arctic Conditions (POAC), Fairbanks, Alaska, Aug. 16-21, 1987.

Blair, S. C., J. J. Sweeney, W. R. Ralph, and D. G. Ruddle, Mechanical Properties of Heavy Oil-Sand and Shale as a Function of Pressure and Temperature, Lawrence Livermore National Laboratory, Livermore, Calif., UCID21093 (1987).

Blair, S. C., R. K. Thorpe, and F. E. Heuze, Physical Models of Hydrofracturing Across Material Interfaces, Lawrence Livermore National Laboratory, UCID-21505 (1988).

Blair, S. C., J. C. Chen, W. R. Ralph, and D. W. Ruddle, Mechanical Properties of Rocks from PSA Flight 1771 Crash Site, Lawrence Livermore National Laboratory, Livermore, Calif., PATC-IR 89-05 (1989).

Bonner, B. P., "Shear Wave Birefringence in Dilating Granite," Geophys. Res. Lett. 1, 217 (1974).

Bonner, B. P., " $V_{p} / V_{s}$ in Saturated Granodiorite Loaded to Failure," Pageoph 113, 25 (1975).

Bonner, B. P., A. E. Abey, H. C. Heard, and R. N. Schock, High Pressure Mechanical Properties of Merlin Alluvium, Lawrence Livermore National Laboratory, Livermore, Calif., UCRL-51252 (1972).

Bonner, B. P., B. J. Wanamaker, and S. R. Taylor, "Amplitude Dependent Attenuation and Implications for the Seismic Source," proceedings of the DOE/LLNL Symposium on Explosion Source Phenomenology, Lake Tahoe, Calif., March 14-16, 1989.

Bridgman, P. W., "The Effect of Hydrostatic Pressure on the Fracture of Brittle Substances," J. Appl. Phys. 18, 246 (1947). 
Bridgman, P. W., Studies of Large Plastic Flow and Fracture (McGraw-Hill, New York, N.Y., 1952), p. 39.

Bridgman, P. W., "Certain Effects of Pressure on Seven Rare Earth Metals," Proc. Am. Acad. Arts Sci. 83 (1954).

Brown, S. R., R. L. Kranz, and B. P. Bonner, "Correlation Between the Surfaces of Natural Rock Joints," Geophys. Res. Lett. 13, 1430-1433 (1986).

Carter, N. L., and H. C. Heard, "Temperature and Rate Dependent Deformation of Halite," Am. J. Sci. 269, 193-249 (1970).

Costantino, M. S., and W. B. Daniels, "Dielectric Constant of Compressed Solid Methane at Low Temperature," J. Chem. Phys. 62, 764-770 (1975).

Daily, W. D., W. Lin, and T. Buscheck, "Hydrology of Topopah Spring Tuff, Laboratory Measurements," J. Geophys. Res. 92, 7854-7864, 1987.

Duba, A. G., "Electrical Conductivity of Colorado Oil Shale to $900^{\circ} \mathrm{C}$," Fuel 62, 966-972 (1983).

Duba, A. G., and P. S. Ho, The Electrical Conductivity of Kemmerer Coal, Lawrence Livermore National Laboratory, Livermore, Calif., UCRL-52227 (1977).

Duba, A. G., and I. A. Nicholls, "The Influence of Oxidation State on the Electrical Conductivity of Olivine," Earth Planet. Sci. Lett. 18, 158-162 (1973).

Duba, A. G., H. C. Heard, and R. N. Schock, "Electrical Conductivity of Olivine at High Pressure and Under Controlled Oxygen Fugicity,” J. Geophys. Res. 79, 1667-1673 (1974).

Duba, A. G., H. C. Heard, and R. N. Schock, "Electrical Conductivity of Orthopyroxene to $1400^{\circ} \mathrm{C}$ and the Resulting Selenotherm," Proc. Lunar Sci. Conf. VII, Houston, Texas, 3137-3181 (1976).

Duba, A. G., R. N. Schock, E. L. Amold; and T. J. Shankland, "An Apparatus for Measurement of Electrical Conductivity to $1500^{\circ} \mathrm{C}$ at Known Oxygen Fugacity," The Brittle-Ductile Transition in Rocks, A. Duba, W. B. Durham, J. Handin, H. Wang, Eds. (Geophysical Monograph 56, AGU, Washington, D.C., 1990), pp. 207-210.

Durhiam, W. B., and A. E. Abey, "The Effect of Pressure and Temperature on the Thermal Properties of a Salt and a Quartz Monzonite, 22nd U.S. Symposium on Rock Mechanics (MIT Press, Cambridge, Mass., 1981), 79-84.

Durham, W.B., and A. E. Abey, "Thermal Conductivity and Diffusivity of Climax Stock Quartz Monzonite at High Pressure and Temperature," Proceedings of the 17th ITCC, J. G. Hust, Ed. (Plenum Press, New York, N.Y., 1983), 459-468.

Durham, W.B., and B. P. Bonner, "Three-Dimensional Profilometry of Joint Surfaces" (Abstract), Trans. Am. Geophys. $U$. , AGU 68, 1491 (1987).

Durham, W. B., A. E. Abey, and D. Trimmer, "Thermal Conductivity, Diffusivity, and-Expansion of Avery Island Salt at Pressure and Temperature," Proceedings of $16 \mathrm{th}$ ITCC/7th ITES, D. C. Larson, Ed. (Plenum Press, New York, N.Y., 1983a), 181-192.

Durham, W. B., C. O. Boro, J. M. Beiriger, and D. N. Montan, Thermal Conductivity and Diffusivity of Permian Basin Bedded Salt at Elevated Pressure and Temperature, Lawrence Livermore National Laboratory, Livermore, Calif., UCRL-53476 (1983b).

Durham, W. B., H. C. Heard, and S. H. Kirby, "Experimental Deformation of Polycrystalline $\mathrm{H}_{2} \mathrm{O}$ Ice at High Pressure and Low Temperature: Preliminary Results," J. Geophys. Res. 88, B377-B392 (1983c).

Durham, W. B., C. O. Boro, J. M: Beiriger, and D. N. Montan, "Thermal Conductivity and Diffusivity of Permian Basin Bedded Salt at.Elevated Pressure and Temperature, Proceedings of the 18th ITCC, T. Ashworth, Ed. (Plenum Press, New.York, N.Y., 1985), pp. 687-698.

Durham, W. B., H. C. Heard, C. O. Boro, K. T. Keller, W. E. Ralph, and D. A. Trimmer, Thermal Properties of Permian Basin Evaporites to $373 \mathrm{~K}$ Temperature and $30 \mathrm{MPa}$ Confining Pressure, Battelle Memorial Institute, Columbus, Ohio, BMI/ONWI-633, (1987a).

Durham, W.B., V. V. Mirkovich, and H. C. Heard, "Thermal Diffusivity of Igneous Rocks at Elevated Pressure and Temperature," J. Geophys. Res. 92, 11615-11634 (1987b).

Durham, W. B., S.H. Kirby, and L.A. Stern, "Rheology of Water-Ammonia Ice," (Abstract), Proc. 19th Lunar Planet. Sci. Conf., 285-286.(1988a).

Durham, W. B., S. H. Kirby, H. C. Heard, L. A. Stern, and C. O. Boro, "Water Ice Phases II, III, and V: Plastic Deformation and Phase Relationships," J. Geophys. Res. 93, 10191-10208 (1988b).

Durham, W. B., S. H. Kirby, L. A. Stem, and K. A. Ragaini, "Brittle and Ductile Behavior of Ice/Rock Mixtures,". (Abstract), Proc. 19th Lunar Planet. Sci. Conf., 254-255 (1989).

Gilmore, R. S., High-Pressure, Ultrasonic Studies of the Elastic Constants and Equation of State of Fifteen Materials, Ph.D. thesis, Rensselaer Polytechnic Institute, Troy, N.Y. (1968).

Goetze, C., and B. P. Bonner, "Attenuation Measurements for Polycrystalline Salt Mixtures at High Temperature," Trans. Am. Geophys. Union 59, 376 (1978). 
Griggs, D. T., F. J. Turner, and H. C. Heard, "Rock Deformation," Geol. Soc. America Mem. 79, 39 (1960).

Hall, H. T., "Ultra-High-Pressure, High-Temperature Apparatus: the 'Belt', " Rev. Sci. Instrum. 31, 125-131 (1960).

Heard, H. C., "Effect of Large Changes in Strain Rate in the Experimental Deformation of Yule Marble," J. Geol. 71, $162-195$ (1963).

Heard, H. C., "Steady-State Flow in Polycrystalline Halite at Pressure of 2 Kilobars," Flow and Fracture of Rocks, H.C. Heard, I. Y. Borg, N. L. Carter, C. B. Raleigh, Eds. (Geophysical Monograph 16, AGU, Washington, D.C., 1972), pp. 191-209.

Heard, H. C., and N. L. Carter, "Experimentally Induced 'Natural' Intragranular Flow in Quartz and Quartzite," Am. J. Sci. 266, 1-42 (1968).

Heard, H. C., and A. Duba, Capabilities for Measuring Physicochemical Properties at High Pressure, Lawrence Livermore National Laboratory, Livermore, Calif., UCRL-52420 (1978).

Heard, H. C., and L. Page, "Elastic Moduli, Thermal Expansion and Inferred Permeability of Two Granites to $350^{\circ} \mathrm{C}$ and $55 \mathrm{MPa}$," J. Geophys. Res. 87, 9340-9348 (1982).

Heard, H. C., and C. B. Raleigh, "Steady-State Flow in Marble at $500^{\circ} \mathrm{C}$ to $800^{\circ} \mathrm{C}$." Geol. Soc. Am. Bull 83, 935-936 (1972).

Heard, H. C., A. Duba, A. E. Abey, and R. N. Schock, Mechanical Properties of Blair Dolomite, Lawrence Livermore National Laboratory, Livermore, Calif., UCRL-51465 (1973).

Heard, H. C., A. E. Abey, and B. P. Bonner, High Pressure Mechanical Properties of Indiana Limestone, Lawrence Livermore National Laboratory, Livermore. Calif., UCIR-16501 (1974).

Heard, H. C., A. Duba, A. J. Piwinskii, and R. Schock, "Electrical Conductivity Studies: Refinement of the Selenotherm," Proc. Lunar Sci. Conf. VI, 355 (1975).

Heard, H. C., B. P. Bonner, M. C. Costantino, R. N. Schock, and H. C. Weed, Mechanical Response of Saturated Kemmerer Coal to $4 \mathrm{GPa}$, Lawrence Livermore National Laboratory, Livermore, Calif., UCRL-52063 (1976).

Heard, H. C., W. B. Durham, C. O. Boro, and S. H. Kirby, "A Triaxial Deformation Apparatus for Service at $77 \leq T \leq$ 273 K," The Brittle-Ductile Transition in Rocks, A. Duba, W. B. Durham, J. Handin, H. Wang, Eds. (Geophysical Monograph 56, AGU, Washington, D.C., 1990), pp. 225-228.

Jamieson, J. C., Metallurgy at High Pressures and High Temperatures, K. A. Gschneider, Jr., M. T. Hepworth, and A. D. Parlee, Eds. (Gordon and Breach, N.Y., 1964), 201-228.

Jamieson, J. C., Physics of Solids at High Pressures, C. T. Tomizuka and R. M. Emrick, Eds. (Academic Press, N.Y., 1965) $444-458$.

Johnson, D. P., and D. H. Newhall, "The Piston Gage as a Precise Measurement," Trans. ASME 75, 301-310 (1953).

Keller, K., and B. P. Bonner, “Automatic, Digital System for Profiling Rough Surfaces," Rev. Sci. Instrum. 56, 330$331(1985)$.

Kirby, S. H., W. B. Durham, M. L. Beeman, H. C. Heard, and M. A. Daley, "Inelastic Properties of Ice Ih at Low Temperatures and High Pressures," Journal de Physique 48, supplement, 227-232 (1987), Proc. VIIth Symposium on the Physics and Chemistry of Ice, Grenoble, France.

Lewis, W. F., D. Benson, R. K. Crawford, and W. B. Daniels, "Isochoric Measurement of the Equation of State of Solid Argon at High Pressure," J. Phys. Chem. Solids 35, 383-391 (1972).

Lin, W., and W. D. Daily, Transport Properties of Topopah Spring Tuff, Lawrence Livermore National Laboratory, Livermore, Calif., UCRL-53602 (1984).

Lin, W., and W. D. Daily, Hydrological Properties of Topopah Spring Tuff Under a Thermal Gradien-Laboratory Results, Lawrence Livermore National Laboratory, Livermore, Calif., UCRL-96926 (1988a).

Lin, W., and W. D. Daily, "Laboratory Determined Transport Properties of Cores from Salton Sea Scientific Drilling Project," J. Geophys. Res. 93, 13047-13056 (1988b).

Lin, W., and F. E. Heuze, "Comparison of in situ Dynamic Moduli and Laboratory Moduli of Mesaverde Rocks," Int. J. Rock Mech. Sci. \& Geomech. Abst. 24, 257-263 (1987).

Liu, H. P., R. N. Schock, and D. L. Anderson, "Temperature dependence of single-crystal spiral (MgA1204) elastic constants from $293-423^{\circ} \mathrm{K}$ measured by light-sound scattering in the Raman-Nath region," Geophys.J. Roy. Astron. Soc. 42, 217-250 (1975).

Luth, W. C., and O. F. Tuttle, "Externally heated cold-seal pressure vessels for use to 10,000 bars and $750^{\circ} \mathrm{C}$," $\mathrm{Am}$. Mineral. 48, 1401-1403 (1963).

Mackwell, S. J., D. L. Kohlstedt, and W. B. Durham, "High-Resolution Creep Apparatus," The Brittle-Ductile Transition, A. Duba, W. B. Durham, J. Handin, H. Wang, Eds. (Geophysical Monograph 56, AGU, Washington, D.C., 1990), pp. 235-238. 
Mao, H. K., The Physics and Chemistry of Minerals and Rocks, R. G. J. Strens, Ed. (John Wiley, London, 1976) 573-581.

May, J. E., Jr., "Precise Measurement of Time Delay," Natl. Conv. Rec. 6, 134-142 (1958).

McSkimin, H. J., "Ultrasonic Methods for Measuring the Mechanical Properties of Liquids and Solids," in Physical Acoustics, W. P. Mason, Ed: (Academic Press, New York, N.Y., 1964), vol. 1, part A, p. 334.

Mirkovich, V. V., "Thermal Diffusivity Measurement of Armco Iron by a Novel Method," Rev. Sci. Instrum. 48, 560-565 (1977).

Moss, W. C., J. O. Hallquist, R. Reichlin, K. A. Goettel, and S. Martin, "Finite Element Analysis of the Diamond Anvil Cell: Achieving 4.6 Megabars," Appl. Phys. Lett. 481258 (1986).

Netherton, R., and A. Duba, A System for Simultaneous Measurement of Electrical Conductivity and Oxygen Fugacity, Lawrence Livermore National Laboratory, Livermore, Calif., UCRL-52394 (1978).

Nitsan, U., "Stability Field of Olivine with Respect to Oxidation and Reduction," J. Geophys. Res. 79, 706-711 (1974).

Page, L., and H. C. Heard, "Elastic Moduli, Thermal Expansion and Inferred Permeability of Climax Quartz Monzonite and Subdury Gabbro to $500^{\circ} \mathrm{C}$ and $55 \mathrm{MPa}$," Proc. 22nd U. S. Symp. on Rock Mech. (MIT Press, Cambridge, Mass., 1981), pp. 97-104.

Piwinskii; A. J., "Experimental Studies of Igneous Rock Series, Central Sierra Nevada Batholith, California: Part II," Neues Jahrb. für Mineralogie 5, 193-215 (1973).

Piwinskii, A. J., "Experimental Studies of Granitoid Rocks Near the San Andreas Fault Zone in the Coast and Transverse Ranges and Majave Desert, California," Tectonophysics 25, 217-231 (1975).

Reichlin, R. L., "Measuring the Electrical Resistance of Metals to $40 \mathrm{GPa}$ in the Diamond-Anvil Cell," Rev. Sci. Inst. 54, 1674 (1983).

Reichlin, R., F. Schiferl, S. Martin, C. Vanderborgh, and R. Mills, "Optical Studies of Nitrogen to $130 \mathrm{GPa}$, Phys. Rev. Lett. 15, 1464 (1985).

Reichlin, R., M. Ross, S. Martin, and K. Goettel, "Metalization of CsI," Phys. Rev. Lett. 56, 2858 (1986),

Reichlin, R., C. E. Violet; S. R. Bohlen, and S. Martin, Fe Spin State in Fayalite at High Pressure, Lawrence Livermore National Laboratory, Livermore, Calif.; UCRL-100621; Abstract, International Conference on the Application of the Mössbauer Effect, Budapest, Hungary, September, 1989a.

Reichlin, R., K. E. Brister, M. Ross, A. K. McMahan, S. Martin, Y. K. Vohra, and A. L. Ruoff, "Evidence for the Insulator-Metal Transition in Xenon from.Optical, X-ray, and Band Structure Studies to 170 GPa," Phys. Rev. Lett. 62, 669 (1989b).

Ryerson, F. J., H. C. Weed, and A. J. Piwinskii, "Rheology of Subliquidus Magmas 1. Picritic Compositions," J. Geophys. Res. 93, 3421-3436 (1988).

Ryerson, F. J., W. B. Durham, D. Cherniak, and W: A. Lanford, "Oxygen Diffusion in Olivine: The Effect of Oxygen Fugacity and Implications for Creep,"J. Geophys. Res. 94, 4105-4118 (1989).

Schock, R. N., "The Response of Rocks to Large Stresses," in Impact and explosion cratering: planetary and terres. trial implications: proceedings of the Symposium on Planetary Cratering Mechanics (Pergamon Press; Flagstaff, Ariz., 1976; New York, N. Y., 1977), 657-658.

Schock, R. N., and A. G. Duba, "Quasistatic Deformation of Solids with Pressure," J. Appl. Phys. 43, 2204-2210 (19.72).

Schock, R. N., and A. G. Duba, "Pressure Effects on the Response of Foil Strain Gages," Exp. Mech. 13, 43-44 (1973).

Schock, R. N., and H. C. Heard, "Static Mechanical Properties and Shock Loading Response of Granite," J. Geophys. Res. 79, 1662-1666 (1974).

Schock, R. N., and E. Hinze, "The Electrical Conductivity of Silver Iodide to $410 \mathrm{~K}, 0.2 \mathrm{GPa}$," J. Phys. Chem. Solids 36, 713-721 (1975).

Schock, R. N., and H. Louis, "Strain Behavior of a Granite and a Graywacke Sandstone in Tension," J. Geophys. Res. 87, 7817-7823 (1982).

Schock, R. N., H. Louis, and E. M. Lilley, The Determination of Acoustic Velocities and Dynamic Elastic Moduli in Rocks under Pressure, Lawrence Livermore National Laboratory, Livermore, Calif., UCRL-50750 (1969).

Schock, R. N., H. C. Heard, and D. R. Stephens, Comparison of the Mechanical Properties of Graywacke Standstones from Several Gas Stimulation Sites, Lawrence Livermore National Laboratory, Livermore, Calif., UCRL-51261 (1972).

Schock, R. N., A. E. Abey, H. C. Heard, and H. Louis, Mechanical Properties of Granite from the Taourirt Tan Afella Massif, Algeria, Lawrence Livermore National Laboratory, Livermore, Calif., UCRL-51296 (1972). 
Schock, R. N., A. E. Abey, A. Duba, B. P. Bonner, and H. C. Heard, Mechanical Properties of Nugget Sandstone, Lawrence Livermore National Laboratory, Livermore, Calif., UCRL-51447 (1973).

Schock, R. N., H. C. Heard, and D. R. Stephens, "Stress-Strain Behavior of a Granodiorite and Two Graywalke Sandstones on Compression to 20 Kilobars," J. Geophys. Res. 78, 5922-5941 (1973).

Schock, R. N., A. G. Duba, H. C. Heard, and H. D. Stromberg, High-Pressure Research, Applications in Geophysics (1977).

Schock, R. N., A. G. Duba, and T. J. Shankland, "Electrical Conduction in Olivine," J. Geophys. Res. 94, 5829-5839 (1989).

Sears, F. P, and B. P. Bonner, "Ultrasonic Attenuation Measurement by Spectral Ratios Utilizing Signal Processing Techniques," IEEE Trans. on Geoscience and Remote Sensing GE-19 95, 1981.

Sing, C. M., "New modification of the diamond anvil press: a versatile apparatus for research at high pressure and high temperature," Rev. Sci. Instrum. 47, 1343-1346 (1976).

Smith, G. S., and J. Akella, "Reexamination of the Crystal Structure of a High Pressure Phase in Praseodymium Metal," J. Geophys. Res. 53, 9212-9213 (1982).

Smith, G. S., and J. Akella, "On the possibility of Pr III Having a Thcp Structure," Phys. Rev. Lett. A, 132-133, (1984).

Smith, G. S., and J. Akella, "Crystallographic Calculations for Possible High-Pressure Lanthanide Structure Models," Phys. Rev. Lett. A 118, 136-138 (1986).

Smith, G. S, and J. Akella, "X-Ray Diffraction Applications," Energy Technology Rev., 23-28 (1987).

Smith, G. S., J. Akella, R. Reichlin, Q. Johnson, R. N. Schock, and M. Schwab, "Crystal Structure of Americium in the Pressure Range, 11-13 GPa," Actinides 81 (Extended Abstract), 218-220 (1981).

Stephens, D. R., "The phase diagrams of praseodymium, europium, gadolimium and ytterbium," J. Phys. Chem. Solids 26, 943-948 (1965).

Stephens, D. R., E. M. Lilley, and H. Louis, "Pressure volume equation of state of consolidated and fractured rocks to 40 kb," Int. J. Rock Mech. Min. Sci. 7, 257-296 (1970).

Stromberg, H. D., and R. N. Schock, “A Window Configuration for High Pressure Optical Cells," Rev. Sci. Instrum 41, 1880-1881 (1970).

Stromberg, H. D., and D. R. Stephens, "Effects of Pressure on the Electrical Resistance of Certain Metals," J.Phys. Chem. Solids 25, 1015-1022(1964).

Stromberg, H. D., and D. R. Stephens, “Sintering of diamond at $1800^{\circ} \mathrm{C}-1900^{\circ} \mathrm{C}$ and $60-65 \mathrm{kbar}$," Bull. Am. Ceram. Soc. 49, 1030-1032 (1970).

Swift, R. P., and A. S. Kusubov, "Multiple Fracturing of Boreholes Using Tailored-Pulse Loading," Soc. Petrol. Engineers J. 2, 923-932 (1982).

Trimmer, D. A., B. P. Bonner, H. C., Heard, and A. Duba, "The Effect of Pressure and Stress on Water Transport ion Intact and Fractured Gabbro and Granite," Jour. Geophys. Res. 85, 7059-7071 (1980).

Trimmer, D. A., "Design Criteria for Laboratory Measurements of Low Permeability Rocks," Geophys. Res. Lett. 8, 973-975 (1981).

Wanamaker, B. J., and B. P. Bonner, "Low Frequency Attenuation and Modulus of Thermally Fractured Granite," Trans. Am. Geophys. U. 69(16), 475 (1988).

Wang, H. F., B. P. Bonner, S. R. Carlson, B. J. Kowallis, and H. C. Heard, "Thermal Stress Cracking in Granite," J. Geophys. Res., 94 (B2), 1745-1758 (1989).

Weed, H. C., L. Dibley, and A. J. Piwinskii, A High-Temperature Viscometer for Use at $100 \mathrm{kPa}$, Lawrence Livermore National Laboratory, Livermore, Calif., UCRL-52477 (1978).

Williams, Q., R. Reichlin, S. Martin, E. Knittle, and R. Jeanloz, "High Pressure Electronic Properties of Fayalite," Trans. Am. Geophys. U. 68, 1455 (1987). 
Technical Information Department - Lawrence Livermore National Laboratory University of California . Livermore, California 74551 